Florida International University

FIU Digital Commons

$11-13-2020$

\title{
Data Analytic Approach to Support the Activation of Special Signal Timing Plans in Response to Congestion
}

Mosammat Tahnin Tariq

mtari006@fiu.edu

Follow this and additional works at: https://digitalcommons.fiu.edu/etd

Part of the Transportation Engineering Commons

\section{Recommended Citation}

Tariq, Mosammat Tahnin, "Data Analytic Approach to Support the Activation of Special Signal Timing Plans in Response to Congestion" (2020). FIU Electronic Theses and Dissertations. 4546.

https://digitalcommons.fiu.edu/etd/4546

This work is brought to you for free and open access by the University Graduate School at FIU Digital Commons. It has been accepted for inclusion in FIU Electronic Theses and Dissertations by an authorized administrator of FIU Digital Commons. For more information, please contact dcc@fiu.edu. 


\section{FLORIDA INTERNATIONAL UNIVERSITY}

Miami, Florida

\section{DATA ANALYTIC APPROACH TO SUPPORT THE ACTIVATION OF SPECIAL SIGNAL TIMING PLANS IN RESPONSE TO CONGESTION}

A dissertation submitted in partial fulfillment of

the requirements for the degree of

DOCTOR OF PHILOSOPHY

in

CIVIL ENGINEERING

by

Mosammat Tahnin Tariq 


\section{To: Dean John Volakis}

College of Engineering and Computing

This dissertation, written by Mosammat Tahnin Tariq, and entitled Data Analytic Approach to Support the Activation of Special Signal Timing Plans in Response to Congestion, having been approved in respect to style and intellectual content, is referred to you for judgment.

We have read this dissertation and recommend that it be approved.

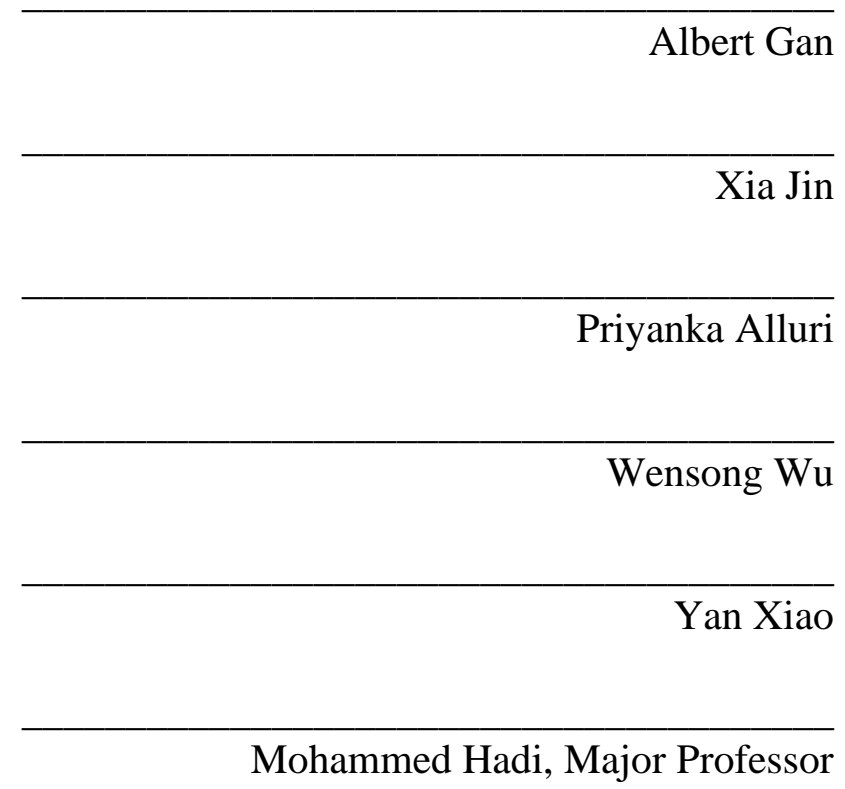

Date of Defense: November 13, 2020.

The dissertation of Mosammat Tahnin Tariq is approved.

Dean John Volakis

College of Engineering and Computing

Andrés G. Gil

Vice President for Research and Economic Development and Dean of the

University Graduate School

Florida International University, 2020 
(C) Copyright 2020 by Mosammat Tahnin Tariq

All rights reserved. 


\section{DEDICATION}

I dedicate this dissertation to my parents, Md Tariqul Islam and Mst Gulnahar Begum, for their unconditional love and support. 


\section{ACKNOWLEDGMENT}

I thank Almighty Allah for blessing me with the opportunity to achieve my dream and giving me the strength to complete this research work.

I would like to take this opportunity to acknowledge everyone who supported me in reaching my dream of achieving a doctoral degree. First and foremost, I would like to express my sincere gratitude to my advisor and mentor, Dr. Mohammed Hadi, for his continuous guidance, kindness, support, immense knowledge, and directive suggestions at every stage of the dissertation. I am thankful to him for his thoughtful insights provided in completing the dissertation and because he taught me how to be compassionate and kind, help one another grow intellectually, support one another in difficult times, and much more. Words cannot express my gratitude toward him. I consider myself fortunate to be a student of Dr. Hadi. I will be grateful to him throughout my lifetime.

I would also like to thank all of my committee members, including Dr. Albert Gan, Dr. Xia Jin, Dr. Priyanka Alluri, Dr. Yan Xiao, and Dr. Wensong Wu, for showing interest in my research. I sincerely appreciate their invaluable time for reading the dissertation and providing comments and suggestions to improve it. I am very grateful to Dr. Albert Gan; I learned the fundamentals of this dissertation topic in his classes. A special thanks to Dr. Wensong Wu for introducing the basics of machine learning, which I have implemented to build the core of my dissertation.

I would also like to thank all of my colleagues at the Lehman Center for Transpiration Research (LCTR) for collaborating with me during various stages of my dissertation, and for all of the good times these years. I am also grateful to my friends for their support and encouragement throughout this journey. 
Furthermore, I would like to acknowledge the Southeastern Transportation Research, Innovation, Development and Education (STRIDE) Center, and the Florida Department of Transportation (FDOT) Research Center for providing financial support for this research.

I owe my deepest gratitude to all of my family members for their endless love, support, and encouragement in pursuing my doctoral degree. 


\title{
ABSTRACT OF THE DISSERTATION
}

\section{DATA ANALYTIC APPROACH TO SUPPORT THE ACTIVATION OF SPECIAL SIGNAL TIMING PLANS IN RESPONSE TO CONGESTION}

by

\author{
Mosammat Tahnin Tariq
}

Florida International University, 2020

Miami, Florida

\section{Professor Mohammed Hadi, Major Professor}

Improving arterial network performance has become a major challenge that is significantly influenced by signal timing control. In recent years, transportation agencies have begun focusing on Active Arterial Management Program (AAM) strategies to manage the performance of arterial streets under the flagship of Transportation Systems Management \& Operations (TSM\&O) initiatives. The activation of special traffic signal plans during non-recurrent events is an essential component of AAM and can provide significant benefits in managing congestion.

Events such as surges in demands or lane blockages can create queue spillbacks, even during off-peak periods resulting in delays and spillbacks to upstream intersections. To address this issue, some transportation agencies have started implementing processes to change the signal timing in real time based on traffic signal engineer/expert observations of incident and traffic conditions at the intersections upstream and downstream of congested locations. This dissertation develops methods to automate and enhance such decisions made at traffic management centers. First, a method is developed to learn from experts' decisions by utilizing a combination of Recursive Partitioning and Regression 
Decision Tree (RPART) and Fuzzy Rule-Based System (FRBS) to deal with the vagueness and uncertainty of human decisions. This study demonstrates the effectiveness of this method in selecting plans to reduce congestion during non-recurrent events. However, the method can only recommend the changes in green time to the movement affected by the incident and does not give an optimized solution that considers all movements. Thus, there was a need to extend the method to decide how the reduction of green times should be distributed to other movements at the intersection.

Considering the above, this dissertation further develops a method to derive optimized signal timing plans during non-recurrent congestion that considers the operations of the critical direction impacted by the incident, the overall corridor, as well as the critical intersection movement performance. The prerequisite of optimizing the signal plans is the accurate measurements of traffic flow conditions and turning movement counts. It is also important to calibrate any utilized simulation and optimization models to replicate the field traffic states according to field traffic conditions and local driver behaviors.

This study evaluates the identified special signal-timing plan based on both the optimization and the DT and FRBS approaches. Although the DT and FRBS model outputs are able to reduce the existing queue and improve all other performance measures, the evaluation results show that the special signal timing plan obtained from the optimization method produced better performance compared to the DT and FRBS approaches for all of the evaluated non-recurrent conditions. However, there are opportunities to combine both approaches for the best selection of signal plans. 


\section{TABLE OF CONTENTS}

CHAPTER

PAGE

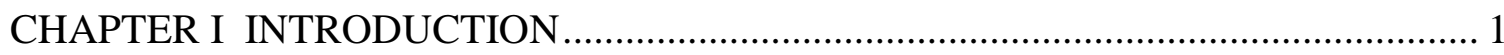

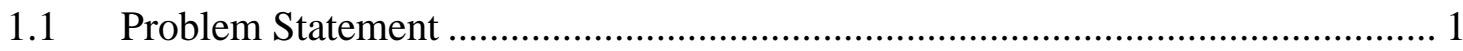

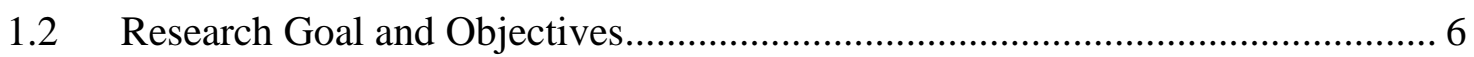

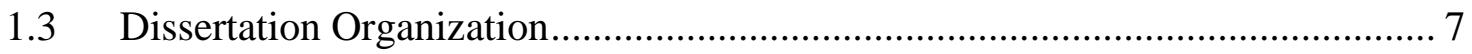

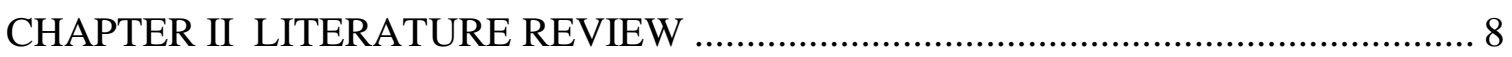

2.1 Review of Literature on Traditional Practice and Previous Studies ...................... 10

2.1.1 Considerations in Selecting Signal Timing Parameters .................................. 10

2.1.2 Traditional Practices for Signal Timing Modification ..................................... 12

2.1.3 Existing Signal Timing Optimization Tools..................................................... 14

2.1.4 Previous Researches on Signal Timing Strategies ........................................... 17

2.1.5 Practice and Need for Simulation Model Calibration ...................................... 21

2.1.6 Use of High-Resolution Controller Data in Signal Timing Performance

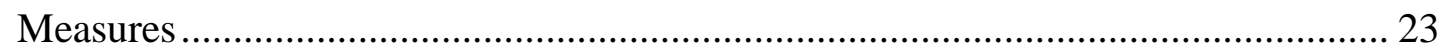

2.1.7 Identification and Partitioning of Traffic Operational Conditions ................... 27

2.2 Utilized Algorithms in Signal Timing Plan Selection....................................... 27

2.2.1 Decision Tree and Fuzzy Rule Based System ............................................... 28

2.2.2 Clustering Methods............................................................................. 30

2.2.3 Optimization Techniques............................................................................. 33

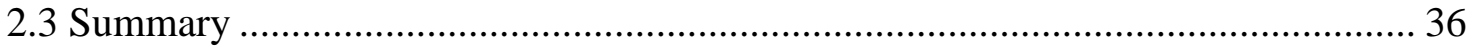

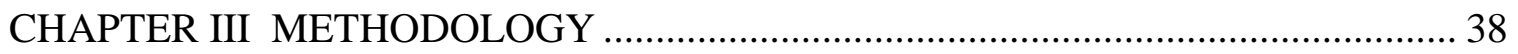

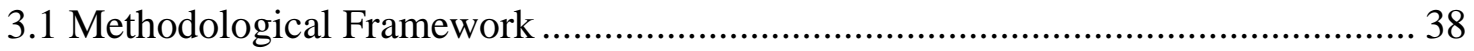

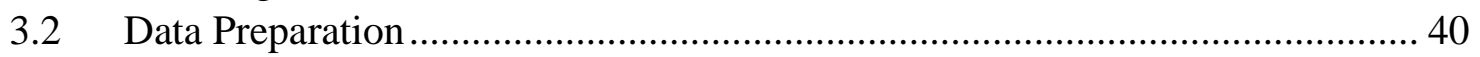

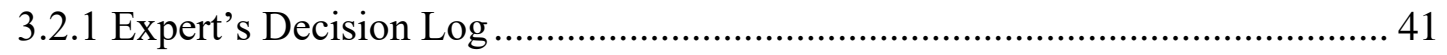

3.2.2 Signal Performance Measures Extraction......................................................... 42

3.3 Automation of Signal Timing Engineer's Decisions .............................................. 46

3.4 Identification and Partitioning Traffic Operational Conditions ............................. 52

3.5 VISSIM Calibration Using High-Resolution Controller Data ............................... 53

3.5.1 Model Development ................................................................................. 55

3.5.2 Selection of Model Calibration Parameters ..................................................... 57

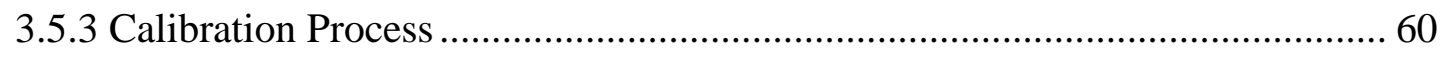




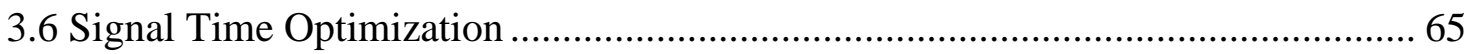

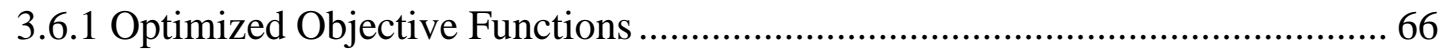

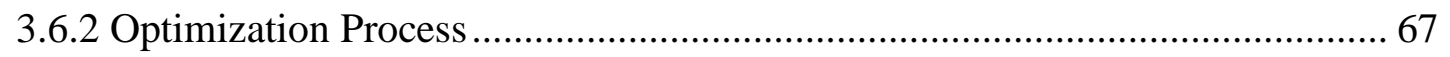

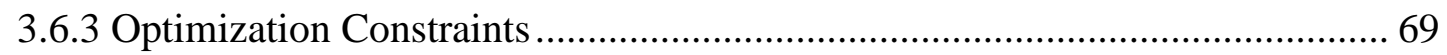

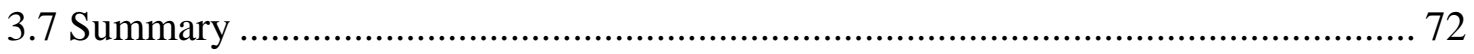

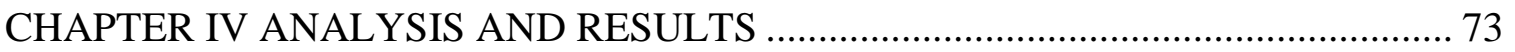

4.1 Automation of Expert's Signal Timing Modification Decisions ....................... 73

4.1.1 Development of the Decision Tree ................................................................. 73

4.1.2 Development of Fuzzy Rule-Based System ..................................................... 75

4.1.3 Validation of the Model........................................................................... 78

4.1.4 Benefit Assessment...................................................................................... 79

4.1.5 Tool Development ................................................................................... 84

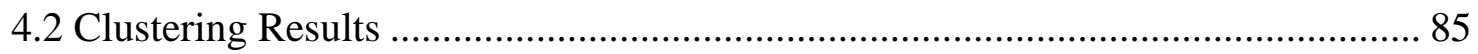

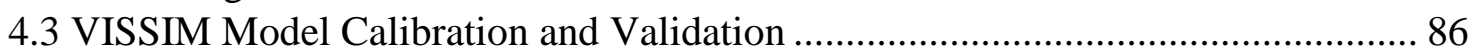

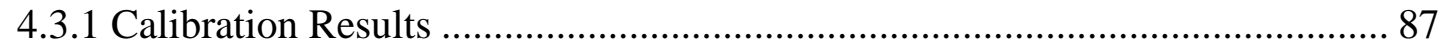

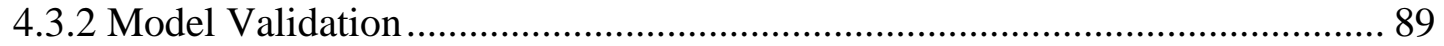

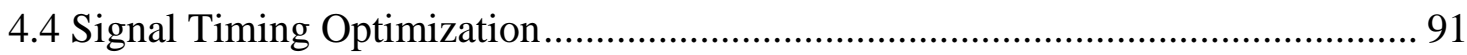

4.4.1 Evaluation for Regular Timing Settings ......................................................... 91

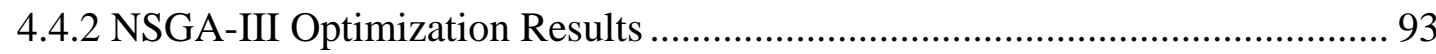

4.4.3 Comparison of the Developed Models .............................................................. 98

4.4.4 Temporal Transferability Assessment ............................................................. 101

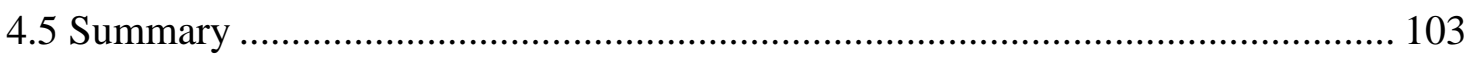

CHAPTER V CONCLUSION AND RECOMMENDATIONS …................................ 104

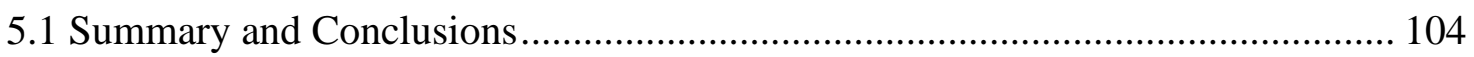

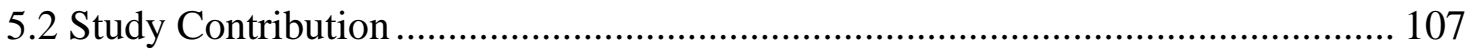

5.3 Recommendations for Future Research .......................................................... 108

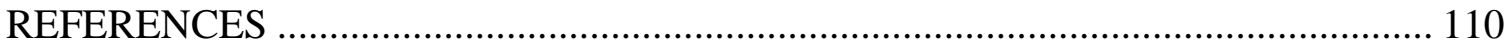

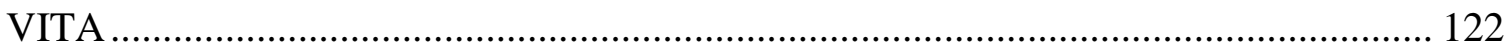




\section{LIST OF TABLES}

TABLE

PAGE

Table 2-1 Existing Signal Timing Optimization Tools.............................................. 16

Table 3-1: List of Adjusted Driver Behavior Parameters ........................................... 59

Table 4-1: Extracted Crisp Rules from the Decision Tree.......................................... 76

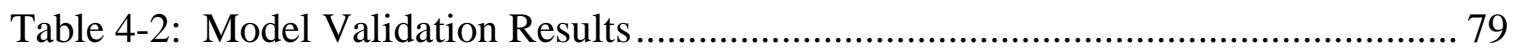

Table 4-3: Modified Signal Timing Based on FRBS Output ..................................... 82

Table 4-4: Impact of Green Time Update based on FRBS Output................................ 83

Table 4-5: Categorization of Traffic Based on the Green Occupancy Ratio ................... 86

Table 4-6: Optimal Solutions and Corresponding Decision Variables............................ 88

Table 4-7: Percentage Error in the Travel Time and SUR with or without Calibrated

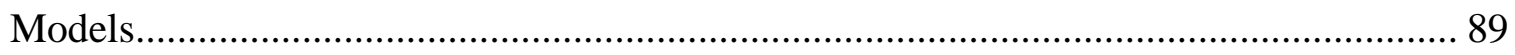

Table 4-8: Error (\%) in the GOR and POG with or without Calibrated Models ............. 90

Table 4-9: Signal Timing Performance Measures for Normal TOD Settings ................. 92

Table 4-10: Pareto Optimal Sets for Non-Recurrent Congestion Conditions................... 97

Table 4-11: Output from the DT and FRBS Model................................................ 100

Table 4-12: Comparison of the Optimized Signal Timing Settings and DT and FRBS

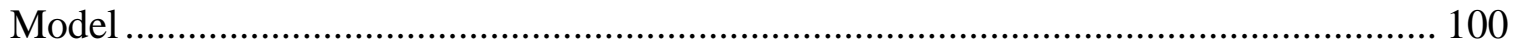

Table 4-13: Evaluation of Optimization Model Temporal Transferability .................... 102 


\section{LIST OF FIGURES}

FIGURE

PAGE

Figure 2-1: Delay Variation with the Cycle Length Estimated Using the Webster and Highway Capacity Manual (HCM) 2000 Methods (Source: Cheng et al., 2003)............ 11

Figure 2-2 Example of High-Resolution Controller Data........................................... 25

Figure 2-3: Different Types of Clustering Methods (Source: Saha et al., 2019) .............. 31

Figure 2-4: Plot of Total Within-Cluster Sum of Square (WSS) Vs. Number of

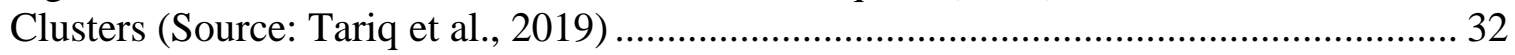

Figure 2-5: A Flow Chart for the Basic Optimization Procedure (Source: Adby, 2013). 33

Figure 2-6: Graphical Representation of Pareto Optimal Solution Process (Source:

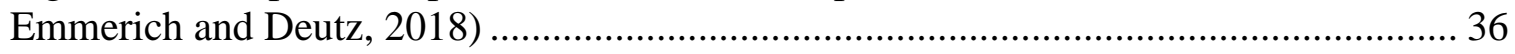

Figure 3-1: Proposed Framework of the Methodology............................................. 39

Figure 3-2: Example of Signal Timing Expert's Decision Log .................................. 42

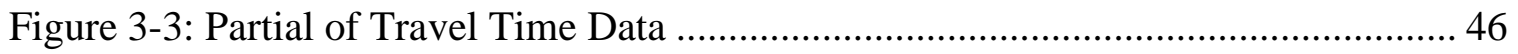

Figure 3-4: Principal Steps of the Utilized Fuzzy Rule-Based Decision System ............ 48

Figure 3-5: Step by Step Process for the Automation Model Development.................... 52

Figure 3-6: Pseudo-Code for the K-means Clustering Algorithm................................ 53

Figure 3-7: VISSIM Simulation Network of the Case Study Segment ......................... 57

Figure 3-8: Pseudo Code for Single Objective Genetic Algorithm Optimization ........... 61

Figure 3-9: NSGA-III Optimization Process Using the VISSIM COM Interface............ 64

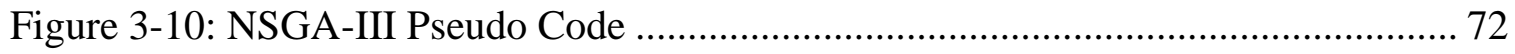

Figure 4-1: Developed Decision Tree from the Traffic Signal Engineer/Expert

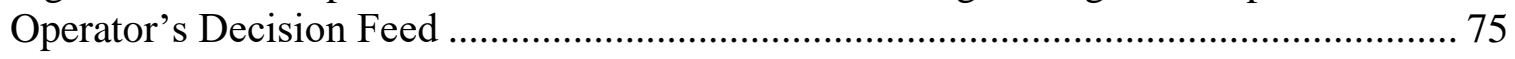

Figure 4-2: Membership Functions of the Derived Knowledge Base ............................ 77 
Figure 4-3: Illustration of the Three Model Scenarios to Assess Expert's Decision

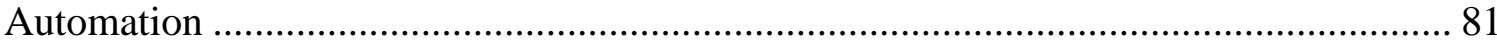

Figure 4-4: Special Signal Timing Modification Tool ………………......................... 84

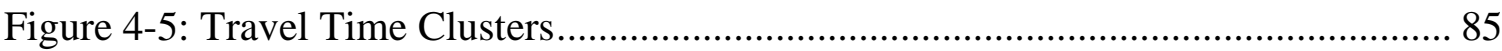

Figure 4-6: Pareto Optimal Solution from NSGA-III Output.......................................... 88

Figure 4-7: 3-D Plot of Resulted Objective Functions in Each NSGA-III Generations... 94

Figure 4-8: Queue Length vs. NSGA-III Fitness Values (One Lane Blockage) ............. 95

Figure 4-9: Queue Length vs. NSGA-III Fitness Values (Two Lane Blockage)............. 95

Figure 4.10: Queue Length vs. NSGA-III Fitness Values (Demand Surge) ................... 96 


\section{ABBREVIATIONS AND ACRONYMS}

AAM

AMP

ATCSs

ATSPMs

CART

CCTV

CHART

CHAID

$\mathrm{COM}$

DI

DT

EB

EBL

EBT

FDOT

FHWA

FRBS

GA

GOR

$\mathrm{HCM}$

HCS

ID3
Active Arterial Management

Arterial Management Program

Adaptive Traffic Control Systems

Automated Traffic Signal Performance Measures

Classification and Regression Trees

Closed Circuit Television Camera

Coordinated Highways Action Report Team

Chi-square Automatic Interaction Detector

Component Object Model

Disutility Index

Decision Tree

Eastbound

Eastbound Left

Eastbound Though

Florida Department of Transportation

Federal Highway Administration

Fuzzy Rule Based System

Genetic Algorithm

Green Occupancy Ratio

Highway Capacity Manual

Highway Capacity Software

Iterative Dichotomizer 3 


\begin{tabular}{ll} 
ICM & Integrated Corridor Management \\
ITS & Intelligent Transportation System \\
MISO & Multiple-Input and Single-Output \\
MOE & Measures of Effectiveness \\
NB & Northbound \\
NBL & Northbound Left \\
NBT & Northbound Though \\
NSGA & Non-dominant Sort Genetic Algorithm \\
NW & Northwest \\
PASSER & Progression Analysis and Signal System Evaluation Routine \\
POG & Percentage Arrival on Green \\
PTV & Planung Transport Verkehr \\
RITIS & Regional Integrated Transportation Information System \\
RPART & Recursive Partitioning and Regression Decision Tree \\
SB & Southbound \\
SBL & Southbound Left \\
SBT & Southbound Though \\
SCOOT & Split, Cycle, Offset Optimization Technique \\
SIGOP & Signal Optimization \\
SUR & Split Utilization Ratio \\
TMC & Traffic management centers \\
TRA & Tric Network Study Tool \\
\hline
\end{tabular}


TSK

TSM\&O

UDOT

USDOT

VISSIM

VISTRO

WB

WBL

WBT

WisDOT
Takagi Sugeno Kang

Transportation Systems Management \& Operations

Utah Department of Transportation

United States Department of Transportation

Verkehr In Städten SIMulationsmodell

Vision Traffix and Optimization

Westbound

Westbound Left

Westbound Though

Wisconsin Department of Transportation 


\section{CHAPTER I}

\section{INTRODUCTION}

\subsection{Problem Statement}

Improving arterial network performance has become a major challenge that is significantly influenced by signal timing control. In recent years, agencies have begun focusing on arterial systems by supporting Active Arterial Management (AAM) strategies (Abdel-Aty et al., 2019). The activation of special traffic signal plans during non-recurrent events is an important component of AAM and can provide significant benefits in terms of performance metrics of the transportation systems. Most of the existing signal controller systems in the United States are operated based on time of day (TOD) signal timing plans. The TOD plans are prepared using historical traffic flow data collected for different times of the day and fine-tuned based on field observations. Such plans lack the consideration of non-recurrent congestion due to incidents and other lane blockage events, as well as surges in demands due to special events. In some cases, agencies have deployed adaptive signal control technology. However, such implementations are still limited, and the adaptive signal control may not be as effective under all conditions, particularly under heavily congested conditions with long queues.

With non-recurrent events that cause reductions in capacity or an increase in demand, congestion can occur and extend to upstream intersections from the bottleneck location. In these conditions, the vehicle queues continue to grow from cycle to cycle, either due to insufficient green times that cannot meet the demands or because of blockages that prevent traffic from efficiently using the assigned green times. The spillback to the upstream 
intersection causes parts of the green time intervals at the upstream intersection to be constrained by the downstream queue. During the red interval(s) of the upstream feeding links to the downstream link, the queue starts decreasing due to the reduction in the arrivals at the back of the queue, creating queuing capacity that accommodates the flows from the upstream links in the next green phase. During the first parts of the upstream link green phases, referred to as the "unconstrained green", the vehicles will be able to leave the stop lines of the feeding links at the saturation flow rates of these links until the queue due to the downstream incident spill backs to the upstream signal again. The rest of the green time can be referred to as the 'constrained green'. As a result of this constraint, the queues can interrupt the flows on the arterial network and can also spill back on freeway ramps, consequently creating congestion on freeway facilities. Thus, it is critical to actively change the signal timings to address the lane blockages and the surges in demands on the arterial networks.

To mitigate the adverse effect of non-recurrent events such as incidents, surges in demands, and work zones, some agencies have hired traffic signal engineers/expert operators to actively manage the traffic signal controls during these events. These agencies have started implementing processes to change signal timing in real time based on traffic signal engineer/expert operator's observations of incident and traffic conditions at the intersections upstream and downstream of the congested locations. Their strategy involves observing the queue formation based on videos received from closed-circuit television (CCTV) cameras and travel time maps produced using public agency data or third-party providers. The decisions to change the signal timing are based on observations such as the 
conditions of the main and side streets, comparison of the queue spillback situation with historical queues, and the anticipated effects of queues on the upstream intersections.

In order to maintain coordination, in many cases, expert operators keep the same cycle length between intersections while changing the green to cycle ratio $(\mathrm{g} / \mathrm{C})$ in the congested direction downstream of the incident location by taking green times from other intersection movements without violating the minimum vehicular and pedestrian greens. If the incident is severe and the congestion cannot be mitigated by increasing the green times within the same cycle, the traffic signal engineer may decide to change the cycle length and put the intersection out of coordination. This process of changing signal timing by human experts is time-consuming and expensive, requiring processes to capture nonrecurrent event characteristics, downloading the existing timing, observing the traffic network conditions, designing new timing plans, and implementing the new plans. Moreover, the expert signal engineers/expert operators may change jobs, resulting in an important loss of acquired knowledge and experience. The experts also do not provide the service 24 hours a day/ 7 days a week at traffic management centers (TMCs). Thus, there is a need to automate the decisions to change signal timing plans. One of the objectives of this study is to automate the process of updating the signal timing plans during nonrecurrent conditions by capturing the history of the responses of the traffic signal engineers to non-recurrent conditions by utilizing this experience to train a machine learning model, which will facilitate a proactive, consistent and easily implementable approach to addressing traffic congestion during non-recurrent events.

Although the expert's intervention during a non-recurrent condition is an effective solution minimizing vehicle delay and long queue formation, this system only recommends 
the changes in green time to the movements that are impacted by events like incidents or demand surges. There is still a need to optimize how decreasing green times should be distributed to other intersection approaches. Thus, it is crucial to further integrate the decision support system with other data and optimization techniques to improve signaltiming decisions. These techniques can be enhanced with the availability of detailed Automated Traffic Signal Performance Measures (ATSPMs) based on high-resolution controller data and micro-simulation tools. In non-recurrent traffic conditions, the application of improved algorithms and optimization procedures to obtain an effective traffic signal setting is an essential requirement for successful arterial operation performance. With such an application, optimization algorithms and high-resolution data can improve travel conditions on the major corridors without serious detriment to minor traffic flows.

Choosing an appropriate objective function for optimizing traffic signal timing is critical because the choice will affect the overall network performance. It is well established that timing traffic signals is a multi-objective problem, in which optimizing the solution based on one variable can often work to the detriment of another. For example, optimizing signal timings by putting a higher weight on the arterial progression can cause excessive delay on the side streets. Optimization based on network delay may not ensure an effective utilization of intersection capacity to the fullest in the case of congested conditions. In these cases, the use of a multi-objective optimization technique can generate the best solution with the inclusion of many performance measures of the arterial network.

Signal timing optimization should be dynamic where the signal timing control strategy and the associated plans are selected based on the assessed traffic conditions, 
including the congestion level. To achieve this goal, it is essential to have accurate congestion condition identification and traffic pattern partitioning based on the collected data.

Conventional traffic data collection and utilization methods aggregate traffic measurements such as vehicle flow, speed, and occupancy in 15 minutes to one-hour resolution (Ali et al., 2017). On arterial networks, day-to-day as well as cycle-to-cycle variations in the measurements are important, including the measurements of volumes, vehicle platoon arrivals, discharge rates, and green time utilization. These measurements at signalized intersections significantly affect the estimation of network performance. In recent years, new data collection technologies are emerging that can be used to support better development and calibration of simulation models, including multi-scenario simulation.

High-resolution controller data identifies when a vehicle arrives at or departs from a vehicle detector, and records the changes of signal status within a $0.1-\mathrm{sec}$ resolution. This data allows estimating vehicle arrivals and departures, green time utilization, signal control timings, and other parameters. This information can be used to obtain representative traffic operational scenarios for a more accurate estimation of arterial network performance measures. It can support the estimation of more detailed, accurate, and microscopic parameters of traffic flow and associated control to enhance traffic simulation modeling quality. In this study, PTV's Verkehr In Städten SIMulationsmodell (VISSIM) microscopic simulation tool is used for generating micro-simulation traffic models.

This study examines methods to design and activate signal timing strategies and associate plans to mitigate detected non-recurrent congestion. The use of multi-objective 
optimization combined with machine learning and fuzzy logic is explored. This study proposes methodology and algorithms to combine data collected from existing and emerging sources with enhanced models and optimization algorithms to optimize and manage signal operations during non-recurrent events. The results from applying the developed methods and algorithms are examined to investigate their ability to reduce travel time and delays at the signalized intersections, increase system throughput and travel time reliability, and provide a better queue management strategy. The methods explored in this study are useful for application to mitigate the adverse impacts during lane blockage conditions due to incidents close to the subject intersection or demand surges from upstream traffic demand feeding sources.

\subsection{Research Goal and Objectives}

This study aims to develop methods to activate signal timing plans that will mitigate detected non-recurrent congested conditions in real-time operations. The specific objectives are:

- Examine the ability to use data from multiple sources and advanced data analytic models to identify congested conditions that require switching to special signal timing plans.

- Develop methods to generate special signal timing plans to mitigate the detected congested conditions.

- Identify the impacts of selecting and activating the special signal plans in response to the identified congestion. 


\subsection{Dissertation Organization}

This dissertation includes a total of five chapters. Chapter II provides a literature review of previous studies on signal timing during congested conditions and the use of emerging data sources and advanced algorithms in signal control strategies. Chapter III presents the methodology that is used to achieve the stated objectives. Chapter IV describes the results from the application of the methodology developed in this study. Finally, Chapter V summarizes the findings from this research and provides recommendations for future studies. 


\section{CHAPTER II}

\section{LITERATURE REVIEW}

Transportation agencies usually operate signal control systems based on time of day plans. These plans are prepared using historical traffic flow data from different times of the day (Urbanik et al., 2015). Time of day signal timing plans lack the consideration of nonrecurrent congestion due to incidents and other lane blockage events and cannot address the congestion due to the stochastic variations in demand and capacity. In particular, lane blockages due to incidents create queue spillbacks even during off-peak periods resulting in unused green times by the constrained traffic at the upstream intersection(s) (Tariq et al., 2020). Some locations have Adaptive Traffic Control Systems (ATCSs). These systems adjust signal timings based on the current traffic conditions, demand, and system capacity in real time. However, the true adaptability of ATCSs during congestion conditions with long queues is questionable. Campbell and Skabardonis (2014) reported three issues with adaptive signal control during oversaturated conditions. The first issue is that the system does not allocate enough green time to the critical approach at the bottleneck intersection. The second issue is that allocated green time at the critical approach of the upstream intersection may be more than necessary, which can oversaturate the bottleneck location. The third is the inefficiency of the offset settings at the downstream intersection of the bottleneck location, resulting in additional delays for traffic departing the bottleneck and creating the potential for queue spillbacks to the bottleneck itself.

The Federal Highway Administration (FHWA) identified the anticipation and response to planned and unplanned events as an important issue. They emphasized the need 
for automating the selection of pre-planned signal timing plans to manage the special events by identifying incident lane closures and increased volume thresholds (Platman et al, 2018). State and local transportation agencies have reached the same conclusion. For example, the Florida Department of Transportation (FDOT) District 5 documented in the District's ITS Master Plan that there is a need to identify incident details through CCTV cameras, emergency responder agency contacts, and other sources during non-recurrent traffic conditions. Such identification will allow traffic signal engineers to determine if the conditions warrant an alternate signal timing plan based on the severity of incidents and the percentage of lanes blocked (FDOT, District 5, 2016; Nafis et al., 2019).

A key application of the special signal timing plan identified in the literature is the sudden increase in demand due to freeway incidents that cause traffic diversion to alternative routes. Such applications are considered a critical component of integrated corridor management (ICM). The benefit assessment of the Maryland CHART (Coordinated Highways Action Report Team) program reported in 2011 that the application of diversion special signal timing plans to accommodate diversion onto parallel arterials during freeway incidents resulted in a total delay time reduction of 33.56 million vehicle-hours, as well as a total fuel consumption reduction of 6.49 million gallons (Chang and Rochon, 2011).

This chapter is divided into two main parts. The first part reviews previous studies on signal timing during congested conditions and the use of emerging data sources for signal control. This part describes important signal timing parameters, traditional state-ofpractice, previous studies on signal timing modification during non-recurrent and/or oversaturated conditions, the use of emerging data sources in signal timing performance 
measures, and traffic pattern identification methods. The second part reviews advanced algorithms in signal control strategies. This part presents algorithms for human decision automation, traffic pattern identification, and optimization.

\subsection{Review of Literature on Traditional Practice and Previous Studies}

This section first describes the basic signal timing parameters. Then, traditional practices and previous studies on signal timing modification during non-recurrent and/or oversaturated conditions are reviewed, followed by the description of the practices and the need for simulation model calibration. Finally, a review on the use of high-resolution controller data in signal timing performance measures and traffic pattern identification methods is presented.

\subsubsection{Considerations in Selecting Signal Timing Parameters}

The basic parameters of the traffic signal control system are cycle length, green splits, and offsets. Signal performance measures are heavily affected by these three parameters, which are discussed in the following section.

\section{Cycle Length:}

The selection of the cycle length is an important feature of signal timing plan selection. To maintain a synchronized traffic flow, adjacent intersections should operate

with a common cycle length. Some restrictions need to be placed on the cycle lengths of individual signals. Vehicle delay is affected by the selection of the cycle length. Delays increase significantly when the cycle length is lower than a minimum and higher than a maximum cycle length, which depends on the degree of saturation (Chaudhary et al., 2002). Figure 2-1 shows the variations in delay with the increase and decrease of the cycle lengths 
using the Webster's equations and Highway Capacity Manual (HCM, 2000) according to Cheng et al. (2003).

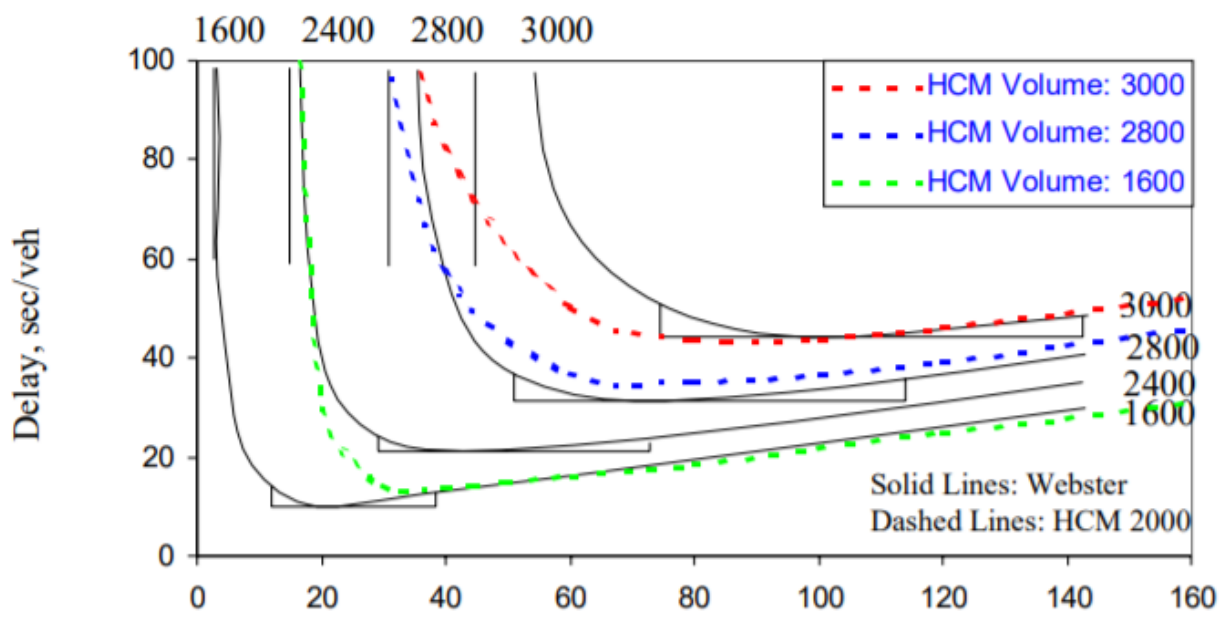

Cycle Length, sec

Figure 2-1: Delay Variation with the Cycle Length Estimated Using the Webster and Highway Capacity Manual (HCM) 2000 Methods (Source: Cheng et al., 2003) (Note: The volume unit in the figure is vehicles per hour.)

These restrictions on the cycle length can be established using Webster's theory to determine the minimum and maximum cycle lengths according to Equations 2-1 and 2-2. (Webster and Cobbe, 1966).

$$
\begin{gathered}
c_{c}=\frac{L}{1-Y} \\
c_{m}=\frac{1.5 L-5}{1-Y}
\end{gathered}
$$

where

$\mathrm{C}_{\mathrm{C}}=$ Critical or minimum cycle length (seconds),

$\mathrm{C}_{\mathrm{m}}=$ Maximum cycle length (seconds),

$\mathrm{L}=$ Total lost time for all critical phases in seconds, and 
$\mathrm{Y}=$ Sum of flow ratios (volume/saturation flow ratios) for all critical phases.

\section{Green Splits:}

The most basic method used to calculate green splits is to allocate the selected signal cycle to signal phases in proportion to the volume-to-saturation flow ratios for the critical movement served by each of these phases. However, more advanced and refined techniques such as optimization and machine learning methods have been used to identify the green splits in order to improve the performance of the signalized system.

\section{Offsets:}

The offsets between the intersections influence progression quality. Therefore, arterial performance is also greatly affected by the offset settings. An important performance measure in signal control performance is the percentage of vehicle arrivals on

green. A large proportion of vehicles arriving during the green time is a sign of good arterial progression.

\subsubsection{Traditional Practices for Signal Timing Modification}

One of the most effective strategies used to mitigate the impacts of non-recurrent events is to prioritize specific movements affected by events in order to minimize the delays to these movements, as well as the overall delay in the network. For example, the Florida Department of Transportation (FDOT) District 4 Arterial Management Program (AMP) uses operators to change the signal timing plans during non-recurrent events in both Broward and Palm Beach counties in South Florida. The estimated Benefit-Cost (B/C) ratios of the program for Palm Beach County and Broward County were estimated to be 7.76 and 5.03, respectively, in 2016 (FDOT District Four, 2017,2018,2019). 
As part of the Dallas US-75 ICM corridor project, incident signal timing plans are developed to flush the diverted vehicles to arterials during freeway incidents (Alexiadis, and Chu, 2016a). Clustering analysis was first conducted to classify incidents into different groups based on different traffic and incident attributes (Alexiadis, and Chu, 2016a). The probable diversion was then estimated using a simulation-based dynamic traffic assignment model, and signal timing plans were developed for the identified clusters and prioritized based on their impacts on the freeway and the surrounding roadway network delays. A database was created that includes criteria-based expert rules for response plan recommendations (Alexiadis, and Chu, 2016a).

Most of the signalized intersections within the San Diego I-15 ICM network are operated utilizing actuated signal control (Alexiadis, and Chu, 2016b). During a congested event, some intersections along the alternative routes switch to a special signal timing plan to provide additional green time to accommodate the increased traffic. The decision to activate the plans is supported by a real-time simulation model. Changing signal timing plans during freeway and major incidents that occur on arterial streets was also proposed in the concept of operation of the I-210 ICM project (Dion et al., 2015). Signal timing changes were modeled in two of the four evaluation scenarios (Patire et al., 2016). In those two scenarios, signal timing plans along the arterial were modified to increase the capacity of the main approaches by increasing the cycle length and the relative green time for the main direction while the green time for the side streets was kept constant. Tariq et al. (2019) estimated the diversion due to freeway incidents based on detector data and argued that the diversion is constrained by the capacity of the signals at the off-ramps and adjacent signals during congested periods, which indicates the need for special signal control plans during 
incidents to increase the capacity of these signals. Saha et al. developed methods for the selection of special signal timing plans to accommodate traffic diversion during freeway incidents to arterial streets (Saha et al., 2020a; Saha et al., 2020b; Saha et al., 2021).

A good example of the adaptive signal control strategy that explicitly considers the oversaturated condition is the "gating" strategy implemented in the Split, Cycle, Offset Optimization Technique (SCOOT) system. Gating provides a feature that terminates upstream movement phases and reduces the upstream traffic flow to high congestion intersections, thus preventing spillbacks (Wood, 1970). Another strategy that has been proposed to control queues at congested intersections is to provide a "reverse offset" instead of a forward offset between intersections. The reverse offset refers to determining the offset at the upstream intersection based on the start of green of the downstream intersection with the consideration of the time required for the recovery shockwave to move to the upstream intersection (Quinn, 1992).

Another practice for a coordinated arterial network is to use "double cycling". An example of double cycling is when all of the signals in a coordinated corridor operate at a cycle length of 120 seconds, except for one signal operating at a 60-second cycle length. Using this technique, the operator can maintain fixed synchronization and reduce vehicle queuing and potentially, wait time (Chaudhary et al., 2002).

\subsubsection{Existing Signal Timing Optimization Tools}

Several signal timing optimization tools have been developed in the past few decades to generate signal timing parameters. These tools optimize traffic delay and number of stops, as well as other measures of effectiveness to improve travel conditions. 
Among the existing tools, Synchro is currently the most widely used signal timing optimization tool used by transportation professionals in the United States. It is a delaybased signal timing design tool, which can compute intersection offsets, as well as cycle lengths and phase splits. The program calculates the cycle length and green splits using Webster's method and calculates the intersection delay using the HCM method (Benekohal et al., 2001). This program does not model platoon dispersion effects, spillback effects, or "bottleneck" situations where upstream traffic deficiencies reduce the traffic volumes reaching downstream of the intersections.

Synchro calculates the "Coordinatability Factor", which is used to recommend whether the signals should be coordinated. This factor considers travel time, volume, distance, vehicle platoons, vehicle queuing, and natural cycle lengths. The potential for vehicle queues exceeding the available storage is also considered in determining the desirability of coordination (Henry and Sabra, 2005). The offsets are selected using a quasiexhaustive search that attempts to minimize delay.

Another software package, the Highway Capacity Software (HCS), is a macroscopic modeling approach that implements the HCM procedures. The HCS can optimize pretimed signal timing at a single intersection for minimum delay using the SOAP2K tool method and also estimate the actuated phase lengths (Cheng et al., 2005). Currently, the Streets module within HCS 2010 can optimize signal timing for an arterial segment based on the HCM 2010 procedures using a Genetic Algorithm. HCS 2010 can optimize the signal timings based on several objective functions, including the Percent Free-Flow Speed for Level of Service, Overall Delay, Arterial Delay, Arterial Stops, Travel Time, and Travel Speed. 
The TRAffic Network StudY Tool (TRANSYT) is a signal timing optimization package developed by the Transport Research Laboratory in the United Kingdom, which is one of the most widely used for signal timing optimization. Version 7 of TRANSYT was "Americanized" by the University of Florida Transportation Research Center for the Federal Highway Administration (FHWA) and named TRANSYT-7F (Cohen and Liu, 1986; Park et al., 2001). TRANSYT-7F uses a system "performance index" (PI) to optimize signal timing (Wallace, C. E. et al., 1998). Optimization of the cycle length, splits, and offsets is done by minimizing a Disutility Index (DI), which is a function of delay, number of stops, fuel consumption, and, optionally, queue spillover.

Some of the frequently used tools and their adapted optimization methods and optimized parameters are listed in Table 2-1.

Table 2-1 Existing Signal Timing Optimization Tools

\begin{tabular}{|c|c|c|c|}
\hline Tools & Source & Methods & Optimization Parameters \\
\hline MAXBAND & $\begin{array}{l}\text { Little et al., } \\
\text { 1966; } \\
\text { Little et al., } \\
1981\end{array}$ & \multirow[t]{2}{*}{$\begin{array}{l}\text { Mixed Integer Linear } \\
\text { Programming (MILP) } \\
\text { method }\end{array}$} & \multirow[t]{2}{*}{$\begin{array}{l}\text { Bandwidth/progression } \\
\text { maximization }\end{array}$} \\
\hline MULTIBAND & $\begin{array}{l}\text { Gartner et al., } \\
1991\end{array}$ & & \\
\hline \multirow[b]{3}{*}{ PASSER II } & \multirow[t]{3}{*}{$\begin{array}{l}\text { Chang and } \\
\text { Messer, } 1991\end{array}$} & Exhaustive search & $\begin{array}{l}\text { Cycle length estimation using } \\
\text { Webster's method }\end{array}$ \\
\hline & & Hill-Climbing optimization & $\begin{array}{l}\text { Adjust splits by minimizing the } \\
\text { delay }\end{array}$ \\
\hline & & $\begin{array}{l}\text { Bandwidth maximization } \\
\text { and fine-tuning using } \\
\text { interference algorithm for } \\
\text { both directions }\end{array}$ & $\begin{array}{l}\text { Optimize phasing sequence and } \\
\text { offset }\end{array}$ \\
\hline \multirow[t]{2}{*}{ PASSER V } & \multirow[t]{2}{*}{$\begin{array}{l}\text { Chaudhary and } \\
\text { Chu, } 2003\end{array}$} & $\begin{array}{l}\text { Genetic Algorithm -Based } \\
\text { Optimizer and } \\
\text { Bandwidth maximization } \\
\text { algorithms }\end{array}$ & $\begin{array}{l}\text { Minimizing delay } \\
\text { bandwidth/progression } \\
\text { maximization }\end{array}$ \\
\hline & & $\begin{array}{l}\text { Interference algorithm and } \\
\text { Time space diagram tool }\end{array}$ & Fine tuning offset \\
\hline
\end{tabular}




\begin{tabular}{|l|l|l|l|}
\hline Tools & Source & Methods & Optimization Parameters \\
\hline TRANSYT \& \\
TRANSYT-7F & $\begin{array}{l}\text { Wallace et al., } \\
1998\end{array}$ & $\begin{array}{l}\text { Exhaustive search for cycle } \\
\text { length, Hill-Climbing and } \\
\text { Genetic Algorithm (GA) } \\
\text { based optimization methods }\end{array}$ & $\begin{array}{l}\text { Optimize progression } \\
\text { bandwidth/function of delay, stops, } \\
\text { fuel consumption / and, optionally, } \\
\text { queue spillover. A later version } \\
\text { considered "throughput measure" } \\
\text { and “queuing measures" in } \\
\text { objective functions }\end{array}$ \\
\hline HCS & $\begin{array}{l}\text { Benekohal et } \\
\text { al., 2002 }\end{array}$ & $\begin{array}{l}\text { SOAP2K tool method, } \\
\text { Genetic Algorithm }\end{array}$ & $\begin{array}{l}\text { Split optimization by minimizing } \\
\text { Delay }\end{array}$ \\
\hline SYNCRO & $\begin{array}{l}\text { Henry and } \\
\text { Sabra, 2005 }\end{array}$ & Exhaustive search technique & $\begin{array}{l}\text { Minimizes delay, number of stopa } \\
\text { and queue size by applying } \\
\text { penalties for these measures }\end{array}$ \\
\hline SIGOP & $\begin{array}{l}\text { Lieberman et } \\
\text { al., 1976 }\end{array}$ & $\begin{array}{l}\text { Monte Carlo simulation and } \\
\text { gradual increment method } \\
\text { for offset optimization }\end{array}$ & $\begin{array}{l}\text { Delay, number of stops and excess } \\
\text { queue }\end{array}$ \\
\hline VISGAOST & $\begin{array}{l}\text { Stevanovic } \\
\text { et.al., 2007 }\end{array}$ & $\begin{array}{l}\text { VISSIM-based Genetic } \\
\text { Algorithm }\end{array}$ & $\begin{array}{l}\text { Optimizes the fitness function } \\
\text { combination of delay, travel time, } \\
\text { number of stops, and throughput }\end{array}$ \\
\hline VISTRO & $\begin{array}{l}\text { PTV Group, } \\
\text { 2014 }\end{array}$ & $\begin{array}{l}\text { Hill Climbing and Genetic } \\
\text { Algorithm }\end{array}$ & $\begin{array}{l}\text { Optimizes the weighted sum of } \\
\text { delays and number of stops }\end{array}$ \\
\hline
\end{tabular}

\subsubsection{Previous Researches on Signal Timing Strategies}

Several research and development efforts addressed selecting traffic signal control during oversaturated conditions. Liberman et al. (2000) proposed a real-time traffic control policy to select signal timing based on estimated queue lengths. The goal was to control and stabilize queue lengths and provide equitable service to competing traffic streams by metering traffic at intersections, thus servicing oversaturated approaches while fully utilizing storage capacity and preventing queue spillback from maximizing the throughput that controls the interaction between incoming platoons and standing queues.

Researchers investigated the incorporation of knowledge-based artificial intelligent layers to support traffic management (Han and May, 1988; Scemama, 1994; Ritchie, 1990; Cuena et al., 1995). Some of these studies proposed the use of fuzzy decision support systems used for providing traffic control under different traffic situations (Cuena et al., 1995; Hegyi et al., 2001). For example, a knowledge-based decision support system was 
developed to identify critical traffic states, propose possible changes in the current signal timing plan, and decide which action should be taken (Cuena et al., 1995). Other systems have used "expert" systems, which represent traffic engineers' knowledge (Cuena et al.,1992; Deeter and Ritchie, 1993; Wild, 1994).

Optimization of a traffic signal setting is one of the most important requirements of a successful arterial performance. Choosing an appropriate objective function for optimizing traffic signal timing is critical because the choice will affect the overall network performance. Delay minimization is mostly used as an objective function for signal timing optimization, sometimes combined with the number of stops (Eriskin et al., 2017). However, instead of only delay minimization, a combination of delay minimization, system throughput maximization and queue maintenance are crucial for oversaturated conditions (Hadi et al., 1999; Li and Gan, 1999; Abu-Lebdeh and Benekohal, 2003; Lieberman et al., 2000; Lieberman and Chang 2005). Signal timing optimization should be dynamic in that the signal timing control strategy and the associated plans should be selected based on the assessed conditions, including the congestion level. It is essential to have accurate congestion condition identification and queue estimation methods based on the collected data to achieve this goal. The following section discusses previous research conducted for signal timing optimization for oversaturated conditions.

Signal optimization for oversaturated conditions has been studied since the 1960s. In early studies, many researchers suggested that the objective function used in oversaturated intersection optimization should be based on maximizing system throughput instead of minimizing delay (Gazis and Potts, 1963; Gazis, 1964; Gordon, 1969; Singh and Tamura,1974; Mcshane et al., 1978). 
On the other hand, Michalopoulos and Stephanopoulos (Michalopoulos and G. Stephanopoulos, 1978) proposed a so-called "bang-bang” control model to minimize the delay of oversaturated intersections with queue-length constraints. Michalopoulos and Stephanopoulos developed timing strategies for undersaturated and oversaturated conditions and two-staged timing methods to identify switching over point (Michalopoulos and G. Stephanopoulos, 1978). Chang and Lin extended this work to identify the timing of switching strategies (Chan and Lin, 2000). Chang and Sun further extended the model for oversaturated networks by introducing the traffic flow propagation model in an integrated approach with TRANSYT-7F, where TRANSYT-7F identifies signal timings for undersaturated intersections while utilizing the two-stage model for oversaturated intersections (Chang and Sun, 2004).

While these methods concentrate on changing timing strategies between undersaturated and oversaturated conditions, other researchers have focused on solely identifying optimum cycle lengths and green times for oversaturated conditions (Chang, 2001). Liberman et al. (2000) proposed a real-time traffic control policy to develop the relationship between the queue and signal timing (Lieberman et al., 2000) (Chang, 2001). This proposed queue estimation method uses input-output balancing of the advanced detector's occupancy profile. Lieberman and Chang (2005) used a mixed-integer linear programming approach and heuristic optimization methods to the extent of this methodology. They implemented their method to a grid network by decomposing it into its constituent arterial subsystems in response to user-specified priorities (Lieberman and Chang, 2005). 
Girianna and Benekohal (2004) used genetic algorithm optimization to design a discrete-time signal-coordination model for coordinated oversaturated intersections to distribute the queue of the oversaturated intersections and ensure that the queues are reduced or cleared before released platoons arrive at a downstream signal system. A quadratic programming approach was used to minimize and balance the link queues for real-time network-wide signal control in large-scale urban traffic networks (Aboudolas et al., 2010).

Hadi and Wallace (1993) developed a hybrid genetic algorithm approach to be implemented in the TRANSYT-7F program. Their method optimizes cycle length, phase sequence, and offsets, whereas TRANSYT-7F is used to optimize green splits. Hadi and Wallace (1995) proposed an enhancement function to TRANSYT-7F to enable the program to analyze and optimize signal-timing plans under congested conditions. The enhancement improved the program's capability by implementing extensions to the objective function that considers queuing and/or throughput if queue spillback occurs (Wallace et al., 1998).

Park et al. (1999) proposed a genetic algorithm (GA) optimization strategy that includes a combination of delay minimization with a penalty function and throughput maximization based on the TRANSYT-7F model for optimal signal timing and queue management of oversaturated conditions (Park et al., 1999). Later, they tested three different optimization strategies and evaluated the strategies for different intersection configurations (Park et al., 2000).

Abu-Lebdeh and Benekohal (1997, 2000, 2003) presented a set of dynamic control and queue management algorithms for signal optimization to manage the queue formation and dissipation on oversaturated network links. They maximized the throughput by 
managing queue formation and dissipation under oversaturated traffic conditions. (AbuLebdeh and Benekohal,1997; Abu-Lebdeh and Benekohal, 2000; Abu-Lebdeh and Benekohal, 2003). Abu-Lebdeh et al. (2007) presented several models that can capture intersection traffic throughput while explicitly considering the interactions between traffic streams at adjacent signals.

Version 13 of TRANSYT included a cell transmission model as an alternative method to its embedded platoon dispersion model, enabling the model to consider the spillback effects and the time-varying flow evolution (Binning et al. 2008). Li (2010) proposed a model to capture traffic dynamics with the cell transmission concept by considering complex flow interactions among different lane groups under oversaturated conditions.

Liu and Chang (2011) developed a genetic algorithm for signal timing optimization during blockage and spillback conditions by minimizing the travel time or maximizing system throughput. They also compared their results with the output from TRANSYT-7F (version 8) and showed that their proposed model works better under congested and high demand traffic conditions. Long et al. (2011) developed a traffic control utilizing vehicle movement ban strategies to avoid gridlock situations during incidents in a grid network. They evaluated the control strategies in a simulated environment and found promising results in reducing congestion.

\subsubsection{Practice and Need for Simulation Model Calibration}

Calibration of traffic simulation models is a critical component of simulation modeling. The increasing complexity of the transportation network and the adoption of the emerging vehicle and infrastructure-based technologies and strategies have motivated the 
development of new methods that utilize new data sources in the calibration. There has been increasing recognition for the need for more detailed and specific guidance for utilizing simulation tools, considering the increasing complexity of simulation modeling. Several states have developed guidelines for utilizing simulation modeling, including a strong emphasis on calibration. The FHWA Traffic Analysis Toolbox documents have provided valuable information regarding the use of traffic analysis tools, including simulation model calibration (Wunderlich et al., 2019). However, the existing simulation calibration guidance focuses on the use of field-measured macroscopic traffic flow parameters such as average travel times, approach volumes, turning movement counts, and queue lengths as measures of effectiveness (MOEs) to calibrate microscopic driving behavior parameters (Benekohal and Abu-Lebdeh, 1994; Hellinga, 1998; Ma and Abdulhai, 2002; Arafat et al., 2020). More recently, there has been an increasing interest in using microscopic parameters such as vehicle trajectories in simulation model calibration (Jie et al., 2013; Kesting and Treiber, 2008; Essa and Sayed, 2015).

In practice, the calibration of simulation models has relied on a manual iterative process to adjust the simulation model parameters to allow the model to better represent field traffic conditions. However, several researchers automate the calibration process using optimization-based approaches such as gradient search, simplex-based, and genetic algorithm (GA), aiming to minimize the error between field and simulation traffic parameters (Ma and Abdulhai, 2002; Kim and Rilett, 2003; Kim et al., 2005; Park and Qi, 2005). However, these studies calibrated the models based on macroscopic measures, even when using advanced optimization techniques. Combining the use of more detailed traffic measurements and advanced optimization techniques has the potential to achieve a more 
accurate and reliable replication of traffic conditions in the simulation model. Such combinations are investigated in this study.

\subsubsection{Use of High-Resolution Controller Data in Signal Timing Performance Measures}

Detailed signalized intersection parameters such as the number of vehicles utilizing an intersection, detector occupancy during green time and red time, and percentage of vehicle arrival on green are very important measures used to evaluate the performance of an intersection. Data from existing system detectors have been used to analyze the performance of signalized intersections for a long time. In the past, the most popular type of detector was inductive loop technology, which was installed at intersection approaches. More recently, video image detections at stop lines and microwave detectors for midblock detections have been used due to concerns with the maintenance requirements of inductive loops. Inductive detector failures are common, and maintaining them requires lane closures. The use of microwave sensors, video image processing, Bluetooth, or Wi-Fi readers has increased in recent years for the automatic collection of data on arterials.

In recent years, advanced data collection, processing, archiving, and mining techniques have motivated and enabled the retrieval of event-based high-resolution controller data from signal controllers (Smaglik et al., 2007a; Day et al., 2007; Wu and Liu, 2014). This data is being widely used by signal control agencies to assess their signal control performance and identify required changes to the system.

There are several studies in which researchers utilize the event-based controller data for the estimation of measures, such as arterial progression quality, which uses the coordination diagram (Day and Bullock, 2012), split utilization (Bullock and Day, 2009), green occupancy ratio (Day and Bullock, 2011; Gettman et al., 2013), arrival type (Dakic 
et al., 2017; Smaglik et al., 2007b), and vehicle arrival on green (Dakic et al., 2017; AlAbbas, 2018). This section provides a brief description of the data and the derived parameters based on the data.

The FDOT adopted an ATSPM software that was originally developed by the Utah Department of Transportation (UDOT). Agencies in Florida have used the ATSPM software tools, with Seminole County being the first to use the FDOT tool in Florida. Other agencies have used other commercially available tools for this purpose.

One objective of this study is to investigate the use of this data in traffic pattern recognition, and in the calibration and validation of microscopic simulation models. This study hypothesizes that it is possible to capture the multidimensional features of arterial traffic by using various performance measures derived based on high-resolution control data.

\section{Data description}

The use of high-resolution data collected by traffic signal controllers has been developed and used for engineering-related performance measures over the past ten years. High-resolution controller data includes signal timing and detection at the highest time resolution of the controller ( 0.1 seconds), combined with data from other sources to support ATSPM. This data consists of various signal controller events that are logged in 0.1-s intervals based on a standardized set of event parameters and event identification codes. Figure 2-2 shows a sample of high-resolution event data. 


\begin{tabular}{|c|c|c|c|c|}
\hline Intersection ID & Date & Time & Event Code & Event Parameter \\
\hline $459196 \mathrm{~A} 1-55 \mathrm{~B} 0-4339-\mathrm{B} 1 \mathrm{E} 1-8868 \mathrm{D} 9 \mathrm{~A} 026 \mathrm{FA}$ & $11 / 1 / 2019$ & $12: 00: 07 \mathrm{AM}$ & 81 & 62 \\
\hline $459196 \mathrm{~A} 1-55 \mathrm{~B} 0-4339-\mathrm{B} 1 \mathrm{E} 1-8868 \mathrm{D} 9 \mathrm{~A} 026 \mathrm{FA}$ & $11 / 1 / 2019$ & $12: 00: 07 \mathrm{AM}$ & 44 & 5 \\
\hline $459196 \mathrm{~A} 1-55 \mathrm{~B} 0-4339-\mathrm{B} 1 \mathrm{E} 1-8868 \mathrm{D} 9 \mathrm{~A} 026 \mathrm{FA}$ & $11 / 1 / 2019$ & $12: 00: 07 \mathrm{AM}$ & 81 & 54 \\
\hline $459196 \mathrm{~A} 1-55 \mathrm{~B} 0-4339-\mathrm{B} 1 \mathrm{E} 1-8868 \mathrm{D} 9 \mathrm{~A} 026 \mathrm{FA}$ & $11 / 1 / 2019$ & $12: 00: 07 \mathrm{AM}$ & 81 & 42 \\
\hline $459196 \mathrm{~A} 1-55 \mathrm{~B} 0-4339-\mathrm{B} 1 \mathrm{E} 1-8868 \mathrm{D} 9 \mathrm{~A} 026 \mathrm{FA}$ & $11 / 1 / 2019$ & $12: 00: 08 \mathrm{AM}$ & 81 & 41 \\
\hline $459196 \mathrm{~A} 1-55 \mathrm{~B} 0-4339-\mathrm{B} 1 \mathrm{E} 1-8868 \mathrm{D} 9 \mathrm{~A} 026 \mathrm{FA}$ & $11 / 1 / 2019$ & $12: 00: 08 \mathrm{AM}$ & 81 & 49 \\
\hline $459196 \mathrm{~A} 1-55 \mathrm{~B} 0-4339-\mathrm{B} 1 \mathrm{E} 1-8868 \mathrm{D} 9 \mathrm{~A} 026 \mathrm{FA}$ & $11 / 1 / 2019$ & $12: 00: 11 \mathrm{AM}$ & 82 & 55 \\
\hline $459196 \mathrm{~A} 1-55 \mathrm{~B} 0-4339-\mathrm{B} 1 \mathrm{E} 1-8868 \mathrm{D} 9 \mathrm{~A} 026 \mathrm{FA}$ & $11 / 1 / 2019$ & $12: 00: 11 \mathrm{AM}$ & 82 & 56 \\
\hline $459196 \mathrm{~A} 1-55 \mathrm{~B} 0-4339-\mathrm{B} 1 \mathrm{E} 1-8868 \mathrm{D} 9 \mathrm{~A} 026 \mathrm{FA}$ & $11 / 1 / 2019$ & $12: 00: 12 \mathrm{AM}$ & 82 & 53 \\
\hline $459196 \mathrm{~A} 1-55 \mathrm{~B} 0-4339-\mathrm{B} 1 \mathrm{E} 1-8868 \mathrm{D} 9 \mathrm{~A} 026 \mathrm{FA}$ & $11 / 1 / 2019$ & $12: 00: 12 \mathrm{AM}$ & 82 & 62 \\
\hline $459196 \mathrm{~A} 1-55 \mathrm{~B} 0-4339-\mathrm{B} 1 \mathrm{E} 1-8868 \mathrm{D} 9 \mathrm{~A} 026 \mathrm{FA}$ & $11 / 1 / 2019$ & $12: 00: 12 \mathrm{AM}$ & 1 & 2 \\
\hline $459196 \mathrm{~A} 1-55 \mathrm{~B} 0-4339-\mathrm{B} 1 \mathrm{E} 1-8868 \mathrm{D} 9 \mathrm{~A} 026 \mathrm{FA}$ & $11 / 1 / 2019$ & $12: 00: 13 \mathrm{AM}$ & 1 & 6 \\
\hline $459196 \mathrm{~A} 1-55 \mathrm{~B} 0-4339-\mathrm{B} 1 \mathrm{E} 1-8868 \mathrm{D} 9 \mathrm{~A} 026 \mathrm{FA}$ & $11 / 1 / 2019$ & $12: 00: 13 \mathrm{AM}$ & 82 & 45 \\
\hline $459196 \mathrm{~A} 1-55 \mathrm{~B} 0-4339-\mathrm{B} 1 \mathrm{E} 1-8868 \mathrm{D} 9 \mathrm{~A} 026 \mathrm{FA}$ & $11 / 1 / 2019$ & $12: 00: 13 \mathrm{AM}$ & 82 & 47 \\
\hline $459196 \mathrm{~A} 1-55 \mathrm{~B} 0-4339-\mathrm{B} 1 \mathrm{E} 1-8868 \mathrm{D} 9 \mathrm{~A} 026 \mathrm{FA}$ & $11 / 1 / 2019$ & $12: 00: 14 \mathrm{AM}$ & 81 & 45 \\
\hline $459196 \mathrm{~A} 1-55 \mathrm{~B} 0-4339-\mathrm{B} 1 \mathrm{E} 1-8868 \mathrm{D} 9 \mathrm{~A} 026 \mathrm{FA}$ & $11 / 1 / 2019$ & $12: 00: 14 \mathrm{AM}$ & 82 & 46 \\
\hline $459196 \mathrm{~A} 1-55 \mathrm{~B} 0-4339-\mathrm{B} 1 \mathrm{E} 1-8868 \mathrm{D} 9 \mathrm{~A} 026 \mathrm{FA}$ & $11 / 1 / 2019$ & $12: 00: 14 \mathrm{AM}$ & 81 & 47 \\
\hline $459196 \mathrm{~A} 1-55 \mathrm{~B} 0-4339-\mathrm{B} 1 \mathrm{E} 1-8868 \mathrm{D} 9 \mathrm{~A} 026 \mathrm{FA}$ & $11 / 1 / 2019$ & $12: 00: 15 \mathrm{AM}$ & 2 & 5 \\
\hline $459196 \mathrm{~A} 1-55 \mathrm{~B} 0-4339-\mathrm{B} 1 \mathrm{E} 1-8868 \mathrm{D} 9 \mathrm{~A} 026 \mathrm{FA}$ & $11 / 1 / 2019$ & $12: 00: 15 \mathrm{AM}$ & 82 & 46 \\
\hline $459196 \mathrm{~A} 1-55 \mathrm{~B} 0-4339-\mathrm{B} 1 \mathrm{E} 1-8868 \mathrm{D} 9 \mathrm{~A} 026 \mathrm{FA}$ & $11 / 1 / 2019$ & $12: 00: 15 \mathrm{AM}$ & 43 & 7 \\
\hline $459196 \mathrm{~A} 1-55 \mathrm{~B} 0-4339-\mathrm{B} 1 \mathrm{E} 1-8868 \mathrm{D} 9 \mathrm{~A} 026 \mathrm{FA}$ & $11 / 1 / 2019$ & $12: 00: 15 \mathrm{AM}$ & 81 & 56 \\
\hline $459196 \mathrm{~A} 1-55 \mathrm{~B} 0-4339-\mathrm{B} 1 \mathrm{E} 1-8868 \mathrm{D} 9 \mathrm{~A} 026 \mathrm{FA}$ & $11 / 1 / 2019$ & $12: 00: 15 \mathrm{AM}$ & 82 & 27 \\
\hline $459196 \mathrm{~A} 1-55 \mathrm{~B} 0-4339-\mathrm{B} 1 \mathrm{E} 1-8868 \mathrm{D} 9 \mathrm{~A} 026 \mathrm{FA}$ & $11 / 1 / 2019$ & $12: 00: 15 \mathrm{AM}$ & 81 & 46 \\
\hline $459196 \mathrm{~A} 1-55 \mathrm{~B} 0-4339-\mathrm{B} 1 \mathrm{E} 1-8868 \mathrm{D} 9 \mathrm{~A} 026 \mathrm{FA}$ & $11 / 1 / 2019$ & $12: 00: 15 \mathrm{AM}$ & 81 & 53 \\
\hline $459196 \mathrm{~A} 1-55 \mathrm{~B} 0-4339-\mathrm{B} 1 \mathrm{E} 1-8868 \mathrm{D} 9 \mathrm{~A} 026 \mathrm{FA}$ & $11 / 1 / 2019$ & $12: 00: 16 \mathrm{AM}$ & 82 & 56 \\
\hline $459196 \mathrm{~A} 1-55 \mathrm{~B} 0-4339-\mathrm{B} 1 \mathrm{E} 1-8868 \mathrm{D} 9 \mathrm{~A} 026 \mathrm{FA}$ & $11 / 1 / 2019$ & $12: 00: 17 \mathrm{AM}$ & 7 & 2 \\
\hline $459196 \mathrm{~A} 1-55 \mathrm{~B} 0-4339-\mathrm{B} 1 \mathrm{E} 1-8868 \mathrm{D} 9 \mathrm{~A} 026 \mathrm{FA}$ & $11 / 1 / 2019$ & $12: 00: 18 \mathrm{AM}$ & 7 & 6 \\
\hline
\end{tabular}

\section{Figure 2-2 Example of High-Resolution Controller Data}

The high-resolution data consists of signal controller events based on a standardized set of event parameters and event identification codes. The stored parameters include the Timestamp, which contains the date and time of activities, and the Event Code and Event Parameters. The Event Code describes the type of event. The Event Parameters indicate the specific detector or signal phase where the event occurs. The definitions of Event Code and Event Parameter are provided in the Indiana Traffic Signal High-Resolution Data Logger (Sturdevant et al., 2012).

\section{Utilized Performance Measures}

In this study, performance measures based on high-resolution data are utilized for partitioning traffic operational scenarios. This data is also used for simulation model calibration and validation as part of the optimization process. The utilized measures are vehicle throughput, green occupancy ratio, split utilization ratio, and percentage arrival on green in each cycle. 
The high-resolution controller data provides the opportunity for cycle-by-cycle estimation of the throughputs. Having a separate detection channel per lane is required if lane-by-lane detection of the throughput is needed. The Green Occupancy Ratio (GOR) is a performance measure that reflects the degree of green utilization in each phase. It is defined as the stop bar detector occupancy during the green interval (Day and Bullock, 2011). Higher values of GOR reflect higher utilization of the green time. This value increases to values above 0.5 in the peak periods.

The Split Utilization Ratio (SUR) measures are derived for each intersection movement, which allows for the assessment of the congestion level in all intersection approaches. SUR is defined as the ratio of the number of vehicles passing the detector to the maximum number of vehicles that can pass during the effective green time (Day and Bullock, 2012) and can be calculated as follows:

$$
X_{k}=\frac{h_{k} \times N_{k}}{g_{k}}
$$

where

$\mathrm{X}_{\mathrm{k}}=$ Split utilization ratio of phase $\mathrm{k}$, $\mathrm{N}_{\mathrm{k}}=$ The vehicle counts at phase $\mathrm{k}$, $\mathrm{h}_{\mathrm{k}}=$ Saturation headway of phase $\mathrm{k}$ (seconds), and $\mathrm{g}_{\mathrm{k}}=$ Effective green time of phase $\mathrm{k}$ (seconds).

The Percent Arrivals on Green (POG) is calculated as the proportion of vehicles that arrive at the green signal indication versus the proportion of vehicles that arrive at the red signal (Bullock and Day, 2009). This measure reflects the progression of traffic. 


\subsubsection{Identification and Partitioning of Traffic Operational Conditions}

Clustering analysis is an unsupervised machine learning method that is capable of classifying each data point into a specific group. Clustering analysis is the most practical method for the identification of traffic patterns that are representative of traffic conditions in support of analysis, modeling, and simulation (AMS) (Rausch, 2007) (Yelchuru et al., 2017; Hadi et al., 2019; Vasudevan, M., and Wunderlich, 2013). This type of analysis has been recommended for the development and calibration of simulation, particularly those used to assess transportation system operations and management strategies. Partitioning the field traffic conditions allows agencies to better plan, design, and evaluate new technologies and traffic operation strategies (Saha et al., 2019). The most extensive example of the utilization of clustering analysis in transportation engineering is its use in

the AMS testbed effort funded by the FHWA (Wunderlich et al., 2013; Vasudevan and Wunderlich, 2013).

Recent guidance provided in the updated Traffic Analysis Toolbox Volume III (FHWA) recommends using clustering to identify operational scenarios for use in calibration, such as different congestion levels, incident conditions, and weather conditions (Wunderlich et al., 2019). In this study, clustering analysis is performed using parameters derived based on high-resolution controller data and travel time data to identify traffic patterns that represent field traffic conditions.

\subsection{Utilized Algorithms in Signal Timing Plan Selection}

This study applies advanced machine learning and optimization algorithms to support the development and activation of special signal timing plans in response to nonrecurrent congestion. This research uses data cleansing, clustering analysis, combination 
of decision tree and fuzzy rule-based system, and optimization techniques that are implemented in this research and can be used to provide an efficient solution for nonrecurrent congestion in arterial networks. The following section presents an overview of the algorithms utilized in this study.

\subsubsection{Decision Tree and Fuzzy Rule Based System}

A combination of a Decision Tree and Fuzzy Rule-Based System is used in this study to automate the decisions made by TMC signal engineers/expert operators when they observe and identify non-recurrent congestion. The Decision Tree (DT) is one of the most popular and effective supervised machine learning techniques for prediction and classification problems. A DT is developed to estimate the outcome variable based on a training dataset. DT can work with high dimensional data, can be developed in an efficient manner, and can produce results that are easy to present and be understood by humans (Han, 2011). DT can be used to produce sets of decision rules by converting the resulting tree structure to "if" and "then" rules. If the condition of the first rule is true, then it uses the prediction of the first rule. If not, then it goes to the next rule and checks if it applies and so on.

There are many algorithms available for the development of the decision trees; with the most widely used being the Iterative Dichotomizer 3 (ID3), and C4.5, which is a successor of ID3, Classification and Regression Trees (CART), and Chi-square Automatic Interaction Detector (CHAID) (Singh, 2014). In general, the DT algorithms search for the dominant attribute among all of the other attributes. Then, the most dominant attribute is put on the top of the tree as the top-level decision node. This search is repeated for the other attributes at the next levels of the DT. In the tree development process, the algorithms 
assess the measure of the effectiveness of partitioning the DT. Three popular impurity quantification methods can be used as alternative measures of effectiveness: Entropy or information gain, Gini Index, and Classification Error (Tan et al., 2006).

Often, in the case of human decision rule definitions, the rules cannot be delimited by sharp boundaries and associated with one-to-many relations or ambiguousness. The Fuzzy Rule-Based System (FRBS) extends the problem of classification and prediction to consider the vagueness and uncertainty in data more efficiently based on the fuzzy logic and fuzzy sets theory (Sugeno and Yasukawa, 1993; Yuan and Shaw, 1995). There is another advantage of FRBS in that an expert can augment the rules in the system. In this study, all the rules are extracted from the DT, and there are no additional rules that have been added to the system. However, agencies may decide to augment the derived rules with additional rules as they apply the method in the real world.

Many researchers have used binary decision trees to extract the linguistic rules for developing FRBS models and creating a discrete set of fuzzy classes or class membership functions (Mitra et al., 2002; Hall and Lande, 1997). The overlap percentages of the fuzzy classes can be chosen empirically. Decisions that are made based on the tree are fuzzier and soft when the overlap is large (Hall and Lande, 1997; Olaru and Wehenkel, 2003). The process of representing binary trees as crisp logical rules and transforming these rules into a fuzzy model involves four steps. The first step is to create the Decision Tree by minimizing impurities in the data. Second, membership class/functions are created to reflect the intervals of input and output variables and consideration of the crisp characteristic set generated by the Decision Tree. The third step is to formulate simplified fuzzy rules based on the rules generated by the partitioning of the tree and the characteristic 
points of the fuzzy sets. The final step is to run the fuzzy interface engine to predict the crisp output class from the fuzzy class for any new sample of the dataset (Abonyi et al., 2003). Two popular FRBS models are the Mamdani model and the Takagi Sugeno Kang (TSK) model. The Mamdani model is a multiple-input and single-output (MISO) system. This type of model consists of a fuzzy logic-based inference engine and linguistic variables in both the antecedent (input) and consequent (output) parts of the rules (Mamdani, 1974; Mamdani and Assilian, 1975). The TSK model is similar to the Mamdani model, except that the consequent part in the TSK model is represented by a function of input variables (Takagi and Sugeno, 1993; Sugen et al., 1988). In this study, the Mamdani-type FRBS model is used due to the ease of the model's interpretability.

\subsubsection{Clustering Methods}

Clustering analysis is an unsupervised learning technique and refers to a grouping or segmenting technique applied to a collection of objects to subgroup them in a way where the objects within a cluster are closely related, compared to objects in different clusters (Hastie et al., 2017). Clustering methods usually utilize a dissimilarity measure to cluster the objects. The most widely used clustering method is the K-means clustering. Several other clustering methods are available, and the methods can be classified under four major approaches: centroid-based methods, hierarchical clustering, distribution-based clustering,

and density-based clustering (Saha et al., 2019; Saha et al., 2020; Sarkar and Sharma, 2018). The classification of clustering methods is shown in Figure 2-3. 


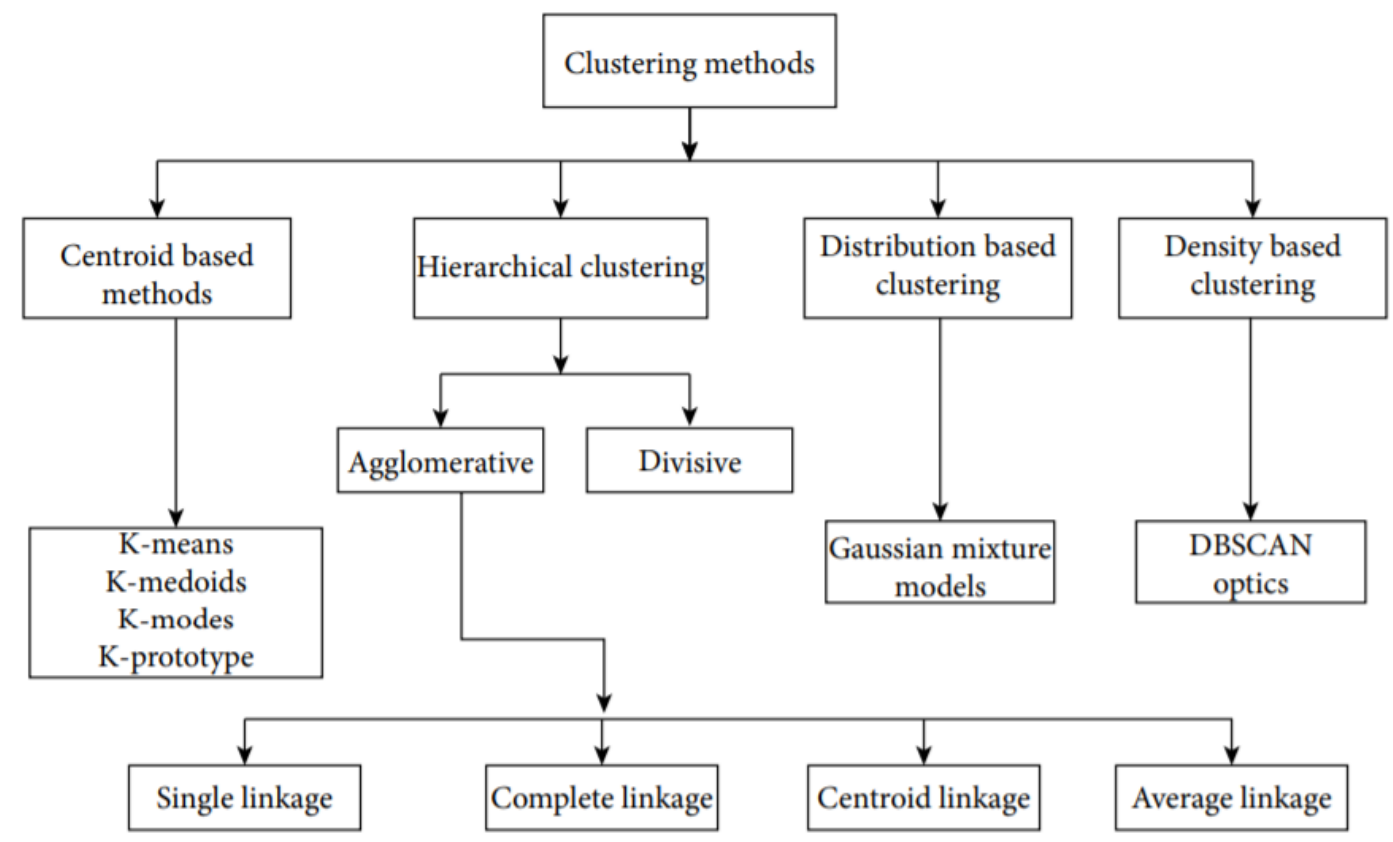

Figure 2-3: Different Types of Clustering Methods (Source: Saha et al., 2019)

Figure 2-3 shows examples of clustering methods for the four major approaches. The K-means algorithm is the most widely used method among all types of clustering methods. This method is based on an iterative algorithm in which the process is initiated by providing a fixed set of centroids. Each data point to be clustered is then assigned to its closest centroid using a squared Euclidian distance measure. When assigning a point to a specific cluster, the goal is to minimize the sum of average pair-wise distance within-cluster dissimilarities. The centroids are then updated by computing the average of all the points assigned to each cluster. This process iterates until the assignment of the data points to each centroid does not change significantly (Hartigan and Wong, 1979; Hartigan, 1975; Huang, 1998). This method produces good results when applied to a large data set with quantitative values. 
One important aspect of clustering is to determine the number of clusters to use in the clustering process. This study utilizes a method referred to as the "Elbow Method" to determine the required number of clusters (Ketchen and Shook, 1996). The Elbow Method is an empirical method that provides an objective approach to determine the optimal number of clusters and requires minimal prior knowledge about the dataset and the attributes of the dataset. The Elbow Method allows for clustering based on the optimal number of clusters, which is determined based on the total within-cluster sum of square (WSS) for each number of clusters (Ketchen and Shook, 1996). A graph is drawn between the total WSS and the number of clusters, and the location of the bend in the plot is generally considered an indicator of the appropriate number of clusters, as shown in Figure $2-4$.

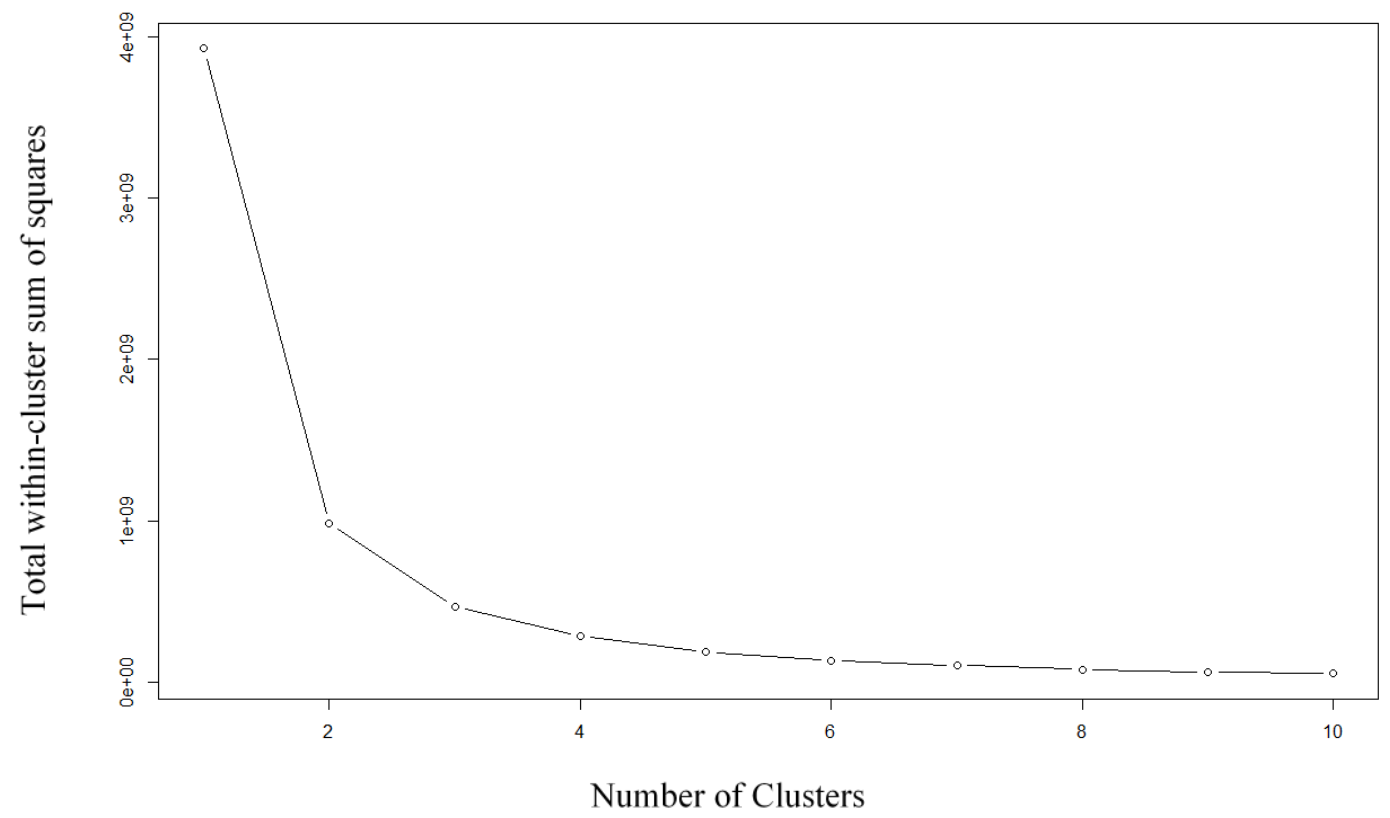

Figure 2-4: Plot of Total Within-Cluster Sum of Square (WSS) vs. Number of Clusters (Source: Tariq et al., 2019) 


\subsubsection{Optimization Techniques}

Various optimization techniques have been used in signal timing optimization. There are three major components in an optimization algorithm: selecting the decision variables, designing the objective function, and formulating constraints. The first step of an optimization problem formulation is to identify the underlying decision variables to consider in the optimization process. Also, in most optimization problems, the bounds on the variables are set as the minimum and the maximum bounds.

The optimization objective functions could simply involve minimizing or maximizing certain functions depending on the research objective. Another component in the algorithm is the formulation of constraints for the solution area. The constraints represent some functional relationships among the decision variables and other design parameters satisfying certain physical phenomena and certain resource limitations. The basic operation of an optimization algorithm is shown in Figure 2-5.

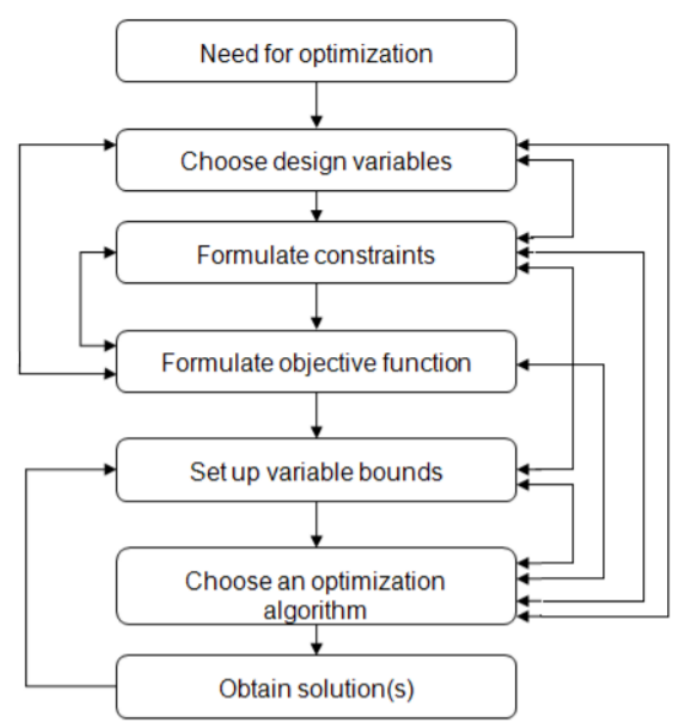

Figure 2-5: A Flow Chart for the Basic Optimization Procedure (Source: Adby, 2013) 
The optimization methods can be mainly divided into deterministic approaches and heuristic approaches. If an algorithm works in a mechanically deterministic manner without any random nature, it is called deterministic. Such algorithms will reach the same final solution if the optimization starts from the same initial point. The deterministic approaches can converge to a global or approximate global optimal solution by utilizing the analytical properties of the problem. Examples of deterministic approaches are linear programming, nonlinear programming, and mixed-integer nonlinear programming (Lin et al., 2012; Yang, 2013; Antoniou and Lu, 2007).

On the other hand, heuristic or stochastic approaches have been found to be more flexible than deterministic approaches. These algorithms are governed by probabilistic translation rules. However, the ability to find a global optimum solution is not guaranteed with these methods. Due to the randomness in these algorithms, it generally reaches a different solution in each run of the algorithm (Lin et al., 2012; Yang, 2013; Antoniou and $\mathrm{Lu}, 2007)$.

The Genetic Algorithm (GA) has become a widely used optimization technique in transportation engineering research. It is a heuristic optimization technique motivated by Darwin's principles of natural selection, survival of the fittest, and evolution. GA is widely used because of its robustness, computational efficiency, and ability to find a solution closest to the globally optimal solution. The three main components in genetic algorithms are: crossover, mutation, and selection of the fittest. Each solution is encoded in a string (often binary or decimal) called a chromosome. The crossover of two parent strings produce off-springs or new solutions by exchanging parts or genes of the chromosomes. 
On the other hand, mutation is carried out by flipping some digits of a string, generating new solutions.

New solutions generated in each generation are evaluated by their fitness, which is linked to the objective function of the optimization problem. The new solutions are selected according to their fitness, which is called selection of the fittest. Sometimes, in order to make sure that the best solutions remain in the population, the best solutions are passed onto the next generation without much change; this is called elitism. (Whitley, 1994; Goldberg, 1989; Beasley et al., 1993)

When an optimization problem consists of multiple objectives instead of only one, it is called multi-objective, or a many objectives optimization. GA can be modified to deal with multiple objectives by incorporating the concept of Pareto domination in its selection operator and applying a niching pressure to spread its population out along the Paretooptimal trade-off surface.

The Non-dominated Sorting Genetic Algorithms (NSGA-II and NSGA-III) are multi-objective algorithms based on GA. The NSGA-II algorithm is used when there are two objective functions to be optimized. On the other hand, the NSGA-III is applied for more than two objective function problems. Unlike the basic GA, the NSGA-III belongs to a set of multi-objective algorithms aiming to find the Pareto front of compromised solutions of all objectives rather than integrating all objectives together in one objective function (Yuan et al., 2014).

A solution belongs to the Pareto set if there is no other solution that can improve at least one of the objectives without the degradation of any other objective. NSGA-III is found to be able to maintain a better spread of solutions and converge better in the obtained 
non-dominated front (Yuan et al., 2014, Mishra et al., 2002). The boundary defined by the set of all points mapped from the Pareto-optimal set is called the Pareto-optimal front. Solutions in the Pareto-optimal front define the best trade-off between competing objectives. (Horn et al., 1994; Deb, 2001). Figure 2-6 illustrates the Pareto-optimal front and solution sets selecting process (Emmerich and Deutz, 2018).

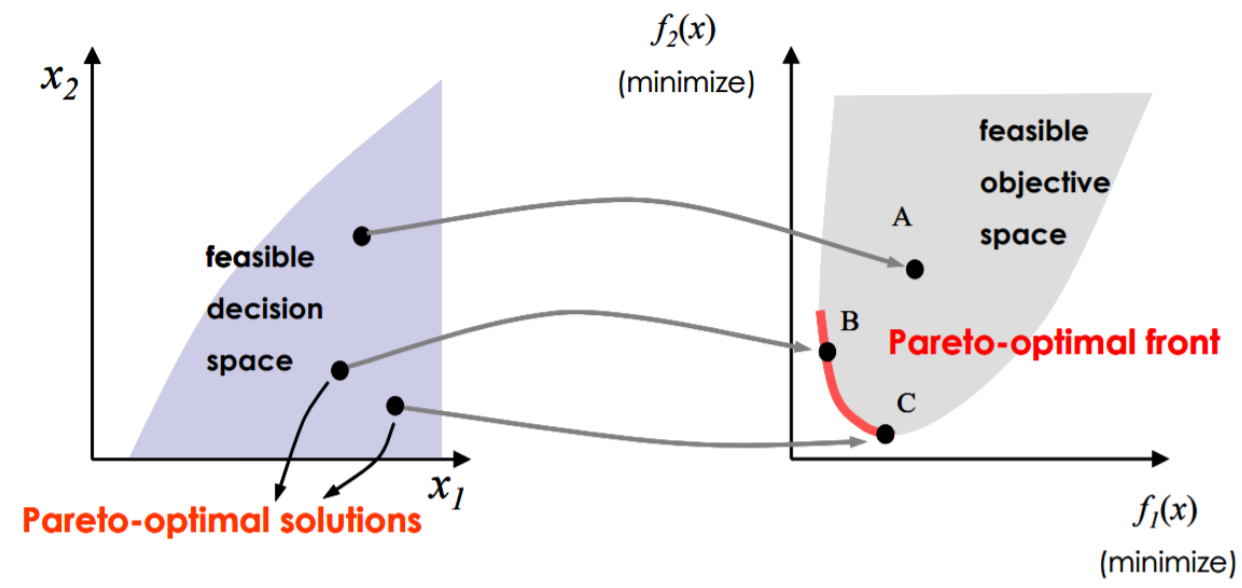

\section{Figure 2-6: Graphical Representation of Pareto-Optimal Solution Process (Source: Emmerich and Deutz, 2018)}

This study uses an optimization process not only for signal timing optimization but also to calibrate the simulation model based on a combination of traffic measurements incorporating parameters based on high-resolution controller data.

\subsection{Summary}

This chapter presented a comprehensive review of literature on signal timing parameters, traditional practice and previous studies for signal timing strategies, use of emerging data sources for signal timing performance measures, criteria for microsimulation modeling, and advanced algorithms for data classification, machine learning, and optimization. Transportation agencies are manually modifying signal timing 
parameters to accommodate non-recurrent congestion. Automated and effective strategies are required for signal timing modification during traffic incidents, work-zone, weather events, or sudden demand surge. Although several existing studies on signal timing optimization address recurrent congested conditions, solutions to the non-recurrent congestion problem on arterial streets still need to be explored. Proper calibration of the simulation-based optimization models is expected to be critical in order to provide solutions for local traffic conditions. Therefore, in this study, a methodology is developed to support proper signal timing modification decisions for non-recurrent congestion utilizing advanced data analytic and simulation-based optimization combined with emerging data sources. 


\section{CHAPTER III}

\section{METHODOLOGY}

This chapter provides a detailed description of the methods developed and proposed as a part of this dissertation to achieve the defined objectives. The first section, the methodological framework, provides an overview of the method of this study. A detailed description of each step is then presented in the subsequent sections.

\subsection{Methodological Framework}

The proposed method provides signal timing modification strategies to mitigate detected non-recurrent congested conditions. The methodology in this study is developed utilizing machine learning and optimization techniques combined with emerging data sources. The effectiveness of the developed method is tested with alternative traffic operation scenarios.

The framework of the method is shown in Figure 3-1. In the methodological framework, the automation of experts' decisions and signal timing optimization are used to generate special signal timing plans to mitigate the detected congested conditions. The study assesses the impacts of selecting and activating the special signal plans in response to non-recurrent congestion. 


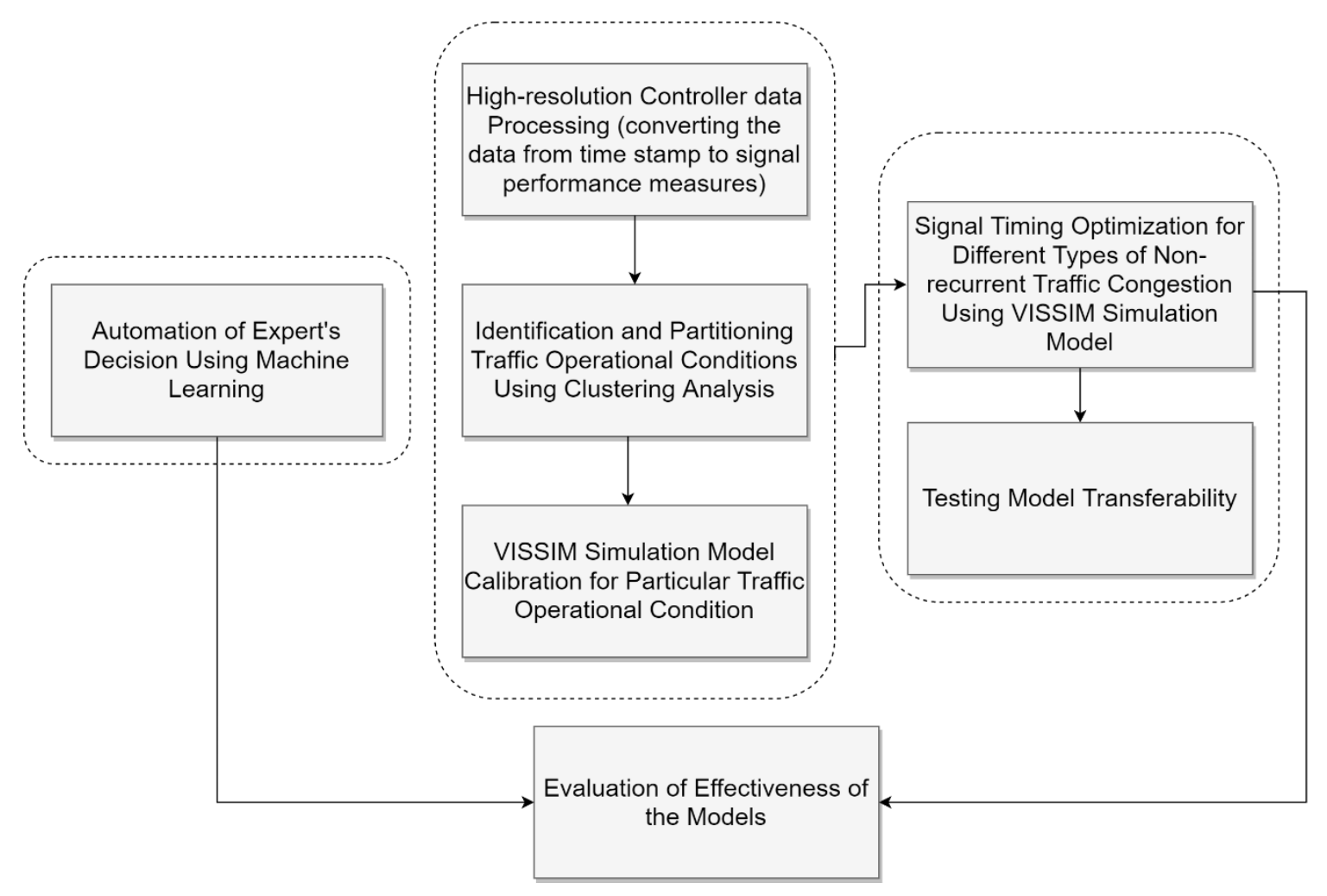

\section{Figure 3-1: Proposed Framework of the Methodology}

The first step of this study is to develop a machine learning model that automates the signal timing modification decisions taken by TMC Engineers. This research uses a combination of Recursive Partitioning and Regression Decision Tree (RPART) and Fuzzy Rule-Based System (FRBS) to deal with the vagueness and uncertainty of human decisions. The method results in a rule based-decision system to identify the changes that need to be made to the signal control during incidents based on past cases of the experts' decisions to change the signal timing. The developed method is designed to capture the cognitive uncertainties associated with human thinking and perception related to an expert implementing signal timing changes in non-recurrent conditions.

The next step is data preparation to estimate the signal timing performance measures. These performance measures are used to identify the field traffic operational conditions. 
The VISSIM microscopic simulation model is calibrated using these signal performance measures to replicate specific traffic operational conditions. As stated earlier, highresolution controller data provides the times when a vehicle arrives at and departs from a vehicle detector and records the changes in signal status within a 0.1 -sec resolution. Therefore, this data allows for the derivation of vehicle arrivals and departures, green time utilization, signal control timings, and other parameters. The results from this derivation are used for partitioning traffic operational conditions and more detailed calibration and validation of simulation models.

The final step develops a method to optimize signal timing parameters for different types of non-recurrent events using optimization models integrated with the calibrated VISSIM simulation models. Calibrated simulation models nearly replicate non-recurrent event scenarios in the field. Signal timing optimization aims to minimize the corridor travel time, intersection delay, queue length upstream of the bottleneck, and maximize vehicle throughput. The utilized algorithm, NSGA-III, is a genetic algorithm optimization technique that deals with many objectives. The NSGA-III algorithm is utilized to generate special signal timing plans for non-recurrent congestion, such as arterial lane blockage and demand surge, which is due, for example, to diversion because of incidents on alternative routes. The assessment of the developed models shows the benefits of selecting and activating the special signal plans in response to non-recurrent congestion.

\subsection{Data Preparation}

This section describes the data sources used in the methodology described in this chapter. This study used the expert's decision log as important input to the methodology. 
Other utilized data include high-resolution controller data, VISSIM direct output (raw data), and travel time data. The following section describes the data used in this study.

\subsubsection{Expert's Decision Log}

The traffic signal engineer/expert operator modifies the signal timing plans in real time based on the observations of incidents, prior experience, and the prevailing traffic conditions at upstream and downstream intersections. Their observed and recorded traffic

parameters are queue length, upstream intersection importance, time of day, estimated demand increment ratio in case of demand surge situations, and estimated capacity reduction ratio during lane blockage conditions. Queue lengths are observed using CCTV cameras, and congestion is displayed in the Google Map Application. The Expert categorizes the upstream intersection importance into three levels, depending on the type of cross street at the upstream intersection, e.g., local road, major road, or road connected to a freeway ramp. The time of day is recorded as AM peak, PM peak, or midday. The capacity reduction ratio is estimated utilizing the capacity adjustment factors suggested by Dowling et al. (2013). The demand increment ratio is obtained by dividing the traffic demand in the critical direction during the demand surge by the historical traffic data. The Experts also recorded the modified green time, old green time, and cycle length for each non-recurrent event. An example of the Expert's Decision Log is shown in Figure 3-2. 


\begin{tabular}{|c|c|c|c|c|c|c|c|c|c|c|c|c|c|}
\hline Intersection Name & $\begin{array}{c}\text { Congestion } \\
\text { Direction }\end{array}$ & $\begin{array}{l}\text { Start } \\
\text { period }\end{array}$ & Incident type & $\begin{array}{l}\text { Upstream } \\
\text { cross ST } \\
\text { importance }\end{array}$ & $\begin{array}{c}\text { Queue } \\
\text { Length (ft) }\end{array}$ & Regular Remand & $\begin{array}{l}\text { Deamand } \\
\text { during } \\
\text { Incident }\end{array}$ & $\begin{array}{c}\text { Demand } \\
\text { Increment }\end{array}$ & $\begin{array}{c}\text { Volume } \\
\text { increment } \\
\text { ratio }\end{array}$ & $\begin{array}{c}\text { Capacity } \\
\text { Reduction } \\
\text { Ratio }\end{array}$ & Old $\mathrm{g} / \mathrm{C}$ & New $g / C$ & $\begin{array}{l}\text { increment } \\
(\%) \text { in } g / \mathrm{c}\end{array}$ \\
\hline Blvd and NE 15 AVE & WBT & PM & 1 lane blockage $(1 / 3)$ & 2 & 3500 & 2143 & N/A & 0 & 0.00 & 0.26 & 0.40 & 0.51 & | 28.13 \\
\hline Blvd and NE 15 AVE & WBT & Midday & 1 lane blockage $(1 / 3)$ & 2 & 3500 & 1922 & N/A & 0 & 0.00 & 0.26 & 0.29 & 0.40 & 39.13 \\
\hline SR 7 and Griffin & SBL & AM & congestion & 3 & 7392 & 1050 & 350 & 700 & 3.00 & 0 & 0.12 & 0.26 & 121.05 \\
\hline lland and Rock Island & EBT & AM & 1 lane blockage $(1 / 3)$ & 1 & 4000 & 1741 & N/A & 0 & 0.00 & 0.26 & 0.64 & 0.74 & 15.52 \\
\hline us1 and se 9th st & SBT & Midday 2 & 2 lane blockage $(2 / 3)$ & 2 & 3500 & 1634 & N/A & 0 & 0.00 & 0.49 & 0.49 & 0.57 & 15.19 \\
\hline SR 7 and Griffin & NBL & Midday & congestion & 2 & 7920 & 950 & 360 & 590 & 2.64 & 0 & 0.13 & 0.24 & 88.17 \\
\hline SR 7 and Griffin & SBT & AM & 1 lane blockage $(1 / 3)$ & 3 & 4752 & 1950 & N/A & 0 & 0.00 & 0.26 & 0.34 & 0.44 & 27.27 \\
\hline SR 7 and Griffin & SBT & AM & 1 lane blockage $(1 / 3)$ & 3 & 4752 & 1900 & N/A & 0 & 0.00 & 0.26 & 0.31 & 0.46 & 48.00 \\
\hline Us 1 and SE 17 th st & NBT & Midday & 1 lane blockage & 2 & 3000 & 2176 & N/A & 0 & 0.00 & 0.26 & 0.23 & 0.29 & 27.03 \\
\hline werline and Oakland & EBL & Midday & congestion & 3 & 2500 & 640 & 218 & 422 & 2.94 & 0 & 0.14 & 0.24 & 69.23 \\
\hline Sunrise and Andrews & EBT & Midday & 1 lane blockage $(1 / 3)$ & 3 & 3000 & 1515 & N/A & 0 & 0.00 & 0.26 & 0.47 & 0.53 & 11.76 \\
\hline unrise and NE 15th st & EBT & Midday & 1 lane blocked (1/3) & 2 & 3500 & 1766 & N/A & 0 & 0.00 & 0.26 & 0.41 & 0.49 & 20.27 \\
\hline ersity and Peteres Rd & SBT & Midday 2 & 2 lane blockage $(2 / 3)$ & 2 & 5280 & 1470 & N/A & 0 & 0.00 & 0.49 & 0.44 & 0.56 & 28.57 \\
\hline ersity and Peteres Rd & SBT & Midday 2 & 2 lane blockage $(2 / 3)$ & 2 & 5913.6 & 1571 & N/A & 0 & 0.00 & 0.49 & 0.44 & 0.61 & 40.00 \\
\hline ersity and Peteres Rd & SBT & PM & 2 lane blockage $(2 / 3)$ & 2 & 8976 & 1787 & $\mathrm{~N} / \mathrm{A}$ & 0 & 0.00 & 0.49 & 0.43 & 0.63 & 47.06 \\
\hline Girifin RD at SR-7 & NBT & PM & congestion & 2 & 7920 & 2363 & 2033 & 330 & 1.16 & 0 & 0.38 & 0.48 & 24.59 \\
\hline Ivd and NW 47th Ave & EBT & Midday & congestion & 3 & 3000 & 2456 & 1963 & 493 & 1.25 & 0 & 0.48 & 0.54 & 11.49 \\
\hline Ivd and Powerline Rd & EBT & $\mathrm{AM}$ & congestion & 3 & 2800 & 1920 & 1766 & 154 & 1.09 & 0 & 0.43 & 0.49 & 14.71 \\
\hline Beach Blvd \& W 8 Ave & EBT & Midday & 1 lane blockage $(1 / 3)$ & 3 & 1800 & 1650 & N/A & 0 & 0.00 & 0.26 & 0.41 & 0.44 & 9.23 \\
\hline e Beach Blvd and US1 & WBT & Midday & 1 lane blockage $(1 / 3)$ & 1 & 5000 & 1335 & N/A & 0 & 0.00 & 0.26 & 0.26 & 0.29 & 11.90 \\
\hline e Beach Blvd and US1 & EBT & Midday & 1 lane blockage $(1 / 3)$ & 2 & 3500 & 1250 & N/A & 0 & 0.00 & 0.26 & 0.26 & 0.29 & 11.90 \\
\hline iiversity \& 1900 Block & SBT & PM & Congestion & 3 & 1600 & 2680 & 2326 & 354 & 1.15 & 0 & 0.48 & 0.56 & 16.28 \\
\hline US 1 \& Broward Blvd & NBT & Midday & 1 lane blockage $(1 / 3)$ & 2 & 4000 & 1650 & N/A & 0 & 0.00 & 0.26 & 0.25 & 0.34 & 35.00 \\
\hline ise Blvd@ @ NE 15 Ave & WBT & PM & congestion & 2 & 4000 & 2236 & 1722 & 514 & 1.30 & 0 & 0.34 & 0.42 & 24.59 \\
\hline
\end{tabular}

Figure 3-2: Example of Signal Timing Expert's Decision Log

\subsubsection{Signal Performance Measures Extraction}

High-resolution controller data, VISSIM raw data, and travel time data are analyzed and converted into signal timing performance measures for the purpose of this study. The following section discusses these data items.

\section{High-Resolution Controller Data:}

High-resolution controller data consists of various signal controller events that are logged in as 0.1-s intervals based on a standardized set of event parameters and event identification codes. Figure 2-2 in Chapter 2 shows an example of this data. The highresolution data is logged in 24 hours a day as "h:m:s" (hour, minute, second). The stored parameters include the timestamp that contains the date and time of activities, Event Code, and Event Parameters. These data are formatted as timestamp data and provide 0.1-sec resolution event data that are classified as Event Type Code and Event Parameter.

The Event Code describes the type of event and is coded in numbers. For example, the beginning of a green phase is coded as 1 . Vehicle detections are encoded as 82 . The 
code descriptions of the "Event Type" are provided in the Indiana Traffic Signal HighResolution Data Logger (Sturdevant, J. R. et al., 2012).

The Event Parameter expresses the phase indication number or detector channel number in which the event occurs. For example, a data point Event Code 1 and Event Parameter 4 indicate that the green light of Phase 4 started during the time logged for the data point. These data provide complete records of the time vehicles arrive at and depart from a vehicle detector and record the signal status changes within a 0.1 -sec resolution.

High-Resolution ATSPM data is used to estimate detailed measures, including vehicle throughput, actuated phase timing, split utilization ratio, green occupancy ratio, and percentage arrival on green in each cycle (Tariq et al, 2021).

As mentioned earlier, the high-resolution controller data provides the opportunity for a cycle-by-cycle estimation of various measures including the throughputs. Having a separate detection channel per lane is required if lane-by-lane detection of the throughput is needed. A "Detector On" code or Event Code 82 is encoded when a vehicle enters a detection zone. A "Detector Off" code or Event Code 81 in high-resolution data is encoded when a vehicle exits a detection zone. The event parameter expresses the phase indication number or detector channel number in which the event occurs. For example, a data point Event Code 1 and Event Parameter 4 indicate that the green light of Phase 4 started during the time logged for the data point. These data provide complete records of the time vehicles arrive at and depart from a vehicle detector and record the signal status changes within a 0.1-sec resolution. Event Code 81 is used to calculate vehicle throughput in each lane per cycle. The volumes of the right-turn movements are calculated by subtracting the number 
of vehicles departing the rightmost exit detector from the number of vehicles departing the rightmost lane stop line detector.

The actuated green time is calculated using Event Code 1 (Green Phase Begin) and Event Code 7 (Green Phase Termination) for each phase. The calculations of the yellow time and all-red time use Event Code 8 (Yellow Clearance Begin), Event Code 9 (Yellow Clearance End), Event Code 10 (Red Clearance Begin), and Event Code 11 (Red Clearance End).

The Green Occupancy is measured by the time difference between consequent Event Code 82 to Event Code 81, which shows the amount of time the detector is occupied. The total occupancy per cycle is defined as the amount of time a detector is occupied. On the other hand, Green Occupancy is defined as the detector occupancy during the green time of each phase.

The Green Occupancy Ratio (GOR) is a performance measure that reflects the degree of green utilization in each phase. It is defined as the stop bar detector occupancy during the green interval (Day and Bullock, 2011). Higher values of GOR reflect higher utilization of the green time. This value increases to values above 0.5 in the peak periods. Equation 3-1 shows the calculation of GOR using the detector occupancy during the green time and the actuated green time. The Split Utilization Ratio (SUR) measure is derived for each intersection movement to allow for the assessment of the congestion level of the movement. SUR is defined as the ratio of the number of vehicles passing the detector to the maximum number of vehicles that can pass during the effective green time (Day and Bullock, 2012). SUR is calculated using Equation 3-2 based on vehicle throughput, actuated green time and saturation headway extracted from high-resolution controller data. 
The Percent Arrivals on Green (POG) is the proportion of vehicles that arrive on the green signal indication versus the proportion of vehicles that arrive at the red signal indication (Bullock and Day, 2009). This measure reflects the progression of traffic. POG is calculated by using the extracted vehicle arrival number from the 'Detector On' Event (Event Code 82) following Equation 3-3.

$$
\begin{gathered}
\text { GOR }=\frac{\text { Occ Green.k }}{g_{k}} \\
X_{k}=\frac{h_{k} \times N_{k}}{g_{k}} \\
P O G=\frac{V_{\text {Green. } . k}}{V_{\text {Cycle.k }}} \times 100
\end{gathered}
$$

where

$\mathrm{k}=$ Split utilization ratio of phase $k$,

$\mathrm{N}_{\mathrm{k}=}$ The vehicle counts for phase $k$,

$h_{k}=$ Saturation headway for phase $k$ (seconds),

$\mathrm{g}_{\mathrm{k}}=$ The effective green time for phase $k$ (seconds),

Occ $_{\text {Green.k }}=$ Detector Occupancy during green period of phase $\mathrm{k}$,

$\mathrm{V}_{\text {Green.k }}=$ Vehicle arrival during green period at phase $\mathrm{k}$, and

$\mathrm{V}_{\text {Cycle.k }}=$ Vehicle arrival during cycle time at phase $\mathrm{k}$.

\section{VISSIM Direct Output (Raw Data):}

This study utilized raw output from the VISSIM microscopic tool to calculate the signal timing performance measures mentioned above using Equations 3-1, 3-2, and 3-3. The detection and signal phasing timing log files produced by the model are processed, providing $0.1-\sec$ data that emulate real-world high-resolution signal controller event data. The performance measures from high-resolution controller data and emulated high- 
resolution data from VISSIM are used for partitioning traffic operational conditions, as well as for a more detailed calibration and validation of simulation models.

\section{Travel Time Data:}

Travel time data is directly extracted from the Regional Integrated Transportation Information System (RITIS) website for the segments of the major corridor of the case study network. The vehicle travel times used in this study are estimated by a third-party vendor (HERE) based on probe vehicles. Figure 3-3 shows the corridor travel time data format. The travel time data consist of tmc_code, time stamp, and travel time data in seconds. The tmc_code in the data is used for roadway segment and movement direction identification.

\begin{tabular}{|r|r|r|}
\hline tmc_code & measurement_tstamp & travel_time_seconds \\
\hline $102-05676$ & $11 / 1 / 20190: 00$ & 43.81 \\
\hline $102-05676$ & $11 / 1 / 20190: 05$ & 46.02 \\
\hline $102-05676$ & $11 / 1 / 20190: 10$ & 48.73 \\
\hline $102-05676$ & $11 / 1 / 20190: 15$ & 55.52 \\
\hline $102-05676$ & $11 / 1 / 20190: 20$ & 55.91 \\
\hline $102-05676$ & $11 / 1 / 20190: 25$ & 44.23 \\
\hline $102-05676$ & $11 / 1 / 20190: 30$ & 45.33 \\
\hline $102-05676$ & $11 / 1 / 20190: 35$ & 46.26 \\
\hline $102-05676$ & $11 / 1 / 20190: 40$ & 47.46 \\
\hline $102-05676$ & $11 / 1 / 20190: 45$ & 46.89 \\
\hline $102-05676$ & $11 / 1 / 20190: 50$ & 37.93 \\
\hline $102-05676$ & $11 / 1 / 20190: 55$ & 35.06 \\
\hline $102-05676$ & $11 / 1 / 20191: 00$ & 35.47 \\
\hline $102-05676$ & $11 / 1 / 20191: 05$ & 35.34 \\
\hline $102-05676$ & $11 / 1 / 20191: 10$ & 35.06 \\
\hline $102-05676$ & $11 / 1 / 20191: 15$ & 39.4 \\
\hline $102-05676$ & $11 / 1 / 20191: 20$ & 52.06 \\
\hline $102-05676$ & $11 / 1 / 20191: 25$ & 52.06 \\
\hline $102-05676$ & $11 / 1 / 20191: 30$ & 71.15 \\
\hline & & \\
\hline
\end{tabular}

Figure 3-3: Partial of Travel Time Data

\subsection{Automation of Signal Timing Engineer's Decisions}

An important component of this research is to capture the decisions of the traffic signal engineers at the TMC in changing signal timing parameters during non-recurrent 
congestion. In such cases, the traffic signal engineers/experts modify the signal timing plans in real time based on the observations of incidents, prior experience, and the prevailing traffic conditions at upstream and downstream intersections. One of the goals of this study is to automate the decision-making process of the traffic signal engineer/expert operators to offer a proactive, consistent, and easily implementable solution.

This study investigates automating the process of updating the signal timing plans during non-recurrent conditions by capturing the history of the traffic signal engineer's responses to non-recurrent conditions and utilizing this experience to train a machine learning model. This study intends to automate experts' decisions using machine learning techniques, to facilitate a proactive, consistent, and easily implementable approach to addressing traffic congestion during non-recurrent events.

The proposed methodology includes utilizing a Fuzzy Rule-Based decision system that is supported by the Decision Tree machine learning approach to capture and automate the traffic signal engineer's decision. The developed model learns from complex yet reasonable decisions made by traffic signal engineers/experts. Figure 3-4 shows the steps for constructing the rule-based decision system. As indicated in Figure 3-4, this construction comprises the Decision Tree generation and Fuzzy Rule-Based System development. 


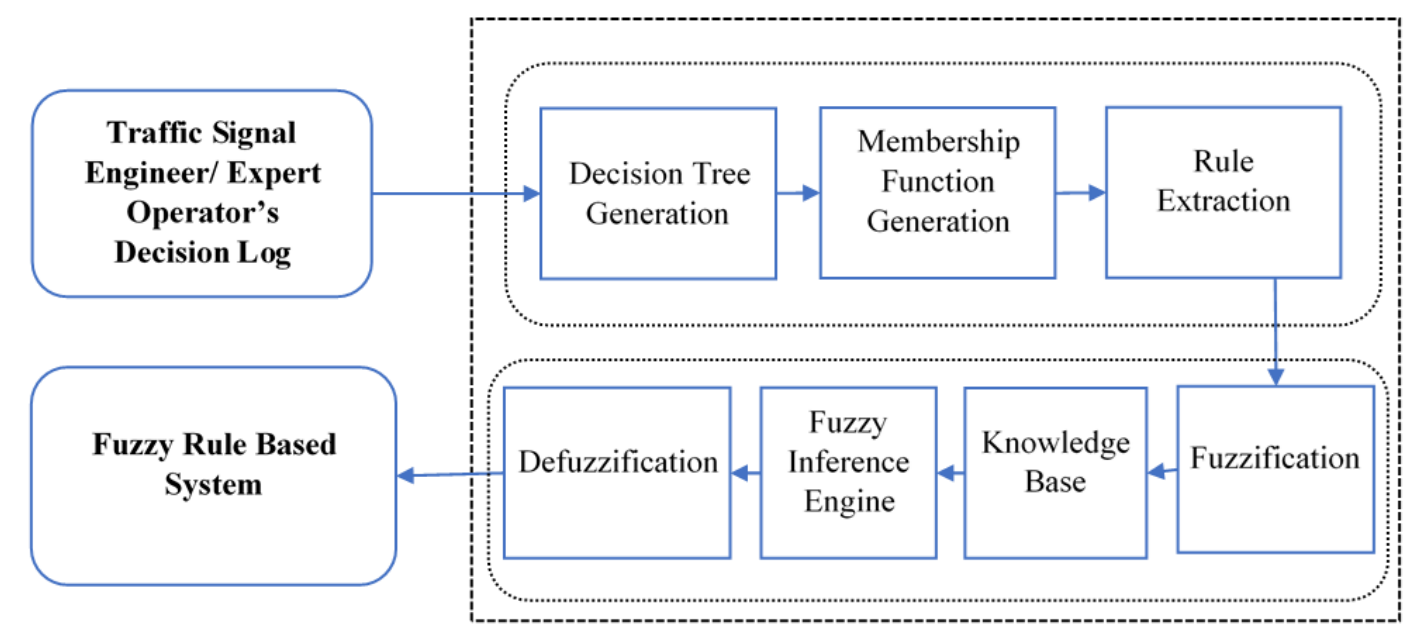

Figure 3-4: Principal Steps of the Utilized Fuzzy Rule-Based Decision System

The first step in the automation of the experts' decisions is the Decision Tree formation, which provides the structure of the partitioning and classification of the traffic signal engineer's decisions feeds to change the timing parameters. In assessing the quality of the model, this study utilized the Gini Impurity Index as an impurity measure for the subset selection of the developed decision tree. The Gini Impurity Index measures the probability of an element in the subset to be mislabeled, assuming it is randomly labeled according to the distribution of all of the classes in the set. DT also eliminates variables that do not contribute to predicting the output from inclusion in the tree utilizing a procedure referred to as feature selection. This is important since having irrelevant features in a dataset can decrease the accuracy of the developed model. The resulting Decision Tree with the remaining features and derived structure is then utilized to induce the knowledge base or rule-based system by converting the Decision Tree structure into crisp if-then rules. These crisp rules are extracted based on the DT results and capture the traffic signal engineer's decisions. The next step is to fuzzify these crisp rules with consideration of the 
uncertainties in assessing the traffic signal engineers according to the input and output parameters.

In this study, the Recursive Partitioning and Regression Trees (RPART) method is implemented to derive the Decision Tree based on the traffic signal engineer's data feed. RPART is a function that implements the Classification and Regression Tree (CART) algorithm, which is a popular algorithm for the development of decision trees. It is used to build Decision Tree in a binary form (Atkinson and Therneau, 2000). In the implementation of RPART in this study, the 'rpart' and 'rpart.plot' functions in the R studio are used to extract the logical rules by partitioning the dataset.

When developing a DT, RPART first selects the variable that best splits the dataset into two groups. The subsets are then partitioned again using the same process. This method is recursive, which means that the process continues to partition the subsets from the previous split until no other improvements can be made to the tree (Therneau, 1983). The Gini Impurity Index is used for the subset selection when building the Decision Tree (Atkinson and Therneau, 2000). The Gini Impurity Index measures the probability of an element in the subset to be mislabeled, assuming it is randomly labeled according to the distribution of all of the classes in the set. As such, it estimates the heterogeneity of the classes in a subset created by the split. The Gini Impurity Index is scored between 0 to 1 , with 0 being the best and 1 being the worst. If all of the elements in a set are in the same class, the Gini Impurity Index is 0 . If there are an equal number of elements of the two classes in a subset, the Gini Impurity Index is $1 / 2$ (Tan et al., 2006). The development of the decision tree in this model uses the Gini rule for splitting and two parameters referred to as 'minsplit' and complexity parameter ('cp)' as the control parameter of the nodes. This 
model minimizes the Gini Index in a recursive pattern. The 'minsplit' parameter is the minimum number of observations that must exist in a node for a split to be attempted. A 'minsplit' of 3 is used in the DT model. The Complexity Parameter 'cp' in the 'rpart' function is the minimum improvement in the model needed at each node. It is the amount by which splitting that node improves the relative error. For example, if splitting the original root node drops the relative error from 1.0 to 0.5 , the $\mathrm{cp}$ of the root node is calculated as 0.5. A cp of 0.01 is used in the developed DT in this study. This means that if splitting a node results in an improvement of 0.01 or less, the tree building at that node stops.

An FRBS is developed in this study using the 'frbs.gen' function in the R studio. The 'frbs.gen' function performs inference based on human knowledge. The purpose of this function is to build an FRBS model manually from user-given inputs or from the knowledge of human experts without a learning process (Riza, 2014; Riza, 2015).

As mentioned earlier, the Mamdani model is utilized in this study to develop the FRBS. The Mamdani model consists of four major steps: fuzzification, knowledge base creation, fuzzy rule inference, and defuzzification. Fuzzification is the process of converting the input variables into fuzzy sets. This step requires the use of membership functions representing the degree of truth in fuzzy logic and can be developed from the expert's opinion or learned from statistical data. Instead of a precise set of bi-valued logic or boundaries, the membership functions or fuzzy sets have indeterminate boundaries. In this study, the membership functions are developed using the expert's database, which contains input variables recorded based on real-world events, including queue length, upstream intersection importance, demand increment ratio, incident start period, and lane 
blockage data, as well as the output variable increment in the $\mathrm{g} / \mathrm{C}$ ratio. Queue length is observed using CCTV cameras and the Google Maps. Upstream intersection importance is categorized from 1 to 3 , depending on the type of cross street at the upstream intersection, e.g., local road, major road, or road connected to freeway ramp. Also, the linguistic terms of the input variables are converted to fuzzy numbers in this stage. The dataset used for the developed model only contains the cases involving green time modifications. In these cases, the cycle length and offset were not changed in order to maintain the progression. Thus, this study does not consider the cases when the cycle length is changed.

The knowledge base in the fuzzy logic system is composed of a database and a rule base. The database includes the fuzzy-set membership functions. The rule base represents the reasoning of human experts in a set of if-then rules, which are extracted from the Decision Tree as crisp if-then rules with antecedent and consequent parts. When a rule is formatted as "IF A THEN B", where A and B are fuzzy sets, A is called the antecedent and B is called the consequent parts of the fuzzy rule.

The fuzzy rule inference engine converts the fuzzy input to fuzzy output using the ifthen rules. It establishes the rule strength of the antecedent part according to the combination of the membership functions and fuzzy rules. Then, it determines the consequent rule based on the rule strength and the output membership function. The defuzzification converts the fuzzy output of the inference engine to a crisp output. This process is conducted by aggregating all of the qualified consequents of the rules to get the defuzzified outputs.

The methodology developed in this step is a general process and can be applied by traffic management centers anywhere to recommend changes to the green time splits during 
non-recurrent events while keeping the cycle length constant. Figure 3-5 shows a detailed description of the process to be used for application development.

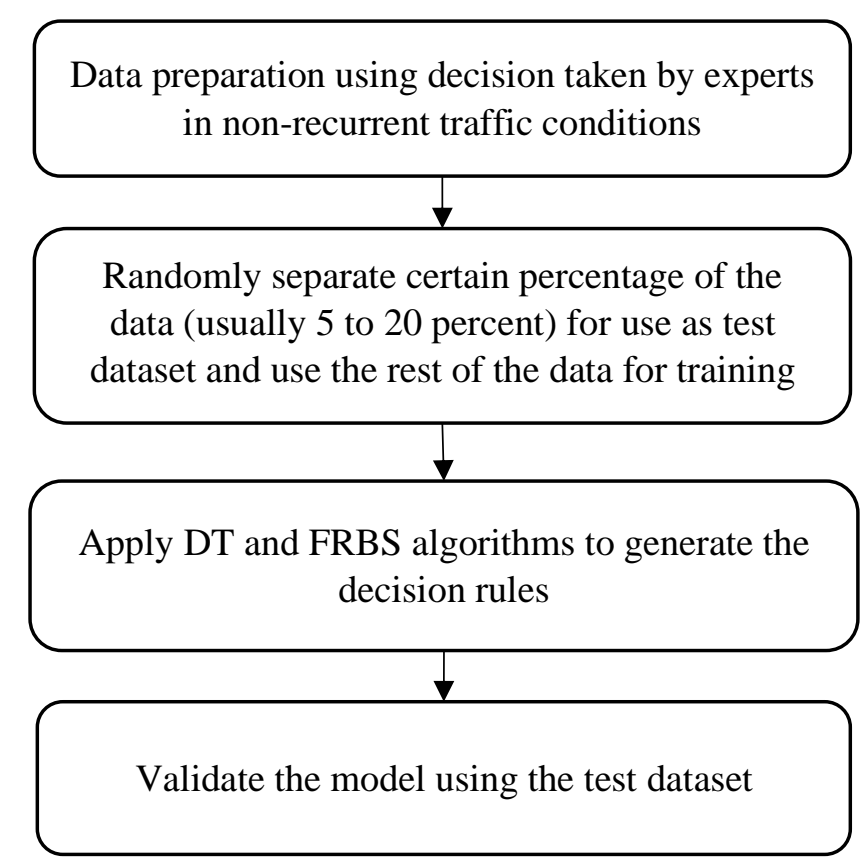

\section{Figure 3-5: Step by Step Process for the Automation Model Development}

\subsection{Identification and Partitioning Traffic Operational Conditions}

This study used K-means clustering, which is widely used in transportation engineering research, for pattern recognition to model representative traffic operational scenarios. The K-means clustering analysis is an iterative process that assigns data points to a particular cluster based on the Euclidean distance. This process iterates until the distances between cluster centers and the assigned data points to each cluster are minimum. One crucial aspect of clustering is to determine the number of clusters to use in the clustering. The Elbow method is used to determine the required number of clusters. Figure 3-6 shows the pseudo-code for the K-means clustering analysis. 


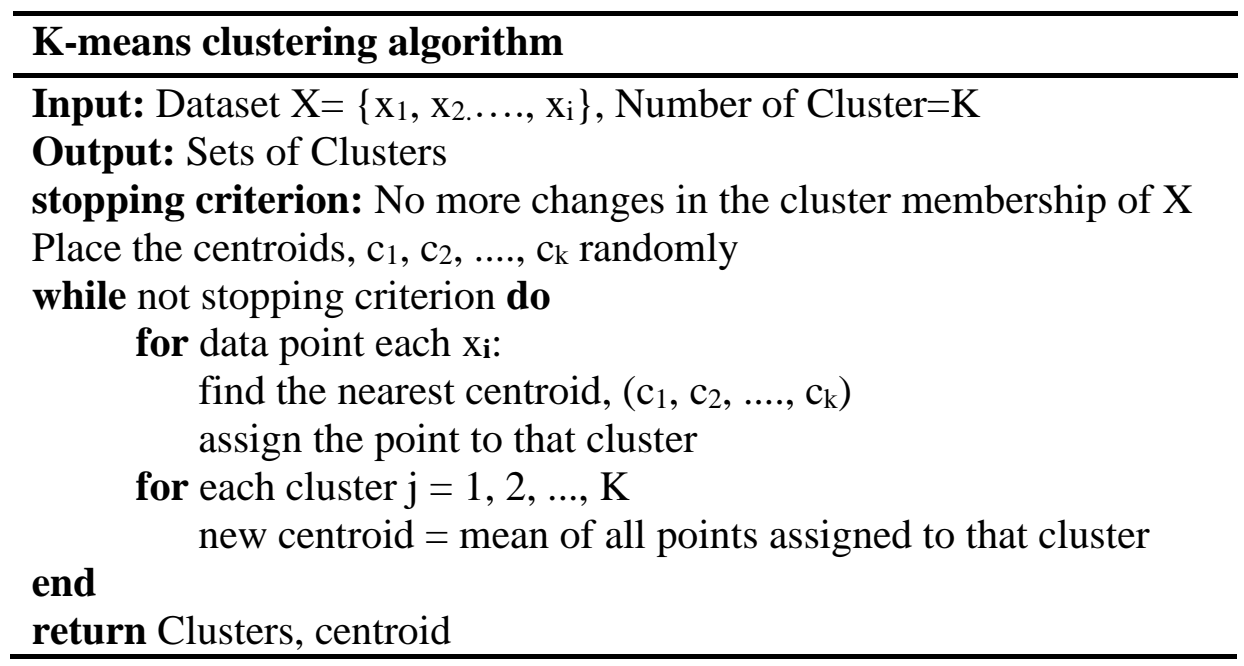

Figure 3-6: Pseudo-Code for the K-means Clustering Algorithm

In this study, traffic pattern recognition is accomplished utilizing the GOR and travel times. The whole clustering process is performed in two levels. First, the study applied clustering for the whole day travel time measurements at 15-minute resolutions for both directions of the study corridor. In this clustering analysis, normal (incident-free) day travel time data for one month is used. The GOR values are included in the next level of clustering that further categorized the travel-time clusters based on the GOR. In this second layer, the clusters are based on the GOR of the major through movements. The data points in each resulting cluster are then further clustered based on the GOR of the left-turn movements. This process ensures that each final cluster represents a distinct traffic operational scenario considering all intersection movements.

\subsection{VISSIM Calibration Using High-Resolution Controller Data}

Microscopic traffic simulation tools are now commonly used to support various transportation agencies' business processes. The use of simulation models and the complexity of these models are expected to increase with the increasing need to assess the emerging vehicle and infrastructure-based technologies and strategies, such as active traffic 
and demand management, connected and automated vehicles, and cooperative driving automation.

Traffic simulation tools are usually set with default values of user-adjustable parameters. However, the models with the default values rarely replicate local traffic conditions. When a microscopic simulation model is used without proper calibration and validation, the simulation results are inaccurate and unreliable and cannot be used to support the agency's decisions. Thus, calibration and validation processes are necessary to minimize the deviation between the simulation results and field observations before using the models for alternative analyses.

The calibration of traffic simulation models is traditionally based on macroscopic traffic parameters, such as traffic volumes and demands, spot speeds, travel times, and where available, queue lengths. The models are usually calibrated for an average peak and/or off-peak hour or period representing typical traffic conditions on the modeled network. However, the recent guidance provided by the updated Traffic Analysis Tool Box Volume III, which is produced by the FHWA, recommends the use of clustering to identify operational scenarios for use in calibration, such as different congestion levels, incident conditions, and weather conditions (Wunderlich et al., 2019).

This study investigates the use of high-resolution controller data in combination with the commonly used traffic data in the calibration and development of simulation models. The data is used first to identify operational scenarios for use in the model based on the clustering analysis, as mentioned above. A microscopic simulation model is then developed and calibrated for the scenarios using a multi-objective optimization technique based on travel time and high-resolution controller-based measurements. 
This study uses an optimization process to calibrate the simulation model based on a combination of traffic measurements, including those derived from high-resolution controller data. The study compared the utilization of GA to calibrate the simulation model based on a single variable (travel time) with calibration based on NSGA-III multi-objective optimization utilizing additional parameters estimated from high-resolution controller data.

The evaluation of the calibration based on the multi-objective function indicates that the proposed optimization technique is able to better replicate intersection performance measures, including measures based on high-resolution controller data such as GOR, green utilization, and arrival on green. On the other hand, optimizing the calibration parameters based on travel time measurements alone produces unacceptable errors in those detailed signal parameters.

The utilized procedure for the development and calibrating microscopic simulation models consists of three main steps: model development, model calibration by optimizing driver behavior parameters to minimize the difference between the field and simulated performance measures, and model validation. The travel time, split utilization ratio, and movement throughput are used to calibrate each operational scenario identified based on clustering analysis. The errors in GOR and POG are checked for model validation.

\subsubsection{Model Development}

The study segment used to demonstrate the proposed method consists of five intersections, from NW 22nd Avenue to NW 7th Avenue on NW 119th Street in MiamiDade County. . This segment, which is about 1.5 miles in length, was selected because it faces moderate to high demands all day long and is often congested during peak hours. In addition, there is an adequate amount of data on this segment from advanced data sources 
such as high-resolution data, travel time data based on Bluetooth reader measurements, traffic counts, and incident data.

Coded signal timing plans in the model are the same as the semi-actuated time-ofday plans implemented in the real world. The signal phase timing plans are obtained from Miami-Dade County and verified using high-resolution controller data. Vehicle inputs at the entry points of the network and the static routes are coded as the traffic volume extracted from high-resolution data, which are verified for correctness based on the turning movement counts taken for one day in the peak periods. The relative flows associated with the static routes are coded based on the traffic volumes extracted from high-resolution data and verified using one-day turning movement counts.

The desired speed distribution in the eastbound (EB) and westbound (WB) directions is coded according to each link's speed limits in the segment. Also, reduced speed areas are placed for the turning movements of the roadway intersections to reflect the turning speeds, which impact the movement saturation flow rates. Figure 3-7 shows an illustration of the study simulation model over an Open Street Network map. 


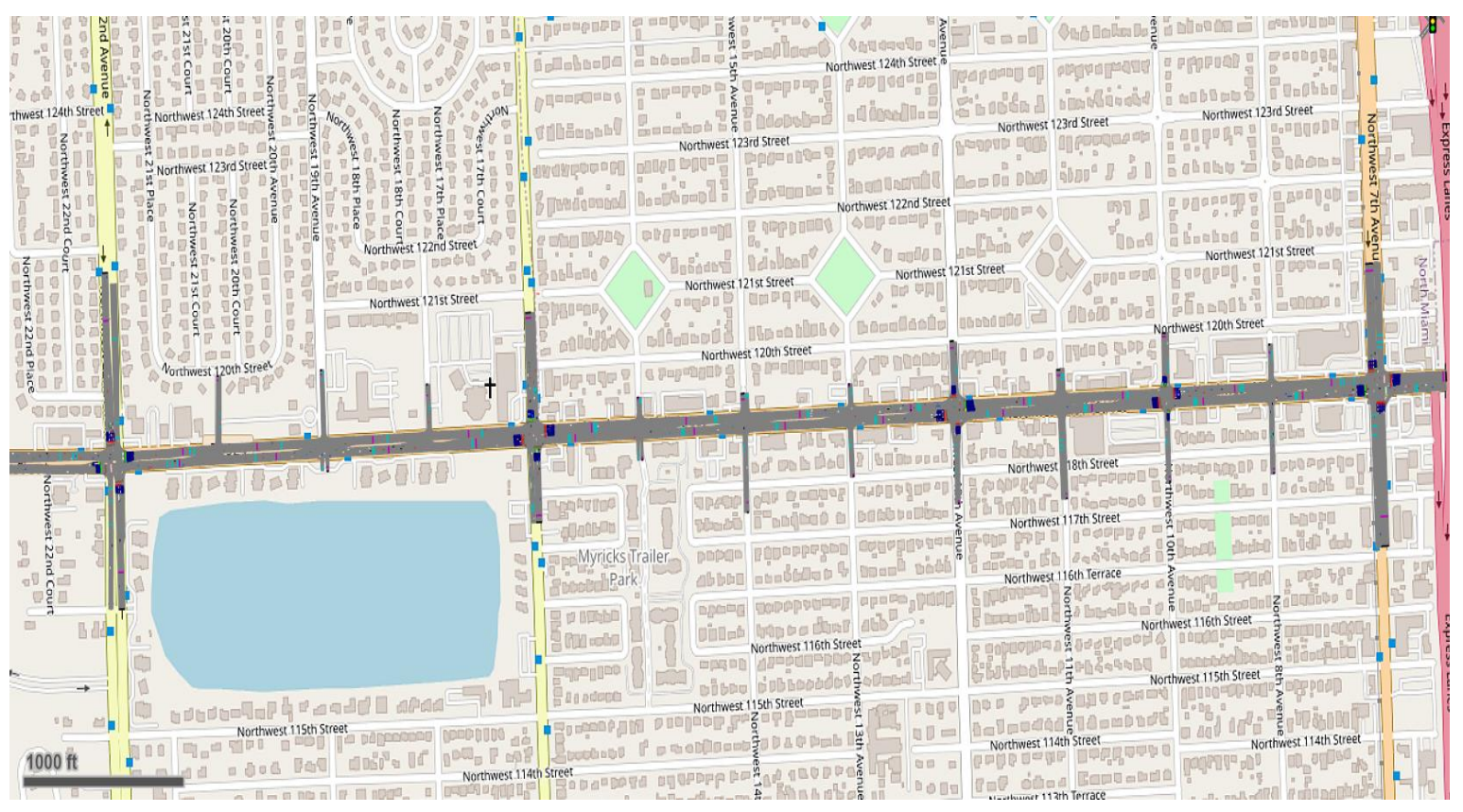

Figure 3-7: VISSIM Simulation Network of the Case Study Segment

\subsubsection{Selection of Model Calibration Parameters}

Simulation models are developed and calibrated for a one-hour analysis period. The study optimized the VISSIM parameters that affect driver behaviors and traffic performance characteristics to improve the microsimulation model's ability to replicate real-world traffic scenarios. VISSIM provides two car-following models to select from: Wiedemann 74 and Wiedemann 99. The Wiedemann 74 model is generally used for urban traffic and merging areas, whereas the Wiedemann 99 is generally used for freeway traffic with no merging areas (WisDOT, 2017). The driver behavior parameters for lane changing, signal control parameters, and the car-following model according to the Wiedemann 74 model are optimized in this study using the NSGA-III algorithm. The specific optimized parameters and the associated ranges of their values are selected following the VISSIM-specific guidelines of the Wisconsin State Department of 
Transportation's (WisDOT) Traffic Engineering, Operations and Safety Manual (WisDOT, 2017), as presented in Table 3-1. 
Table 3-1: List of Adjusted Driver Behavior Parameters

\begin{tabular}{|c|c|c|c|c|c|c|}
\hline $\begin{array}{l}\text { Parameter } \\
\text { Type }\end{array}$ & Parameters & Min* & Max* & $\begin{array}{l}\text { Default } \\
\text { Value }\end{array}$ & Unit & Parameters Description \\
\hline \multirow[t]{3}{*}{$\begin{array}{l}\text { Car Following } \\
\text { Model }\end{array}$} & $\begin{array}{l}\text { Average Stand } \\
\text { Still Distance }\end{array}$ & 3.28 & 6.56 & 6.56 & $\mathrm{ft}$ & $\begin{array}{l}\text { Average desired distance between two cars. Higher } \\
\text { value means larger standstill distance and lower } \\
\text { capacity. }\end{array}$ \\
\hline & $\begin{array}{l}\text { Additive Part of } \\
\text { Safety Distance }\end{array}$ & 2 & 2.2 & 2 & $\mathrm{ft}$ & $\begin{array}{l}\text { Used for desired safety distance. Higher value means } \\
\text { larger standstill distance and lower capacity. }\end{array}$ \\
\hline & $\begin{array}{l}\text { Multiplicative } \\
\text { Part of Safety } \\
\text { Distance }\end{array}$ & 2.8 & 3.3 & 3 & $\mathrm{ft}$ & $\begin{array}{l}\text { Used for the computation of the desired safety } \\
\text { distance. Higher value means larger standstill } \\
\text { distance and lower capacity. }\end{array}$ \\
\hline \multirow[t]{3}{*}{ Lane Change } & $\begin{array}{l}\text { Maximum } \\
\text { Deceleration- } \\
\text { Own }(\mathrm{ft} / \mathrm{s} 2)\end{array}$ & -15 & -12 & -13.12 & $\mathrm{ft} / \mathrm{s}^{2}$ & $\begin{array}{l}\text { Upper bound of deceleration for own vehicles. Higher } \\
\text { absolute value means more aggressive lane-changing } \\
\text { behaviors. }\end{array}$ \\
\hline & $\begin{array}{l}\text { Maximum } \\
\text { Deceleration- } \\
\text { Trail (ft/s2) }\end{array}$ & -12 & -8 & -9.84 & $\mathrm{ft} / \mathrm{s}^{2}$ & $\begin{array}{l}\text { Upper bound of deceleration for trailing vehicles. } \\
\text { Higher absolute value means more aggressive lane- } \\
\text { changing behaviors. }\end{array}$ \\
\hline & $\begin{array}{l}\text { Minimum } \\
\text { Headway }\end{array}$ & 1.5 & 2 & 1.64 & $\mathrm{ft}$ & $\begin{array}{l}\text { The minimum distance between two vehicles that } \\
\text { must be available after a lane change, so that the } \\
\text { change can take place. }\end{array}$ \\
\hline $\begin{array}{l}\text { Signal } \\
\text { Control }\end{array}$ & Factor & 0.6 & 1 & 0.6 & & $\begin{array}{l}\text { Higher value reduces the safety distance between } \\
\text { vehicles close to the signal stop bar. }\end{array}$ \\
\hline
\end{tabular}

* Min= Minimum value, Max= Maximum value, $f t=f e e t, s=$ second $s$ 
Performance measurements, as outputs of the simulation, are collected using the simulation evaluation window in the Python COM interface, as well as the output performance evaluation files, including the detection, signal phasing, and timing log files as follows:

- Vehicles throughput is collected based on data collection points specified at the stop line detector locations.

- Vehicle travel time is collected directly from vehicle travel time measurements in the simulation.

- Green time is measured using the 'signal state run time'.

- The total number of vehicles passing each detector is collected based on detector log.

\subsubsection{Calibration Process}

As stated earlier, the model calibration process investigates the use of the NSGA-III algorithm in multi-objective optimization to calibrate the simulation model with the use of additional parameters estimated based on high-resolution controller data, compared to the utilization of GA to calibrate the simulation model based on a single variable (travel time) in the calibration. There have been several studies that used GA to calibrate simulation models by minimizing the error between field and simulation travel time or turning movement counts (Ma and Abdulhai, 2002; Kim et al., 2005; Park and Qi, 2005). An arterial network traffic movement is affected by several major factors, including movement restrictions due to traffic controllers and traffic feed through cross streets. In this study, the calibration based on GA with a single objective and multi-objective optimization procedure 
is compared to determine their effectiveness in supporting the calibration of simulation models.

When calibrating the driver behavior parameters based on a single objective GA operator, the absolute error between the field travel time and simulation travel time is minimized using Equation 3-4. The pseudo-code for the GA is shown in Figure 3-8.

$$
f(x)=\frac{\left|T T_{\text {Field }}-T T_{\text {simulation }}\right|}{T T_{\text {Field }}}
$$

where

$\mathrm{x}=$ Driver behavior parameters,

$f(x)=$ Objective function,

$\mathrm{TT}_{\text {Field }}=$ Field-measured travel time,

$\mathrm{TT}_{\text {Simulation }}=$ Simulation travel time.

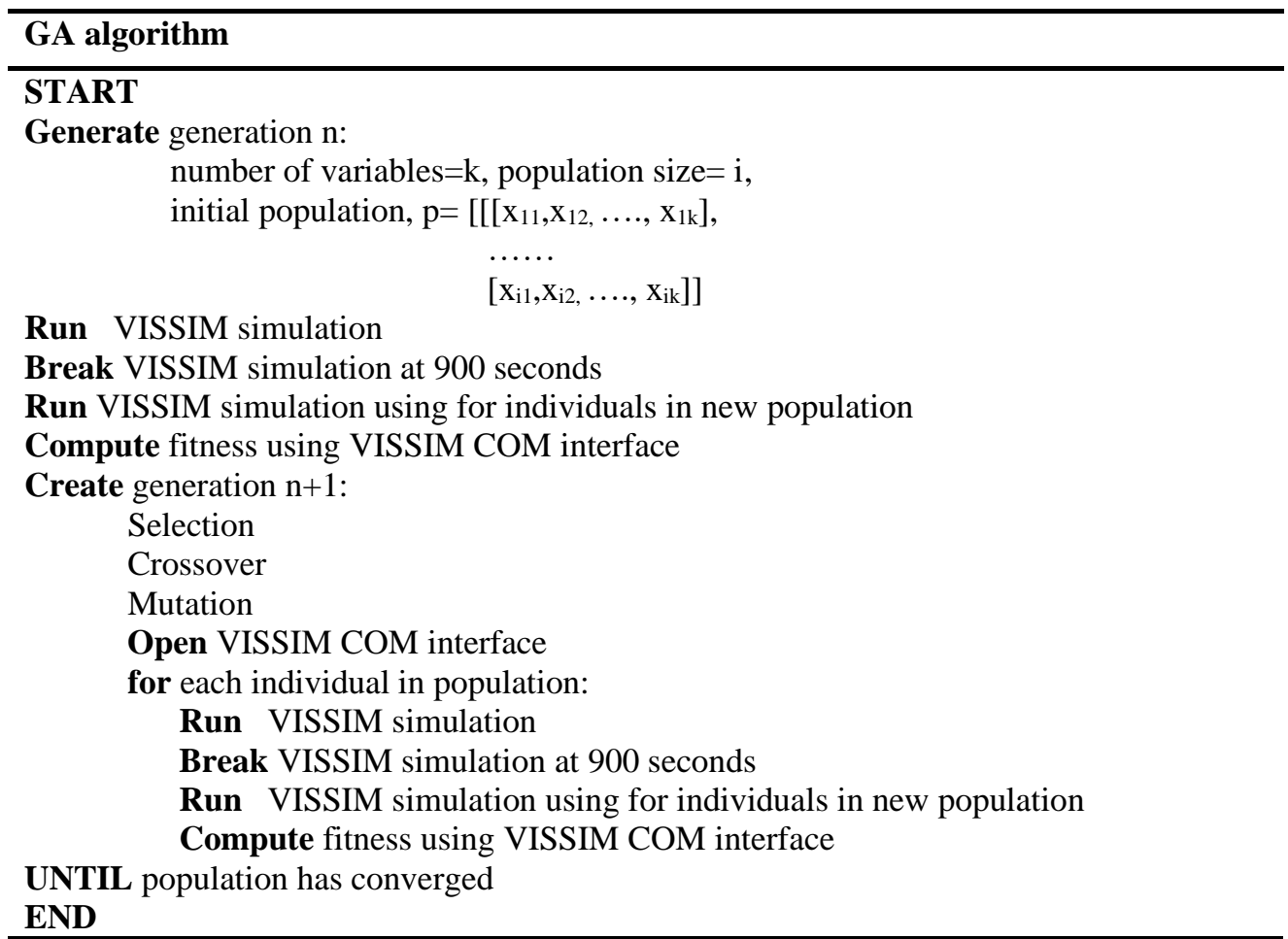

Figure 3-8: Pseudo Code for Single Objective Genetic Algorithm Optimization 
As discussed above, the change in the vehicle movements in an arterial network is influenced by multi-dimensional network features such as traffic signal timing, stop signs, and vehicle feed from cross streets. Therefore, a multi-objective optimization algorithm, referred to as NSGA-III, is applied to minimize the error between field and simulation measures, including corridor travel time, intersections delay, and vehicle throughput. The multi-objective optimization problem for VISSIM calibration can be stated as follows:

$$
\text { minimize } f(x)=\left[f_{1}(x), f_{2}(x), f_{3}(x) \ldots \ldots \ldots, f_{M}(x)\right]
$$

subject to:

$$
x_{i}^{L} \leq x_{i} \leq x_{i}^{U}
$$

where

$M=$ Number of objective functions, (In this study $M=3$, which are travel time, split utilization ratio, and throughput),

$f(x)=$ Objective function values,

$i=$ Number of variables,

$\mathrm{x}_{\mathrm{i}}=$ Decision variables (Adjustable microsimulation parameters),

$\mathrm{x}_{\mathrm{i}}^{\mathrm{L}}=$ Lower bound of decision variables,

$\mathrm{x}_{\mathrm{i}}^{\mathrm{U}}=$ Upper bound of decision variables.

The decision variables in this optimization are listed in Table 3-1, and the lower bound and upper bound of each parameter in the optimization algorithm are set based on the minimum and maximum values in Table 3-1. The objective function values are directly calculated based on the simulation results collected from the COM interface of the utilized tool and the field data for the Category 2 traffic pattern. The objective functions are calculated, as shown below: 


$$
\begin{gathered}
\mathrm{f}_{1}=\frac{\left|T T_{\text {Field }}-T T_{\text {simulation }}\right|}{T T_{\text {Field }}} \\
\mathrm{f}_{2}=\frac{\left|X_{\text {Field }(k)}-X_{\text {Simulation }(k)}\right|}{S_{\text {Field }(k)}} \\
\mathrm{f}_{3}=\frac{\mid \text { Throughput }_{\text {Field }(k)}-\text { Throughput }_{\text {simulation }(k)} \mid}{\text { Throughput }_{\text {Field }}(k)}
\end{gathered}
$$

where

$\mathrm{TT}_{\text {Field }}=$ Field-measured travel time (seconds),

$\mathrm{TT}_{\text {Simulation }}=$ Simulation travel time (seconds),

$\mathrm{X}_{\text {Field }(\mathrm{k})}=$ Field - measured split utilization ratio at phase $\mathrm{k}$,

$\mathrm{X}_{\text {Simulation }(\mathrm{k})}=$ Simulation split utilization ratio at phase $\mathrm{k}$,

Throughput $\mathrm{Field}_{(\mathrm{k})}=$ Field - measured throughput at phase $\mathrm{k}$, and

Throughput Simulation $(\mathrm{k})=$ Simulation throughput at phase $\mathrm{k}$.

The multi-objective optimization process for calibrating driver behaviors in the VISSIM Simulation is shown in the flowchart in Figure 3-9. 


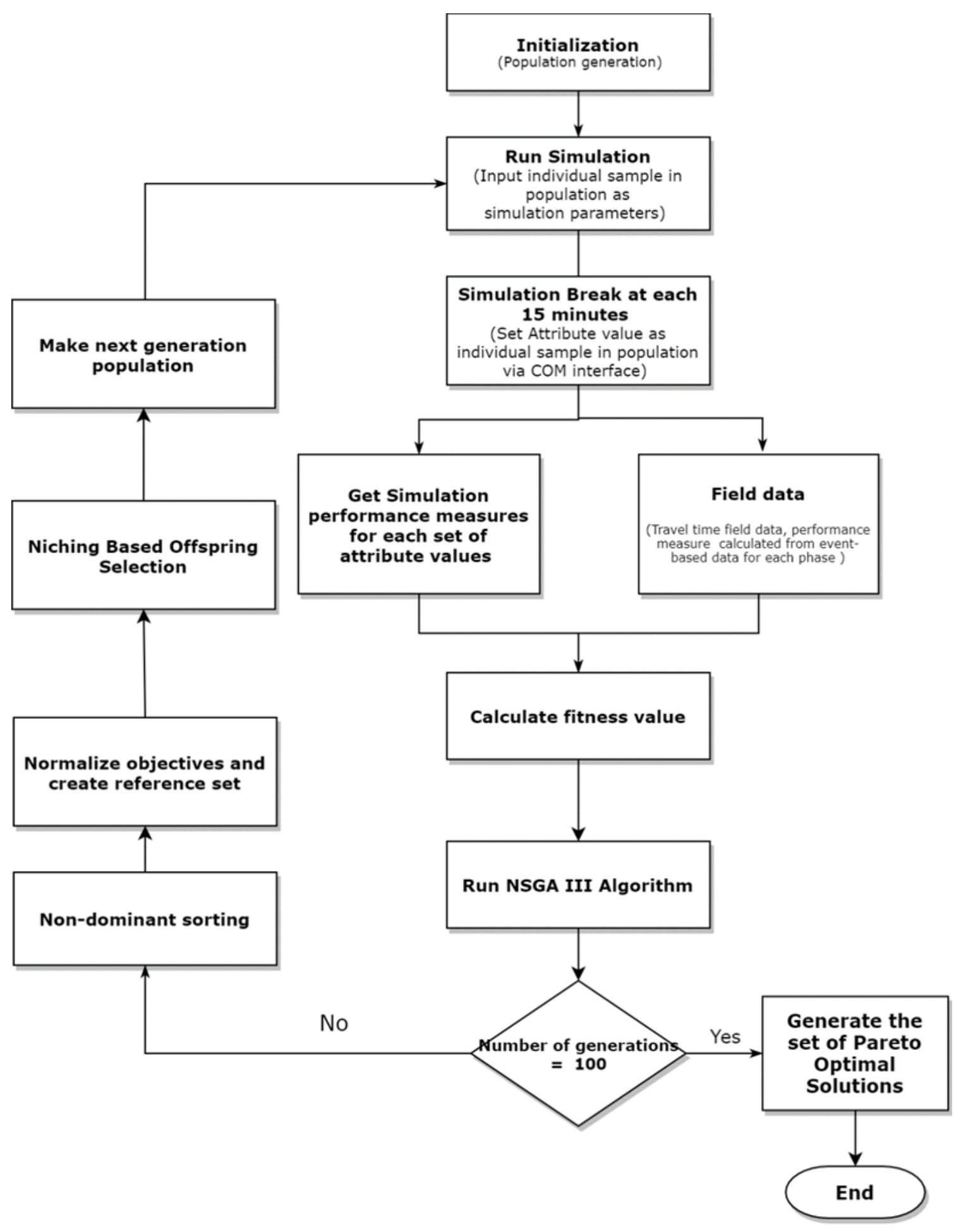

Figure 3-9: NSGA-III Optimization Process Using the VISSIM COM Interface 


\subsection{Signal Time Optimization}

As stated in the literature review section, signal optimization for oversaturated conditions has been studied since the 1960s. However, there are limited resources of practical solutions for non-recurrent congestions such as lane blockage and demand surcharge caused by the diversion from freeway incidents or vehicle rerouting, work zone, etc. This study aims to provide an implementable signal timing plan development system for various types of non-recurrent congestions. Advanced data analytics and replicated field signal timing performance measures within micro-simulation platforms are utilized in this research to generate the signal timing plans for non-recurrent conditions.

Choosing an appropriate objective function for optimizing traffic signal timing is critical because the choice will affect the overall network performance. As mentioned earlier, selecting the parameters of traffic signals in arterial corridors is a multi-objective problem, in which optimizing the solution based on one variable can often work to the detriment of another. Intersection delay minimization for signal timing optimization is by far the most widely used objective function. However, signal timing optimization based on network delay may not ensure utilizing intersection capacity to the fullest in congested conditions. Another consideration is that in addition to the consideration of individual intersections, the performance of the network corridor needs to be considered in the optimization, especially where long queue formation and spillback need to be taken into account.

In these situations, a multi-objective optimization technique is suitable for generating the signal timing plans considering multi-dimensional measures of effectiveness in the arterial network. In this study, the NSGA-III multi-objective optimization technique is 
applied to find the best signal timing plans during non-recurrent events. Calibrated VISSIM models are used as part of the optimization of signal timing for different types of incident and demand surge.

\subsubsection{Optimized Objective Functions}

As mentioned earlier, optimizing traffic signal timing is a multi-objective problem. Three measures of effectiveness have been selected in this study for the optimization problem. All of the objective function values are directly calculated based on the VISSIM simulation model results collected from the COM interface. The objective functions used in the optimization problem include the corridor travel time, intersection delay, and average throughput of all phases.

Delay is defined as the difference between the actual travel time and the travel time at free-flow conditions. At a signalized intersection, intersection delay depends on the vehicle stop time on red or waiting time for queue discharge.

Throughput is the total number of vehicles released from each link during a specific period of time. Throughput maximization increases the system's ability to process more vehicles, but it may cause queue formation at downstream intersections, especially when the downstream intersections have less capacity than demand.

The average time to move vehicles from one point to another point of the network is referred to as vehicle travel time. Corridor travel time is the average time it takes to travel the whole corridor. Minimizing the travel time of the critical direction of the corridor also minimizes the possibility of queue formation along the subject's direction. However, this objective function does not consider all of the movement of the intersection. 
Non-recurrent events generally form long queues, and in some cases, cause spillback to the upstream intersections. Choosing the objective function for this type of traffic condition is crucial. The designed objective functions should give priority to the critical direction (direction of the special events). At the same time, it should not deteriorate the cross-street traffic conditions. The objective functions of minimizing intersection delay and maximizing average throughput balance the individual intersection performance considering all movements. On the other hand, minimizing corridor travel time ensures the critical direction is a prime concern in the overall formulation. The objective functions utilized in the optimization are cited below:

$$
\begin{gathered}
f_{1}(g)=\text { Corridor Travel Time of the critical direction } \\
\qquad f_{2}(g)=\text { Intersection delay } \\
f_{3}(g)=\text { Average throughput of all movements }
\end{gathered}
$$

where

$f_{1}(g), f_{2}(g), f_{3}(g)=$ Objective function values, $\mathrm{g}=$ Green split in each phase.

\subsubsection{Optimization Process}

A knowledge-driven evolutionary algorithm NSGA-III is proposed in this study to select the optimized signal timing plans solutions. The NSGA-III algorithm is a nondominated sorting type GA algorithm that is capable of optimizing many objective functions at once. The non-dominated solution set is a set of all of the solutions that are not dominated by any member of the solution set.

The Pareto-optimal set is the entire feasible decision space of the non-dominated sets from NSGA-III. The final optimized solutions are found from the boundary of all mapped 
points of the Pareto-optimal set. The NSGA-III algorithm optimizes the fitness value in a minimization sense. For this reason, in order to maximize the throughput as one objective function, the negative value of the average throughput is minimized using the NSGA-III operator. The fitness function used in NSGA-III for signal timing optimization is stated in Equation 3-13. The pseudo-code of NSGA-III is shown in Figure 3-8.

$$
\text { minimize } \quad f(g)=\left[f_{1}(g), f_{2}(g),-f_{3}(g)\right]
$$

subject to:

where

$$
\begin{gathered}
C_{m} \leq C \leq C_{c} \\
g_{i}^{L} \leq g_{i} \leq g_{i}^{U} \\
g_{1}+g_{2}=g_{5}+g_{6} \\
g_{3}+g_{4}=g_{7}+g_{8}
\end{gathered}
$$

$\mathrm{i}=$ Phase number,

$g=$ Vector of effective green time at each phase $\mathrm{i}$ (seconds),

$f_{1}(g)=$ Corridor travel time of the critical direction (seconds),

$f_{2}(g)=$ Intersection delay (seconds/vehicle),

$f_{3}(g)=$ Vehicle throughput,

$\mathrm{C}_{\mathrm{m}}=$ Minimum Cycle Length (seconds),

$\mathrm{C}_{\mathrm{C}}=$ Maximum or Critical Cycle Length (seconds),

$\mathrm{C}=$ Cycle Length (seconds),

$\mathrm{g}_{\mathrm{i}}=$ green split at phase $\mathrm{i}$ (seconds),

$\mathrm{g}_{i}^{L}=$ Lower bound of green time at phase $\mathrm{i}$ (seconds),

$\mathrm{g}_{i}^{U}=$ Upper bound of green time at phase $\mathrm{i}$ (seconds),

$\mathrm{g}_{1}=$ Eastbound Left (EBL) phase split (seconds), 
$\mathrm{g}_{2}=$ Westbound Through (WBT) phase split (seconds),

$\mathrm{g}_{3}=$ Southbound Left (SBL) phase split (seconds),

$\mathrm{g}_{4}=$ Northbound Through (NBT) phase split (seconds),

$\mathrm{g}_{5}=$ Westbound Left $(\mathrm{WBL})$ phase split (seconds),

$\mathrm{g}_{6}=$ Eastbound Through (EBT) phase split (seconds),

$\mathrm{g}_{7}=$ Northbound Left (NBL) phase split (seconds), and

$\mathrm{g}_{8}=$ Southbound Through (SBT) phase split (seconds).

\subsubsection{Optimization Constraints}

The signal timing optimization algorithm is constrained by the minimum and maximum cycle lengths, minimum and maximum green times, and phase sequence (ring and barrier settings). Equation 3-14 represents the constraint for the cycle length. The minimum and maximum cycle lengths are calculated according to Webster's method, as cited in Chapter 2 in Equations 2-1 and 2-2, respectively. The barrier is used to separate the east-west movements from the north-south movements to avoid operating conflicting movements at the same time. Equations 3-16 and 3-17 ensure the correct ring and barrier setting of the controller, where the northbound and southbound movements start at the time that the eastbound and westbound movement end, and vice versa.

The minimum and maximum green time constraint is stated in Equation 3-15. The minimum and maximum green times of all approaches, except for the critical approach, are constrained by the controller settings in time-of-day plans. The minimum green on the critical approach is formulated by modifying the control policy principles for oversaturated conditions provided by Lieberman (Lieberman et al., 2000). One of these control policy principles is the signal phase duration of the oversaturated approaches that will stabilize 
queue lengths and provide equitable service to competing traffic streams. The minimum green time provided for the critical approach is formulated according to Equation 3-18. The minimum green time is formulated such that the total incoming vehicle can be served at the maximum capacity of the subject approach to ensure no additional queue on congested directions. On the other hand, the maximum green time is formulated such that it does not oversaturate the downstream approach. Equation 3-19 is formulated such that the total traffic volume feeding to the downstream approach should not exceed the downstream approach capacity.

$$
\begin{gathered}
\text { Minimum Green time }=\frac{\mathrm{V}_{\mathrm{T}} \times \mathrm{h}_{\mathrm{S}} \times \mathrm{C}_{\mathrm{S}}}{\mathrm{N}_{\mathrm{S}} \times 3600} \\
\text { Maximum Green time }=\frac{\mathrm{C}_{\mathrm{S}} \times \mathrm{N}_{\mathrm{D}} \times \mathrm{g}_{\mathrm{D}}}{\mathrm{N}_{\mathrm{S}} \times \mathrm{C}_{\mathrm{D}}}-\frac{\mathrm{N}_{\mathrm{T}} \times \mathrm{h}_{\mathrm{S}} \times \mathrm{C}_{\mathrm{S}}}{\mathrm{N}_{\mathrm{S}} \times 3600}
\end{gathered}
$$

where

$\mathrm{V}_{\mathrm{T}}=$ Total incoming vehicles per hour,

$\mathrm{C}_{\mathrm{S}}=$ Cycle length of the subject intersection (seconds),

$\mathrm{C}_{\mathrm{D}}=$ Cycle length of the downstream intersection (seconds),

$\mathrm{g}_{\mathrm{D}}=$ Available green time at the downstream approach (seconds),

$\mathrm{N}_{\mathrm{S}}=$ Number of lanes in subject approach,

$\mathrm{N}_{\mathrm{D}}=$ Number of lanes in downstream approach,

$\mathrm{h}_{\mathrm{S}}=$ Saturation headway (seconds), and

$\mathrm{N}_{\mathrm{T}}=$ Number of left-turning and right-turning vehicles per hour. 
The following steps are used in the optimization process to calculate the fitness function values based on VISSIM simulation results. The entire process is performed using the Python COM interface.

- Each of the generated population in the NSGA-III algorithm, which represents a signal timing plan is used as input to the simulation model to control traffic during the simulation run.

- After using each timing plan generated by the NSGA-III, the VISSIM outputs are used to estimate the performance measures with the plan.

- The fitness values are then calculated for the individual populations (signal timing plans).

As mentioned earlier, the NSGA-III algorithm is used with three objective functions, as shown in Equations 3-10, 3-11 and 3-12, and are utilized to generate optimum signal timing plans. The pseudo-code of the utilized NSGA-III optimization algorithm is presented in Figure 3-10. 


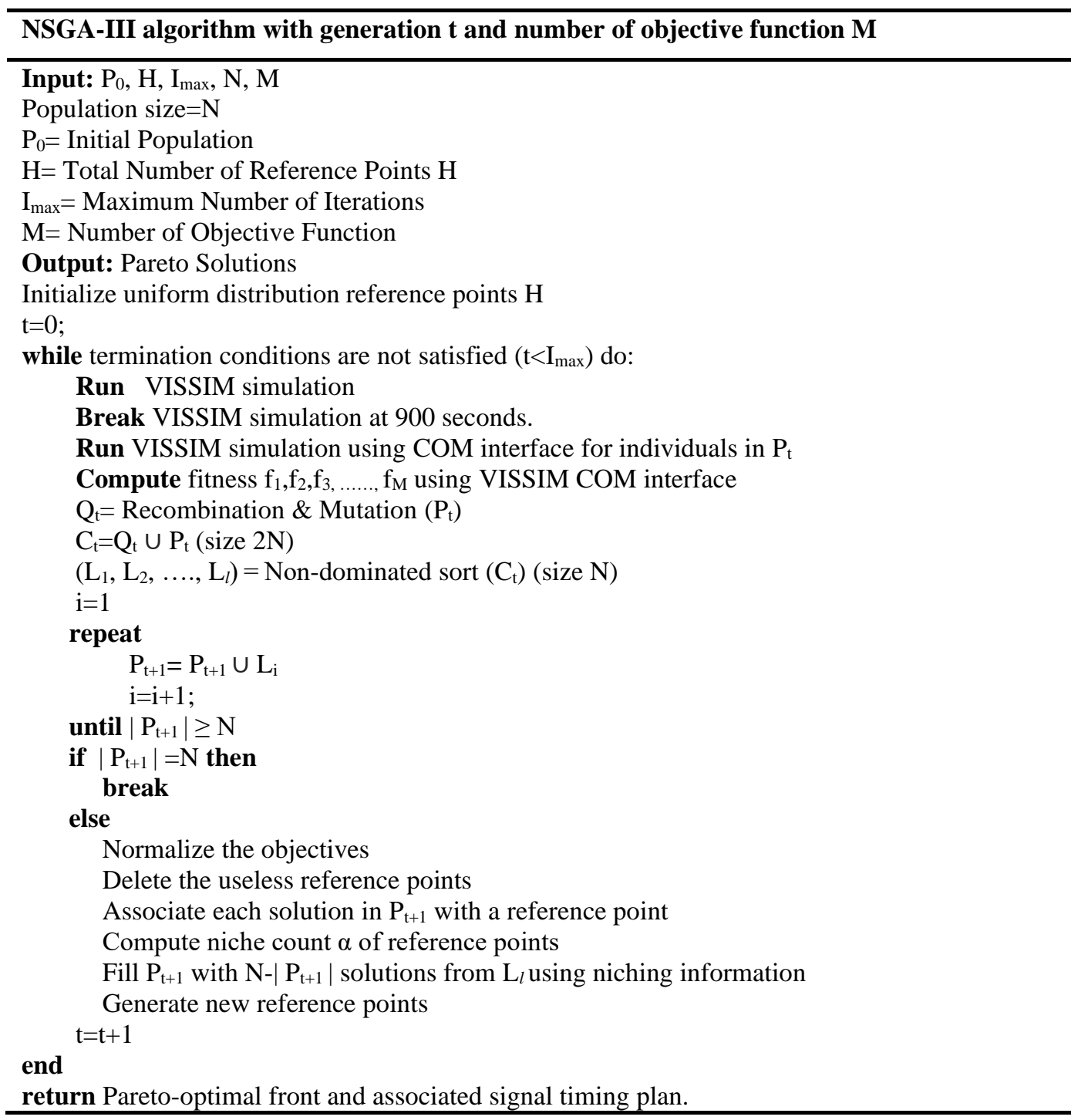

\section{Figure 3-10: NSGA-III Pseudo Code}

\subsection{Summary}

The proposed methodology in this study develops signal timing modification strategies to mitigate detected non-recurrent congested conditions. This chapter elaborates on the whole research methodology process step by step. The pseudo-codes of the developed methods can be transformed into any computer language for future use. In the next chapter, the outputs from applying these methods are analyzed and evaluated. 


\title{
CHAPTER IV
}

\begin{abstract}
ANALYSIS AND RESULTS
The detailed application and analysis results of the proposed methodology described in Chapter III is discussed in this chapter. An important focus of this chapter is assessing the benefits of implementing the developed methodology. At first, the chapter presents an assessment of the impacts of applying the machine learning-based approach for the automation of the expert's signal timing decisions. Then, the traffic operational condition partitioning and VISSIM simulation model calibration and validation analysis results are discussed. The last section presents the signal timing optimization results and the performance evaluation of the special signal timing plans based on arterial network performance measures.
\end{abstract}

\subsection{Automation of Expert's Signal Timing Modification Decisions}

As discussed in Chapter 3, this step utilized a combination of two artificial intelligence approaches, RPART and FRBS, to recommend modifications to signal timings during non-recurrent events such as incidents, construction, and surges in demands. The developed methodology learns from the decisions made by signal engineers/expert operators to change signal timings by extending greens during incidents and produce fuzzy rules that can be used to automate the process. The results from the model development and evaluation are described in the following section.

\subsubsection{Development of the Decision Tree}

A DT is developed in this study for feature selection and for extracting the crisp logical rules based on traffic signal engineers' decisions. The resulting crisp rules are then 
fed into the FRBS algorithm. The building of the DT also eliminates the noncontributing variables to the prediction of the output to improve the prediction performance of the model. In the development of this study, among the potential six input variables, the DT selects five contributing features, which are "queue length", "demand increment ratio", "capacity reduction ratio", "incident start period" and "upstream intersection importance". Figure 4-1 shows the DT generated in this study. The RPART algorithm first divides the dataset depending on the queue length, then the subset that has the queue length lower than 6,057 feet is further divided into subgroups based on the demand increment ratio and capacity reduction ratio. When the queue length is larger than 6,057 feet, the subsets are divided in terms of upstream intersection cross street importance, as well as the incident start period, demand increment ratio, and capacity reduction ratio in the next levels. It should be mentioned that the signal timing experts do not violate the summation of the minimum green times required for pedestrian phases and vehicular movement phase. This and other constraints on the signal timing changes can be added as rules in the Fuzzy RuleBased System. 


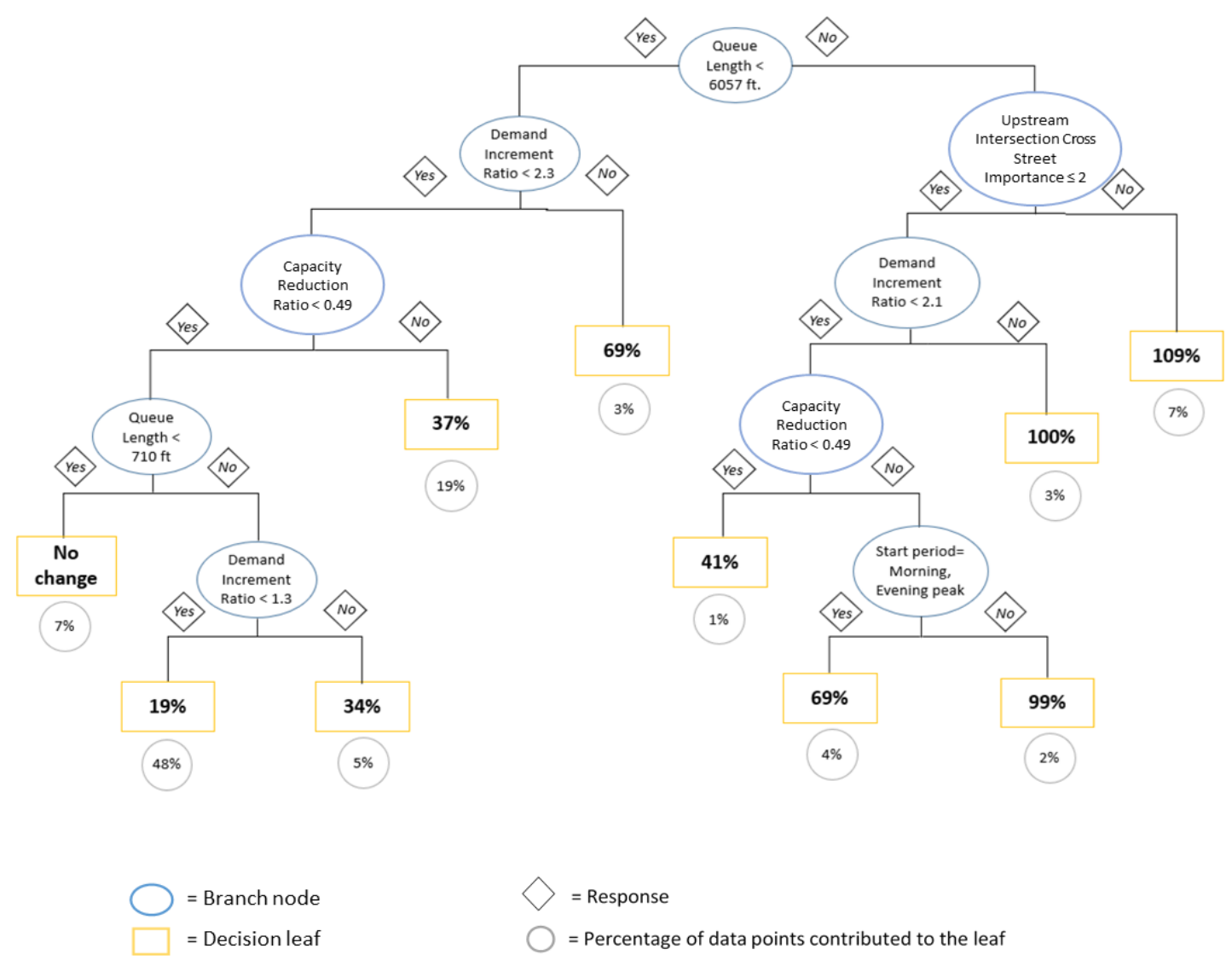

Figure 4-1: Developed Decision Tree from the Traffic Signal Engineer/Expert Operator's Decision Feed

\subsubsection{Development of Fuzzy Rule-Based System}

As stated earlier, developing the knowledge base consists of developing the rule base and database, with the rule base representing the reasoning of human experts in a set of ifthen rules. In the Mamdani model, there are two parts in each rule, the antecedent and the consequent part, which are separated by then ("->"). This study generates the rule base by creating fuzzy if-then rules from the DT, developed as described in the previous section, instead of creating rules as manual inputs from the experts or users, allowing for better estimation. All of the rules are initially extracted from the Decision Tree as sets of simplified crisp rules. The extracted crisp rules are shown in Table 4-1 below. 
Table 4-1: Extracted Crisp Rules from the Decision Tree

\begin{tabular}{|c|c|c|c|c|c|c|c|c|c|c|}
\hline $\begin{array}{l}\text { Incident } \\
\text { Period }\end{array}$ & & $\begin{array}{c}\text { Upstream } \\
\text { Intersection } \\
\text { Cross Street } \\
\text { Importance }\end{array}$ & & $\begin{array}{l}\text { Queue } \\
\text { Length }\end{array}$ & & $\begin{array}{c}\text { Demand } \\
\text { Increment } \\
\text { Ratio }\end{array}$ & & $\begin{array}{c}\text { Capacity } \\
\text { Reduction } \\
\text { Ratio }\end{array}$ & & $\begin{array}{c}\text { Increment } \\
\text { in } \mathrm{g} / \mathrm{C} \\
\text { Ratio }\end{array}$ \\
\hline dont_care & and & dont_care & and & Small & and & Not Large & and & $\begin{array}{c}\text { not Two-lane } \\
\text { Blockage }\end{array}$ & and $->$ & No Change \\
\hline dont_care & and & dont_care & and & Medium & and & None & and & $\begin{array}{c}\text { not Two-lane } \\
\text { Blockage }\end{array}$ & and $->$ & Small \\
\hline dont_care & and & dont_care & and & Medium & and & Small & and & $\begin{array}{c}\text { not Two-lane } \\
\text { Blockage }\end{array}$ & and $->$ & Small \\
\hline dont_care & and & dont_care & and & Medium & and & Medium & and & $\begin{array}{c}\text { not Two-lane } \\
\text { Blockage }\end{array}$ & and $->$ & Medium \\
\hline dont_care & and & dont_care & and & Medium & and & Not Large & and & $\begin{array}{l}\text { Two-lane } \\
\text { Blockage }\end{array}$ & and $->$ & Medium \\
\hline dont_care & and & dont_care & and & Medium & and & Large & and & dont_care & and $\rightarrow$ & Large \\
\hline dont_care & and & $\begin{array}{l}\text { not Very } \\
\text { Important }\end{array}$ & and & Long & and & Not Large & and & $\begin{array}{c}\text { not Two-lane } \\
\text { Blockage }\end{array}$ & and $->$ & Medium \\
\hline $\begin{array}{c}\text { Morning, } \\
\text { Evening } \\
\text { Peak } \\
\end{array}$ & and & $\begin{array}{l}\text { not Very } \\
\text { Important }\end{array}$ & and & Long & and & Not Large & and & $\begin{array}{l}\text { Two-lane } \\
\text { Blockage }\end{array}$ & and $\rightarrow$ & Large \\
\hline Midday & and & $\begin{array}{l}\text { not Very } \\
\text { Important }\end{array}$ & and & Long & and & Not Large & and & $\begin{array}{l}\text { Two-lane } \\
\text { Blockage }\end{array}$ & and $->$ & Very Large \\
\hline dont_care & and & $\begin{array}{l}\text { not Very } \\
\text { Important }\end{array}$ & and & Long & and & Large & and & No Blockage & and $->$ & Very Large \\
\hline dont_care & and & $\begin{array}{c}\text { Very } \\
\text { Important }\end{array}$ & and & Long & and & dont_care & and & dont_care & and $\rightarrow$ & Very Large \\
\hline
\end{tabular}

The membership functions are designed based on the developed DT to transform the crisp inputs into degrees of membership in the fuzzy functions and represent the linguistic terms of the fuzzy sets. Again, this allows for a more accurate representation of expert knowledge. The membership functions are created by defining the shapes and parameters of the functions of the input and output variables. The triangles and trapezoid shapes of the membership functions, which are the most widely used function shapes, are used in this study. The membership parameters and the number of linguistic terms/labels to include are derived based on the partitions of the developed DT. For example, RPART partitioned the queue length in the Decision Tree into three labels as small (less than $710 \mathrm{ft}$ ), medium 
(less than 6,057 ft), and large (more than 6,057 ft). The membership function of the queue length in the fuzzy rule base is labeled in the same manner. The developed membership functions of the input and output variables are shown in Figure 4-2. In Figure 4-2, the xaxes represent the values of the input and output variables used in the decision, and the yaxes represent the probability of a variable value being a member of each of the fuzzy classes.
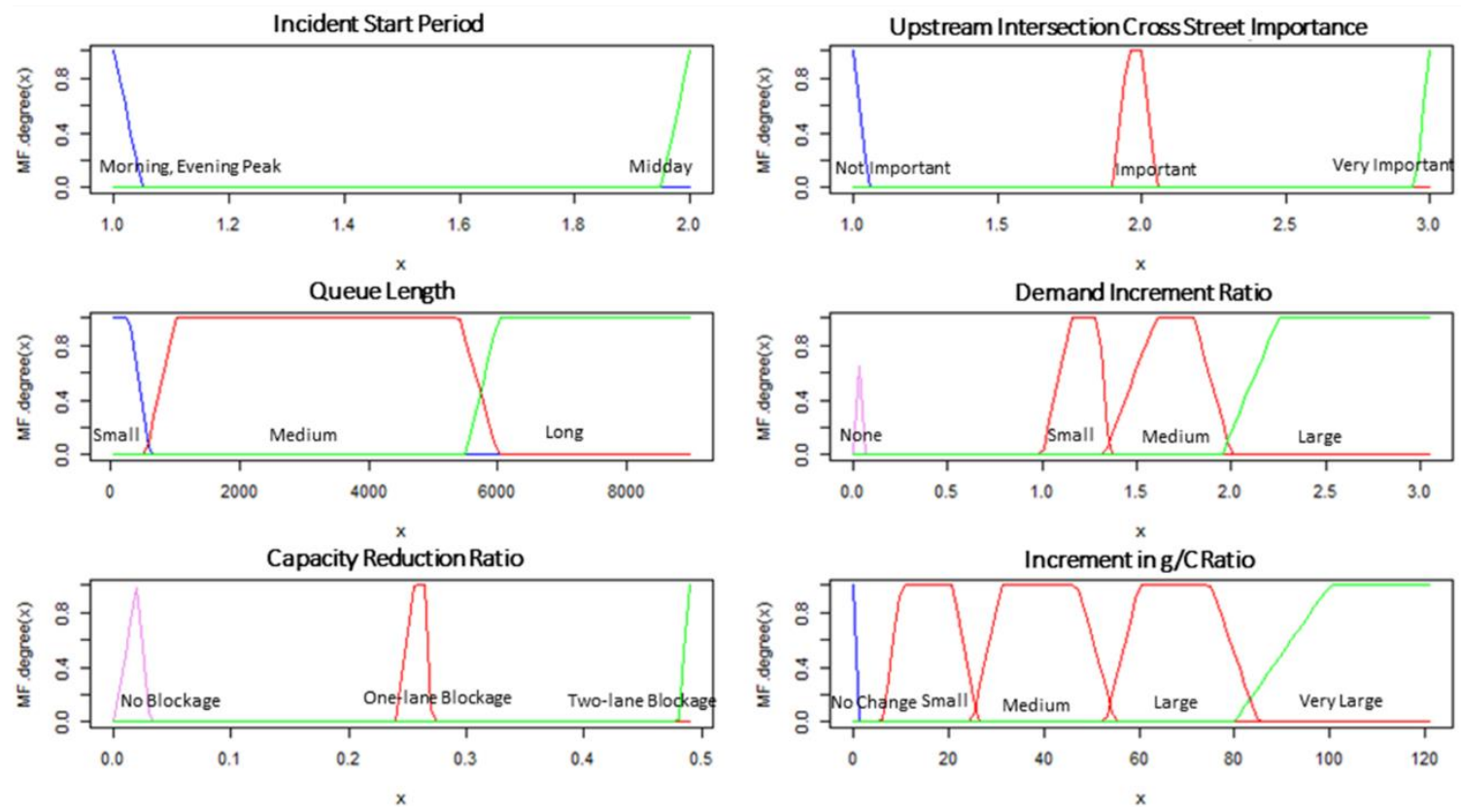

Figure 4-2: Membership Functions of the Derived Knowledge Base

In the final step of developing the FRBS system, the 'frbs.gen' inference engine is used in the R programming tool. For fuzzy inference, the Mamdani model is utilized to perform the inference operation using the fuzzy if-then rules. The defuzzification process is conducted to obtain the crisp values from the fuzzy output set using the weighted average method (WAM) in the defuzzification. 


\subsubsection{Validation of the Model}

Model validation is an important part of developing any machine learning model. The validation is performed to test the accuracy of the model. Ten percent of the data points are randomly selected as the test sample and those are not included in training the model. The accuracy of the model is calculated using the following formula:

$$
\text { Accuracy of the model }(\%)=\frac{\text { Number of Correct Prediction }}{\text { Total Number of Prediction }} \times 100
$$

The model's overall accuracy is found to be $77 \%$, with a $5 \%$ mean absolute error. The mean absolute error is calculated as the absolute value of the difference between the model output value ( $\mathrm{g} / \mathrm{C}$ ratio increase $(\%)$ ) and the actual change in $\mathrm{g} / \mathrm{C}(\%)$ as implemented by the expert. Table 4-2 shows the result of model validation. Comparing the decisions made based on the resulting fuzzy rules from applying the methodology to previously recorded expert decisions for the project case study indicates accurate recommendations for shifts in the green time (about $77 \%$ accuracy or $5 \%$ mean absolute error). The comparison is made for 10 percent of the data points randomly selected as the test sample and those are not included in training the model. 
Table 4-2: Model Validation Results

\begin{tabular}{|l|l|l|l|l|}
\hline $\begin{array}{l}\text { Predicted Increase } \\
\text { in g/C Ratio } \\
\text { Numerical Value) }\end{array}$ & $\begin{array}{l}\text { True Increase in } \\
\text { g/C Ratio } \\
\text { (Numerical Value) }\end{array}$ & $\begin{array}{l}\text { Predicted Increase } \\
\text { in g/C Ratio } \\
\text { (Linguistic Term) }\end{array}$ & $\begin{array}{l}\text { True Increase in g/C } \\
\text { Ratio (Linguistic Term) }\end{array}$ & Validation \\
\hline $60 \%$ & $69.2 \%$ & Large & Large & Correct \\
\hline $10 \%$ & $26.7 \%$ & Small & Medium & Incorrect \\
\hline $100 \%$ & $102.6 \%$ & Very Large & Very Large & Correct \\
\hline $31 \%$ & $34.0 \%$ & Medium & Medium & Correct \\
\hline $31 \%$ & $30.0 \%$ & Medium & Medium & Correct \\
\hline $60 \%$ & $68.0 \%$ & Large & Large & Correct \\
\hline $0.1 \%$ & $0.0 \%$ & No Change & No Change & Correct \\
\hline $31 \%$ & $22.3 \%$ & Medium & Small & Incorrect \\
\hline $100 \%$ & Very Large & Very Large & Correct \\
\hline $10 \%$ & $100.0 \%$ & Small & Small & Correct \\
\hline $10 \%$ & $11.5 \%$ & Small & Medium & Incorrect \\
\hline $31 \%$ & $26.7 \%$ & Medium & Medium & Correct \\
\hline $0.1 \%$ & $28.7 \%$ & No Change & No Change & Correct \\
\hline Accuracy of the Model & $0.0 \%$ & & & $77 \%$ \\
\hline Mean Absolute Error & & & $5 \%$ \\
\hline
\end{tabular}

\subsubsection{Benefit Assessment}

This study assessed the benefits of the developed automation model to decide on changing signal timing during non-recurrent congestion. The assessment involved estimating the changes in delays for the movements impacted by the event and the other movements of the impacted intersection(s). The evaluation of the retiming strategies is performed for an arterial network modeled in the VISSIM simulation tool. The simulation model is used to assess traffic signal operation with and without implementing the timing modifications. The considered timing modifications only involve changing the green time of the movements impacted by the event, and the cycle length and offset were not changed to maintain progression. Three real-world scenarios are selected from the real-world expert database and simulated in VISSIM. Scenario 1 involves one lane blocked out of three lanes. Scenario 2 involves two lanes blocked out of three lanes. An increase in the demand by 1.54 times is modeled in scenario 3. 
The simulation model is initially calibrated using collected volume, travel time, and queuing data utilizing the calibration procedure recommended in the Traffic Analysis Toolbox Volume 3 developed by the Federal Highway Administration (Dowling et al., 2004). The model is then further calibrated for each of the three scenarios by comparing the model to the data recorded by the signal timing experts. The simulated segment with and without incidents is calibrated first to produce the signalized intersection movement capacities per the HCM procedures and the capacity adjustment factors for incident zones, as suggested by Dowling et al. (2013). The simulated queue length and dynamic animations of the three scenarios are observed to ensure that they reflect real-world conditions for the three scenarios. The simulation model is run 10 times with different seed numbers for each simulated condition considering the stochasticity of the simulation model's outputs. The simulation is run during a 3600-second analysis period, with the first 1800 seconds as a warm-up period. The warm-up period is not included in the performance estimation. The delay on all approaches for each scenario are estimated as the average from the ten runs and compared with the results from simulating the base conditions of not changing the signal timing.

\section{Base Scenario Modeling:}

The data associated with real-world scenarios are obtained from the traffic signal engineer's database and used as inputs to estimate the $\mathrm{g} / \mathrm{C}$ ratio and utilizing the developed FRBS model. When there was a one-lane blockage out of a three-lane road, and the queue length is medium, the model recommended a $\mathrm{g} / \mathrm{C}$ increment ratio (increase) of 20 percent. For the second scenario with two blocked lanes out of three lanes and a medium queue length, the model prediction is a 37 percent increment in the $\mathrm{g} / \mathrm{C}$ ratio. Scenario 3 involves 
a demand increment from $1,722 \mathrm{veh} / \mathrm{hr}$ to $2,655 \mathrm{veh} / \mathrm{hr}$ or a demand increment ratio of 1.54 , and the FRBS model predicted a 31 percent increment of the $\mathrm{g} / \mathrm{C}$ ratio for this scenario. The illustrations of the three scenarios in the VISSIM simulation models are shown in Figure 4-3.

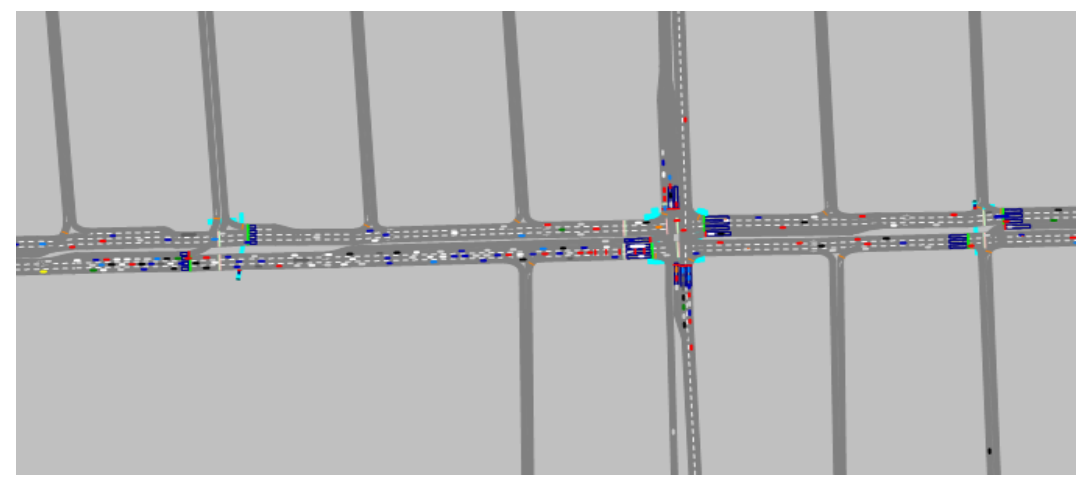

Scenario 1: One lane blocked out of three lanes

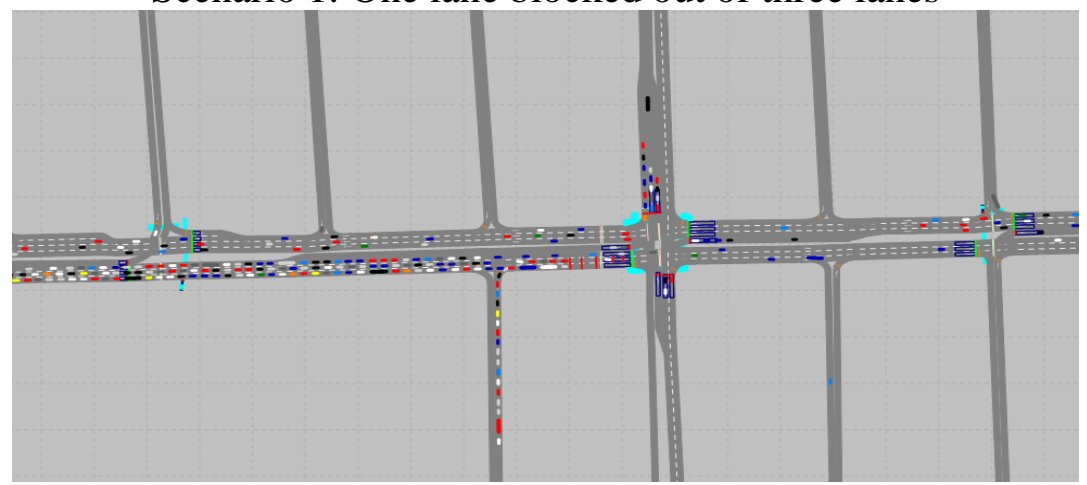

Scenario 2: Two lanes blocked out of three lanes

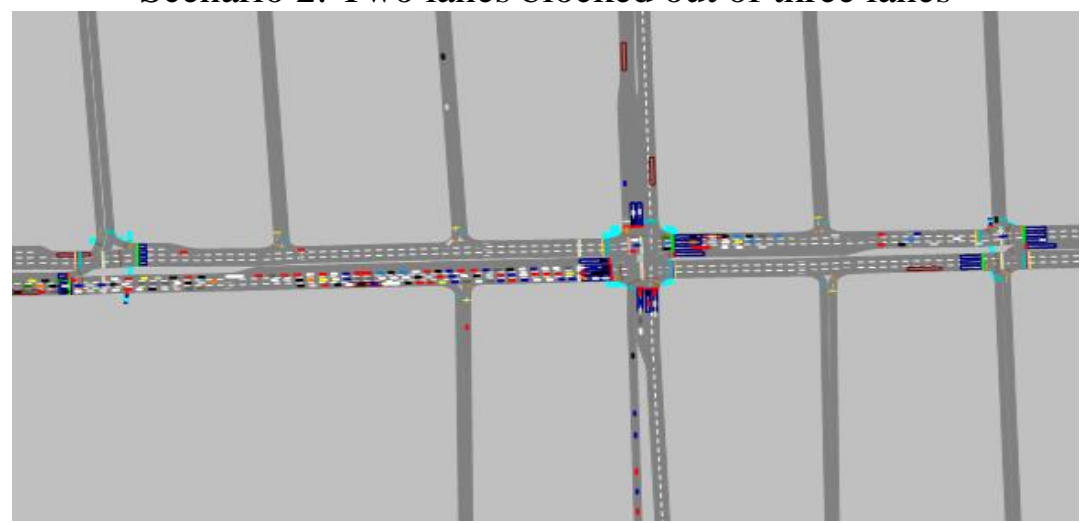

(c) Scenario 3: Demand surge

Figure 4-3: Illustration of the Three Model Scenarios to Assess Expert's Decision Automation 


\section{Signal Re-Timing Based on FRBS Prediction:}

For Scenario 1, the effective green time in the incident direction increases from 77 seconds to 92 seconds, according to the FRBS output. This is done by taking 14 percent of green time from the left turn and 25 percent from the through movements of the crossstreet approaches while maintaining the same cycle length. The decisions of how to reduce the green times of unimpacted movements by the event is made based on the volume to capacity ratio of each of these movements. When two lanes are blocked out of three lanes in Scenario 2, the effective green time is increased from 77 seconds to 105 seconds in the incident direction by taking $30 \%$ and $43 \%$ of the green time from the cross-street left-turn and through movement, respectively. In Scenario 3, the effective green time is increased from 77 seconds to 105 seconds, which is done by taking 24 percent of green time from the left turn and 37 percent from the through movements of the cross-street approaches. The signal timing changes are shown in Table 4-3.

Table 4-3: Modified Signal Timing Based on FRBS Output

\begin{tabular}{|l|c|c|c|c|c|c|c|c|}
\hline \multicolumn{10}{|c|}{ Scenarios 1: Green Time (seconds) } \\
\hline Movement & WL & WT & SL & NT & EL & ET & NL & ST \\
\hline Normal signal timing & 28 & 77 & 30 & 45 & 28 & $\mathbf{7 7}$ & 30 & 45 \\
\hline Modified signal timing & 28 & 92 & 26 & 34 & 28 & $\mathbf{9 2}$ & 26 & 34 \\
\hline \multicolumn{7}{|c|}{ Scenarios 2: Green Time (seconds) } \\
\hline Movement & WL & WT & SL & NT & EL & ET & NL & ST \\
\hline Normal signal timing & 28 & 77 & 30 & 45 & 28 & $\mathbf{7 7}$ & 30 & 45 \\
\hline Modified signal timing & 28 & 105 & 21 & 26 & 28 & $\mathbf{1 0 5}$ & 21 & 26 \\
\hline \multicolumn{8}{|c|}{ Scenarios 3: Green Time (seconds) } \\
\hline Movement & WL & WT & SL & NT & EL & ET & NL & ST \\
\hline Normal signal timing & 28 & 77 & 30 & 45 & 28 & $\mathbf{7 7}$ & 30 & 45 \\
\hline Modified signal timing & 28 & 101 & 23 & 28 & 28 & $\mathbf{1 0 1}$ & 23 & 28 \\
\hline
\end{tabular}




\section{Delay and Queue Length Estimation:}

The simulation results indicate that changing the green times based on the output of the fuzzy rules decrease the delays due to lane blockages or demand surge. The delay is estimated using simulation and compared with the no signal updates and signal updates for all three evaluation scenarios (one-lane blockage, two-lane blockage, and surge in demand). The delay results based on VISSIM simulation modeling are shown in Table 44. Table 4-4 shows that when there is a one-lane blockage in the incident direction, there is an average reduction in delays of 95.4 seconds/vehicle and 23.8 seconds/vehicle for the effected approach (EB) and the whole intersection, respectively. In the case of two-lane blockage incidents, the delay reduction for the impacted direction (the EB) is 110.6 seconds/vehicle, and the overall reduction in the average delay is 45.2 seconds/vehicle. For the surge in demand in Scenario 3, signal retiming reduces the delay of the affected direction by around 130 seconds/vehicle and the average delay for the intersection by about 27.4 seconds/vehicle.

Table 4-4: Impact of Green Time Update Based on FRBS Output

\begin{tabular}{|c|c|c|c|c|c|c|}
\hline Events & & $\begin{array}{l}\text { Critical } \\
\text { Direction } \\
(\mathrm{EB})\end{array}$ & $\begin{array}{c}\text { Opposing } \\
\text { Direction } \\
(\mathrm{WB})\end{array}$ & $\begin{array}{c}\text { Cross } \\
\text { Street } \\
(\mathrm{SB})\end{array}$ & $\begin{array}{l}\text { Cross } \\
\text { Street } \\
(\mathrm{NB})\end{array}$ & $\begin{array}{c}\text { Overall } \\
\text { Intersection }\end{array}$ \\
\hline \multirow{2}{*}{$\begin{array}{l}\text { One Lane } \\
\text { Blockage }\end{array}$} & $\begin{array}{l}\text { Change in Average } \\
\text { Delay (s/veh) }\end{array}$ & -95.4 & -3.0 & +1.6 & +1.6 & -23.8 \\
\hline & $\begin{array}{l}\text { Change in Queue } \\
\text { Length (ft) }\end{array}$ & -1112 & -136 & +273 & +257 & -718 \\
\hline \multirow{2}{*}{$\begin{array}{l}\text { Two Lane } \\
\text { Blockage }\end{array}$} & $\begin{array}{l}\text { Change in Average } \\
\text { Delay (s/veh) }\end{array}$ & -110.6 & +12.2 & +7.6 & +6.5 & -45.2 \\
\hline & $\begin{array}{l}\text { Change in Average } \\
\text { Queue Length (ft) }\end{array}$ & -741 & -257 & +418 & +420 & -160 \\
\hline \multirow{2}{*}{$\begin{array}{l}\text { Demand } \\
\text { Increment Ratio } \\
\text { of } 1.54\end{array}$} & $\begin{array}{l}\text { Change in Average } \\
\text { Delay (s/veh) }\end{array}$ & -130.0 & +8.2 & +5.9 & +6.3 & -27.4 \\
\hline & $\begin{array}{l}\text { Change in Average } \\
\text { Queue Length (ft) }\end{array}$ & -2075 & -234 & +426 & +414 & -1469 \\
\hline
\end{tabular}

Note: '- 'sign indicates reduction and '+' sign indicates increment in delay and queue length 


\subsubsection{Tool Development}

This study develops an application tool utilizing the combination of the DT and FRBS model. This signal timing modification tool allows the user to modify the existing signal plan during non-recurrent events. This tool consists of five inputs and one output based on the DT and FRBS model. The output value from the tools shows the recommended increment in a $\mathrm{g} / \mathrm{C}$ ratio. This application has the potential to benefit agencies by improving the efficiency of the process used to address non-recurrent congested conditions. The main advantage of this application is that the signal maintaining agencies will be able to implement this application utilizing their existing operational platform without requiring any infrastructural upgrades while reducing the dependence on expert staff in making the decisions. Figure 4-4 shows a screen capture of the signal timing modification tool based on the DT and FRBS model.

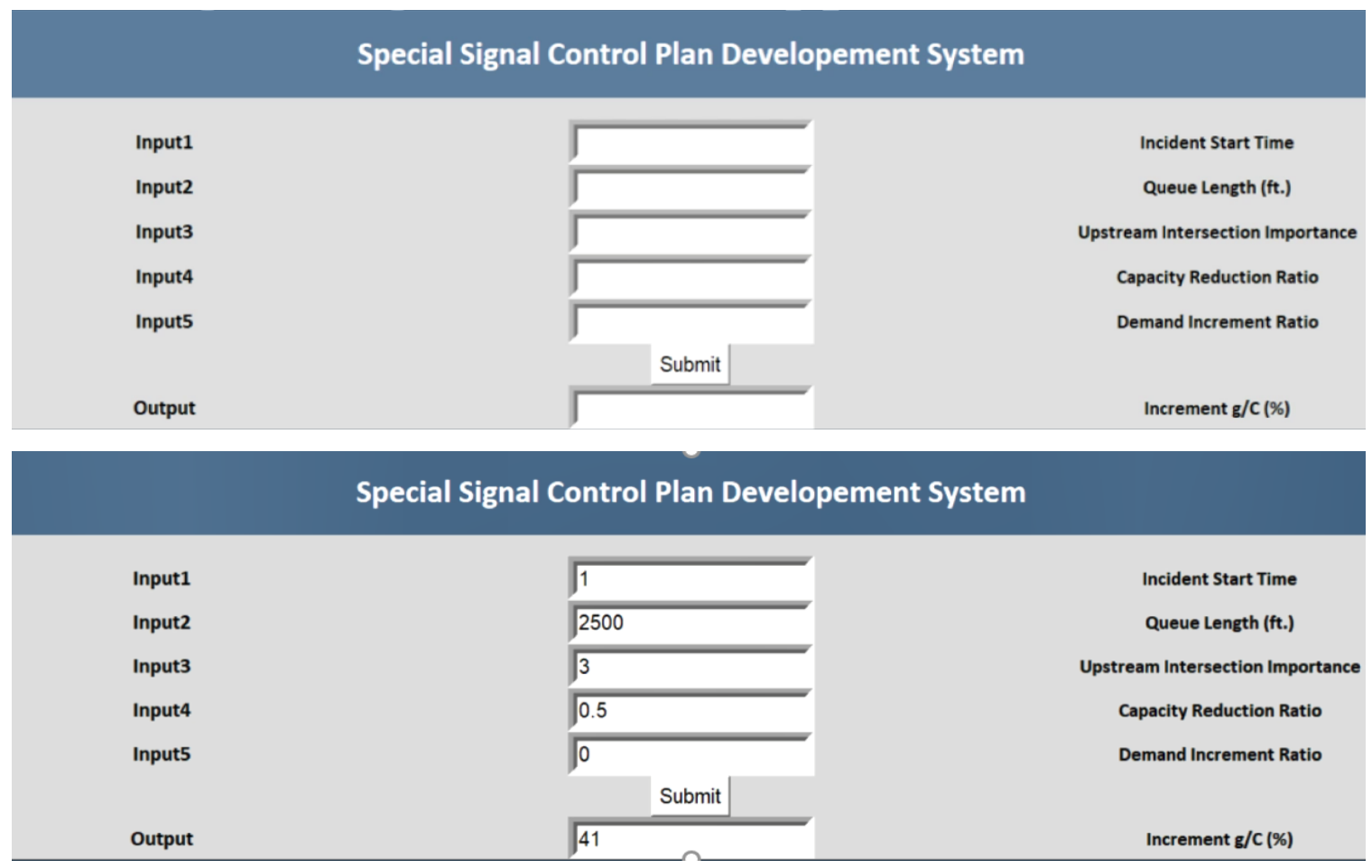

Figure 4-4: Special Signal Timing Modification Tool 


\subsection{Clustering Results}

The study utilizes vehicle Travel time from Bluetooth data and cycle-by-cycle signal performance measures from the high-resolution data in the clustering analysis to separate the traffic operational conditions for further analysis. At first, the travel time data for 24 hours each day is collected and clustered. It is determined that four different clusters are the best number for the travel time-based clustering. Figure 4-5 shows the four separate clusters derived using the K-means methods and their centers based on travel time only. Cluster 2 mainly represents data between 7:00 AM and 9:00 AM with heavy eastbound traffic, Cluster 1 represents moderate traffic in both directions during the midday and postpeak period in the PM (between 7:00 PM and 9:00 PM), and Cluster 3 represents night traffic. In contrast, Cluster 4 represents the PM peak period traffic between 3:00 PM and 7:00 PM that is heavy in the westbound direction. Obviously, the traffic can change significantly within each of these periods, between days and from cycle-to-cycle. Thus, further portioning is needed for the data based on high-resolution controller data, as explained next.

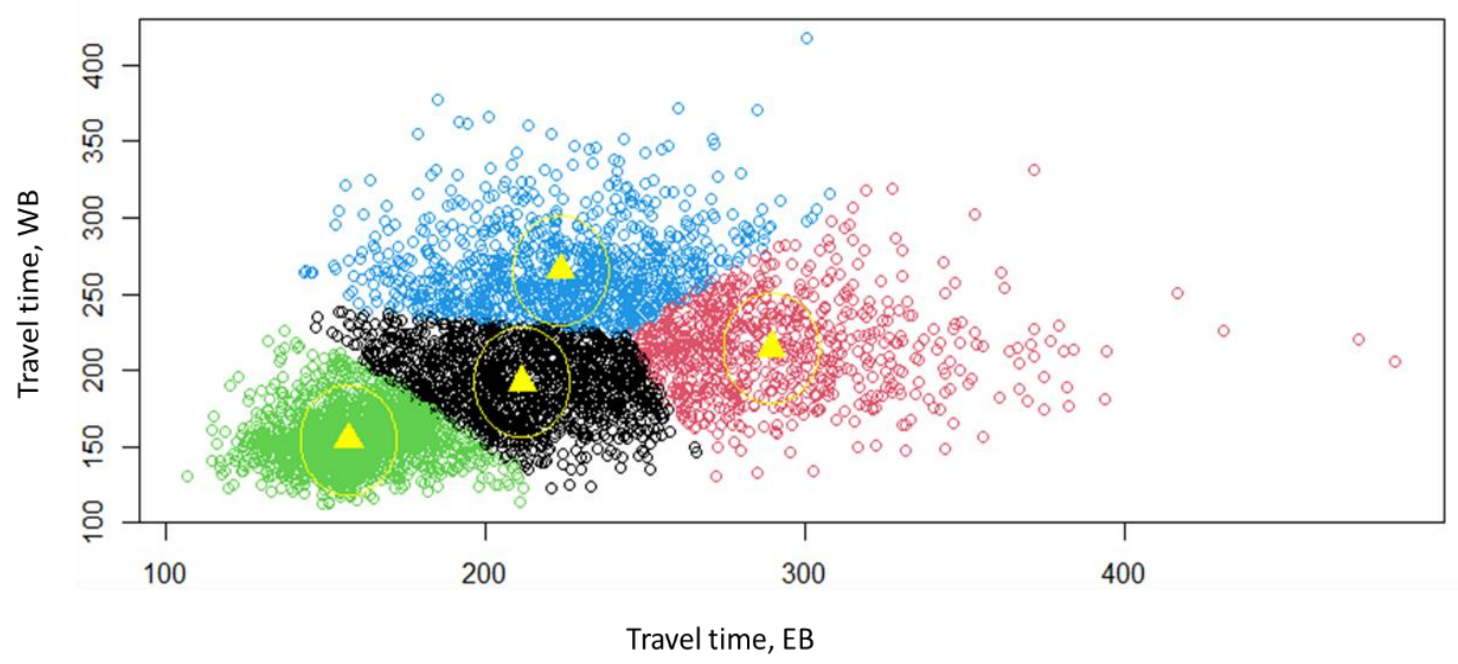

Figure 4-5: Travel Time Clusters 
Further partitioning of the traffic patterns is done by K-means clustering based on the GOR for the 7:00 AM to 9:00 AM peak period utilizing event-based controller data. Table 4-5 presents the resulting categories of traffic conditions in the AM peak based on the GOR of all major movements and the associated travel times of the study segment. This dissertation presents the results of the calibration and validation of a microscopic simulation model for the case study for one of the categories in Table 1 (Category 2).

\section{Table 4-5: Categorization of Traffic Based on the Green Occupancy Ratio}

\begin{tabular}{|c|c|c|c|c|c|c|c|}
\hline \multirow[t]{3}{*}{ Category } & \multirow[t]{3}{*}{$\begin{array}{l}\text { No of Data } \\
\text { Points }\end{array}$} & \multicolumn{2}{|c|}{$\begin{array}{l}\text { Average Travel } \\
\text { Time (seconds) }\end{array}$} & \multirow{2}{*}{\multicolumn{2}{|c|}{$\begin{array}{c}\text { Through } \\
\text { Movement Cluster } \\
\text { Center GOR }\end{array}$}} & \multirow{2}{*}{\multicolumn{2}{|c|}{$\begin{array}{l}\text { Left Turn Cluster } \\
\text { Centers GOR }\end{array}$}} \\
\hline & & \multirow[t]{2}{*}{ EB } & \multirow[t]{2}{*}{ WB } & & & & \\
\hline & & & & EBT & $\underline{\text { SBT }}$ & $\underline{\text { EBL }}$ & $\underline{\text { SBL }}$ \\
\hline Category 1 & 8 & 300.1 & 223.01 & 0.636 & 0.775 & 0.84 & 0.94 \\
\hline Category 2 & 22 & 279.65 & 215.74 & & & 0.84 & 0.77 \\
\hline Category 3 & 5 & 276.6 & 205.26 & & & 0.77 & 0.62 \\
\hline Category 4 & 16 & 265.5 & 213.57 & 0.556 & 0.772 & 0.79 & 0.87 \\
\hline Category 5 & 19 & 280.15 & 217.51 & & & 0.80 & 0.72 \\
\hline Category 6 & 18 & 281.7 & 198.03 & 0.613 & 0.658 & 0.80 & 0.77 \\
\hline
\end{tabular}

\subsection{VISSIM Model Calibration and Validation}

In this step, a microscopic simulation model is developed and calibrated for the test scenario using a multi-objective optimization technique based on travel time and highresolution controller-based measurement. The evaluation of the calibration based on the multi-objective function indicates that the proposed optimization technique is able to better replicate intersection measures assessed based on high-resolution controller data such as GOR, green utilization, and arrival on green, while producing comparable errors in travel time to those obtained when optimizing the calibration parameters based on travel time measurements alone. 


\subsubsection{Calibration Results}

As stated earlier, the NSGA-III algorithm uses a non-dominant sorting procedure and finds a set of Pareto-optimal solutions rather than a single optimal solution. The Paretooptimal solutions are the sets of solution trade-offs when all of the objectives are considered. Figure 4-6 shows the 3D scatter plot of the final set of the Pareto-optimal solution. The Pareto-optimal solution from the NSGA-III algorithm resulted in seven different sets of objective function values, as shown in Figure 4-6(a). Each set represents the trade-offs of solutions between the three objective function values used in this study (Equations 3-6, 3-7, and 3-8). Figure 4-6(b) shows the selected two Pareto-optimal sets in red dots for further evaluation. These two sets are referred to as NSGA Set-I and NSGA Set-II in the remaining part of the model calibration and validation section. Table 4-6 shows the decision variables or driver behavior parameters for both solution sets. Table 46 also shows the GA optimization results using the travel time objective function $(f(x)$ in Equation 3-4). 


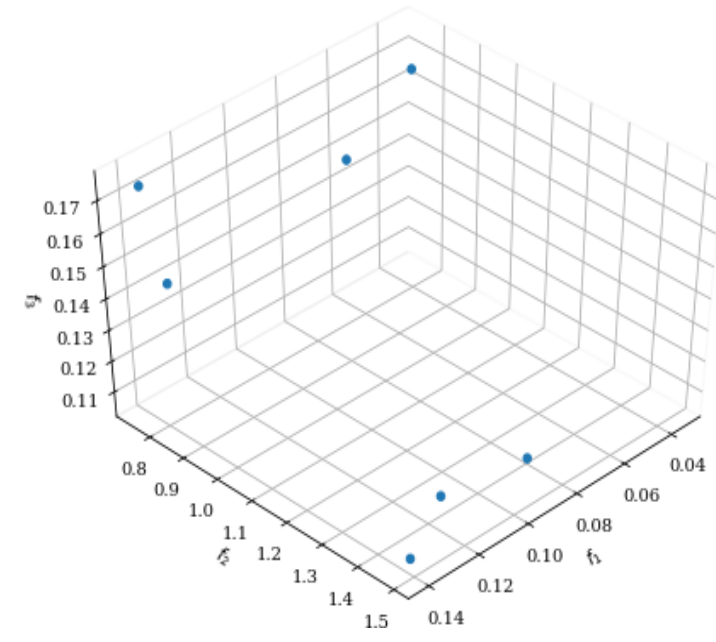

(a)

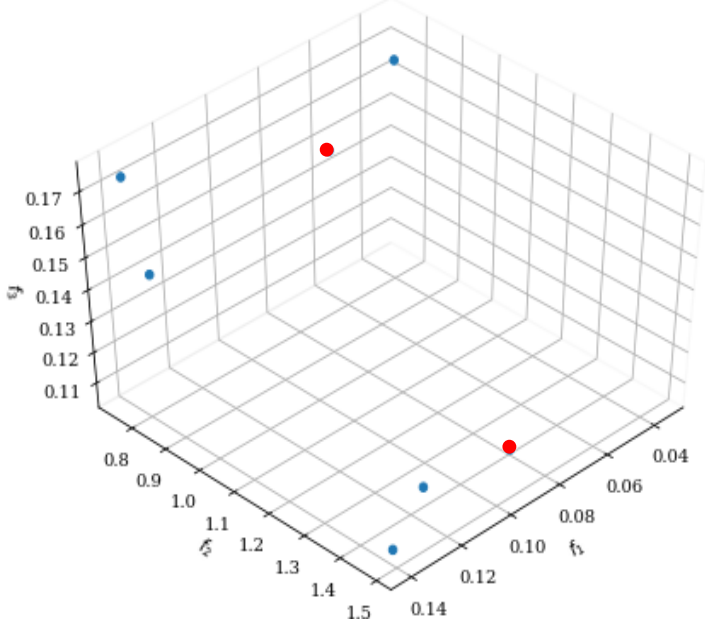

(b)

Figure 4-6: Pareto-Optimal Solution from NSGA-III Output

Table 4-6: Optimal Solutions and Corresponding Decision Variables

\begin{tabular}{|c|c|c|c|c|c|c|c|c|c|c|}
\hline $\begin{array}{c}\text { Pareto } \\
\text { Optimal } \\
\text { Set }\end{array}$ & & $\begin{array}{l}\text { bjective } \\
\text { unction } \\
\text { Values }\end{array}$ & $\begin{array}{c}\text { Average } \\
\text { Stand Still } \\
\text { Distance (ft) }\end{array}$ & $\begin{array}{c}\text { Additive Part } \\
\text { of Safety } \\
\text { Distance (ft) }\end{array}$ & $\begin{array}{l}\text { Multiplicative } \\
\text { Part of Safety } \\
\text { Distance (ft) }\end{array}$ & $\begin{array}{l}\text { Maximum } \\
\text { Deceleration- } \\
\text { Own }\left(\mathbf{f t} / \mathbf{s}^{2}\right)\end{array}$ & $\begin{array}{c}\text { Maximum } \\
\text { Deceleration- } \\
\text { Trail }\left(\mathbf{f t} / \mathbf{s}^{2}\right)\end{array}$ & $\begin{array}{c}\text { Waiting } \\
\text { Time before } \\
\text { Diffusion (s) }\end{array}$ & $\begin{array}{l}\text { Minimum } \\
\text { Headway } \\
\text { (ft) }\end{array}$ & $\begin{array}{c}\text { Safety } \\
\text { Distance } \\
\text { Factor }\end{array}$ \\
\hline \multirow{3}{*}{ Set-1 } & $f_{1}$ & 0.07003 & \multirow{3}{*}{5.963} & \multirow{3}{*}{2.1904} & \multirow{3}{*}{2.828} & \multirow{3}{*}{-14.7358} & \multirow{3}{*}{-11.54} & \multirow{3}{*}{64.85} & \multirow{3}{*}{1.9154} & \multirow{3}{*}{0.738} \\
\hline & $f_{2}$ & 0.82222 & & & & & & & & \\
\hline & $f_{3}$ & 0.15684 & & & & & & & & \\
\hline \multirow{3}{*}{ Set-2 } & $f_{1}$ & 0.09005 & \multirow{3}{*}{5.7823} & \multirow{3}{*}{2.1858} & \multirow{3}{*}{2.844} & \multirow{3}{*}{-14.7247} & \multirow{3}{*}{-11.545} & \multirow{3}{*}{64.60} & \multirow{3}{*}{1.8154} & \multirow{3}{*}{0.738} \\
\hline & $f_{2}$ & 1.46651 & & & & & & & & \\
\hline & $f_{3}$ & 0.11334 & & & & & & & & \\
\hline \multicolumn{11}{|c|}{ GA Optimization Results Using Equation 3-4 } \\
\hline & $f_{l}$ & 0.1075 & 4.9889 & 2.09 & 3.18 & -13.122 & -9.0464 & 94.76 & 1.8121 & 0.8641 \\
\hline
\end{tabular}


As an example of the results, Table 4-7 presents the variation in the performance measures resulting from the utilization of the simulation parameters based on the three solutions presented in Table 4-6 for the intersection of NW 119th Street and NW 17th Avenue. Compared performance measures are the travel times and the split utilization ratio (SUR). Table 4-7 shows that the parameters from all three optimization solutions produced significantly closer travel times than the model with the existing parameters. The travel time errors from the three solutions are comparable. However, the utilization of the parameters provided by the NSGA-III Set-1 solution in the simulation produced significantly more accurate results in terms of the SUR parameter estimated based on highresolution controller data. These results show that the utilization of the NSGA-III Set-1 optimized parameters is able to accurately balance the objective functions providing, less errors in the SUR estimates.

Table 4-7: Percentage Error in the Travel Time and SUR with or without Calibrated Models

\begin{tabular}{lccccc}
\hline $\begin{array}{l}\text { Performance } \\
\text { Measures }\end{array}$ & Direction & $\begin{array}{c}\text { Using Default } \\
\text { Parameter Value }\end{array}$ & $\begin{array}{c}\text { GA (Minimization of } \\
\text { Travel Time Error) }\end{array}$ & $\begin{array}{c}\text { NSGA-III, } \\
\text { Set-1 }\end{array}$ & $\begin{array}{c}\text { NSGA- III, } \\
\text { Set-2 }\end{array}$ \\
\hline $\begin{array}{l}\text { Error (\%) in } \\
\text { Travel Time }\end{array}$ & EB & 20.25 & 9.76 & 4.40 & 8.14 \\
\cline { 2 - 6 } & WB & 5.85 & 4.40 & 7.58 & 5.96 \\
\hline $\begin{array}{l}\text { Error (\%) in } \\
\text { SUR }\end{array}$ & EBT & 75.53 & 36.18 & 7.89 & 9.21 \\
\cline { 2 - 6 } & WBT & 24.25 & 40.00 & 12.50 & 10.00 \\
\cline { 2 - 6 } & SBT & 17.48 & 19.75 & 13.58 & 19.75 \\
\hline
\end{tabular}

\subsubsection{Model Validation}

Validation is the process of determining the degree to which a simulation model is an accurate representation of the real world from the perspective of the intended uses of the model. The simulated and field-observed data sets are further compared to check how the simulation model can replicate the existing traffic conditions based on additional 
measures not used in the calibration. The model validation is performed using additional high-resolution controller intersection-based performance measures that are not used in the optimization, including GOR and percent arrival on green (POG). These performance measures ensure the model's ability to replicate vehicle progression and congestion levels. Table 4-8 shows that the NSGA-III Set-1- and NSGA-III Set 2-based simulation provide a better representation of these parameters relative to real-world measurements, compared to the use of the default model parameters and the parameters optimized using the GA-based travel time optimization. However, according to Table 4-8, the NSGA-III Set-1-based simulation provides significantly lower errors for the measurements of the cross-street movements (southbound and northbound) than the NSGA-III Set 2-based simulation. This shows that the NGSA-III Set 1 solution provides the best set of parameters based on the calibration and validation results.

Table 4-8: Error (\%) in the GOR and POG with or without Calibrated Models

\begin{tabular}{|c|c|c|c|c|c|}
\hline $\begin{array}{l}\text { Performance } \\
\text { Measures }\end{array}$ & Direction & $\begin{array}{l}\text { With the Default } \\
\text { Parameter Value }\end{array}$ & $\begin{array}{l}\text { GA (Minimization of } \\
\text { Travel Time Error) }\end{array}$ & $\begin{array}{l}\text { NSGA-III, } \\
\text { Set-1 }\end{array}$ & $\begin{array}{l}\text { NSGA-III, } \\
\text { Set-2 }\end{array}$ \\
\hline \multirow{8}{*}{$\begin{array}{l}\text { Error }(\%) \text { in } \\
\text { GOR }\end{array}$} & EBL & 47.62 & 44.05 & 14.29 & 11.90 \\
\hline & EBT & 41.82 & 30.82 & 13.21 & 7.23 \\
\hline & WBL & 39.47 & 26.32 & 10.53 & 13.16 \\
\hline & WBT & 53.18 & 18.18 & 11.36 & 13.64 \\
\hline & SBL & 38.96 & 45.45 & 10.39 & 18.18 \\
\hline & SBT & 47.10 & 46.32 & 15.25 & 21.31 \\
\hline & NBL & 50.91 & 54.55 & 7.27 & 21.82 \\
\hline & NBT & 33.33 & 25.42 & 3.75 & 18.48 \\
\hline \multirow{4}{*}{$\begin{array}{l}\text { Error (\%) in } \\
\text { POG }\end{array}$} & EBL & 19.64 & 18.18 & 8.23 & 5.12 \\
\hline & EBT & 21.71 & 20.22 & 2.97 & 7.25 \\
\hline & WBL & 68.04 & 65.62 & 4.78 & 4.09 \\
\hline & WBT & 18.69 & 19.95 & 1.86 & 1.69 \\
\hline
\end{tabular}




\subsection{Signal Timing Optimization}

The main focus of this study is to provide a method for an implementable signal timing plan development for various types of non-recurrent congestion events, as explained in Chapter III. The following section discusses the results of evaluating the generated signal timing plans using the signal timing optimization methodology.

\subsubsection{Evaluation for Regular Timing Settings}

The calibrated VISSIM model for Cluster Category 1 in Table 4-5 is first used to evaluate the effectiveness of regular time-of-day signal timing settings under non-recurrent congestion. This evaluation involves simulating three non-recurrent congestion scenarios in the eastbound $(\mathrm{EB})$ direction upstream of the NW $119^{\text {th }}$ Street and $22^{\text {nd }}$ Avenue intersection. The three scenarios are:

1. One out of three-lane blockage;

2. Two out of three-lane blockage; and

3. Demand surge (increment to 1.3 times of the regular demand).

The Corridor Travel Time (seconds), Intersection Delay (seconds/vehicle), Vehicle Throughput), and Queue Length (feet) are evaluated using the simulation model outputs. Table 4-9 shows the performance of the evaluated regular TOD signal timing for all three non-recurrent scenarios compared to normal traffic conditions. The results show increments in vehicle delays, corridor travel times, and queue lengths upstream of the critical approach during the investigated non-recurrent events. 
Table 4-9: Signal Timing Performance Measures for Normal TOD Settings

\begin{tabular}{|c|c|c|c|c|c|c|c|c|c|c|c|c|c|c|c|c|c|}
\hline \multirow{2}{*}{$\begin{array}{c}\text { Traffic } \\
\text { Conditions }\end{array}$} & \multirow{2}{*}{$\begin{array}{c}\text { Signal } \\
\text { Timing } \\
\text { Strategies }\end{array}$} & \multicolumn{8}{|c|}{ Phase Split (s) } & \multicolumn{4}{|c|}{ Vehicle Delay (sec/veh) } & \multirow{2}{*}{$\begin{array}{c}\text { Corridor } \\
\text { Travel } \\
\text { Time (s) } \\
\end{array}$} & \multirow{2}{*}{$\begin{array}{c}\text { Intersection } \\
\text { Delay } \\
\text { (se/veh) }\end{array}$} & \multirow[b]{2}{*}{ Throughput } & \multirow{2}{*}{$\begin{array}{l}\text { Queue } \\
\text { Length } \\
\text { (ft) }\end{array}$} \\
\hline & & EBL & WBT & SBL & NBT & WBL & EBT & NBL & SBT & EB & SB & WB & NB & & & & \\
\hline $\begin{array}{c}\text { Normal } \\
\text { Traffic } \\
\text { Condition } \\
\end{array}$ & \multirow{4}{*}{$\begin{array}{c}\text { Regular } \\
\text { Timing } \\
\text { Plan }\end{array}$} & \multirow{4}{*}{26} & \multirow{4}{*}{88} & \multirow{4}{*}{22} & \multirow{4}{*}{64} & \multirow{4}{*}{26} & \multirow{4}{*}{88} & \multirow{4}{*}{26} & \multirow{4}{*}{64} & 26.72 & 27.09 & 13.87 & 7.6 & 297.64 & 18.82 & 142 & 86.76 \\
\hline $\begin{array}{c}\text { One Lane } \\
\text { Blocked }\end{array}$ & & & & & & & & & & 263.19 & 35.8 & 26.06 & 7.58 & 557.54 & 83.16 & 114 & 1084.16 \\
\hline $\begin{array}{c}\text { Two Lane } \\
\text { Blocked }\end{array}$ & & & & & & & & & & 288.15 & 51.71 & 30.57 & 4 & 622.38 & 93.61 & 115 & 1685.05 \\
\hline $\begin{array}{c}\text { Demand } \\
\text { Surge }\end{array}$ & & & & & & & & & & 189.02 & 44.3 & 332.5 & 2.81 & 587 & 67.17 & 147 & 1401.9 \\
\hline $\begin{array}{l}\text { Note: } E B L= \\
\text { Westbound } \\
E B=\text { Eastbo }\end{array}$ & Eastbound & Left tu & $r n, W B$ & $T=W e$ & estboun & nd Thro & ugh $n$ & ovemer & $n t, S B L$ & & & Left tur & & $T=$ North & $\begin{array}{l}\text { und Throug } \\
\text { movement, }\end{array}$ & & \\
\hline
\end{tabular}




\subsubsection{NSGA-III Optimization Results}

As described in the literature review and methodology development chapters, the NSGA-III algorithm minimizes the fitness value, which is linked to the objective function of the optimization problem in each generation by selecting the best offspring from the previous generations. Figure 4-7 shows the minimization of the fitness value in each generation for the three aforementioned non-recurrent conditions. An important measure

of effectiveness for the non-recurrent traffic conditions is the queue length upstream of the incident or critical intersection. Figures 4-8, 4-9, and 4-10 show the change in this measure in the process of optimizing the fitness value in the NSGA-III generations. The trend lines in each plot show that the queue length gradually decreased with the decrease in the travel time and intersection delay and increasing throughput.

The NSGA-III algorithm can provide optimal Pareto sets as outputs of the optimization process. Each set in the Pareto-optimal front resulted in the best tradeoff between competing objectives. For example, if one Pareto-optimal set resulted in the lowest travel time, it might have higher intersection delays or lower throughput than the other sets. Understanding the roadway conditions and agency objectives and priorities is important for selecting a solution from the Pareto sets.

Table 4-10 presents the resulted Pareto sets from the optimization for each investigated non-recurrent condition. Among the Pareto-optimal sets, a special signaltiming plan for each non-recurrent condition is chosen to cause lower delay to the competing movements and the critical movements compared to the other solutions. In the case of the one-lane blockage incident, the optimization procedure decreased the cycle 
length to 107 seconds, which is almost half of the regular signal timing settings, possibly indicating that double cycling can be effective when the capacity of an approach is reduced.

a) One-Lane Blockage

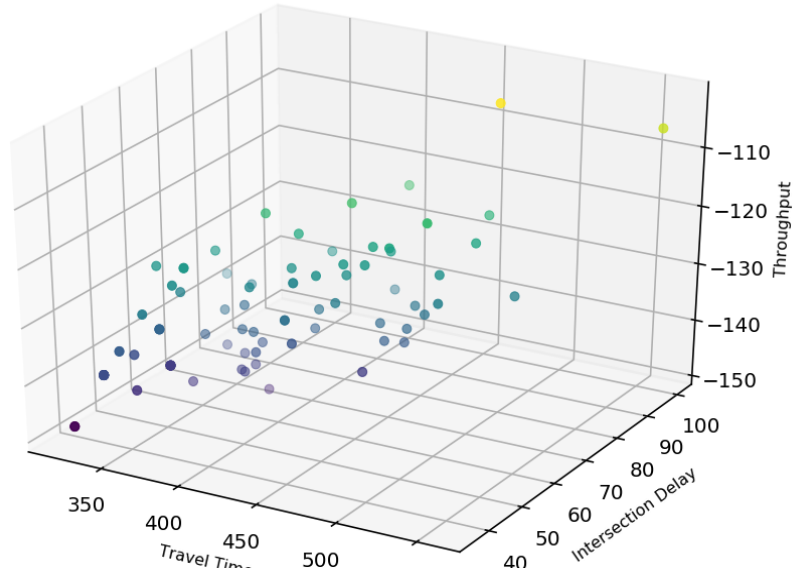

b) Two-Lane Blockage

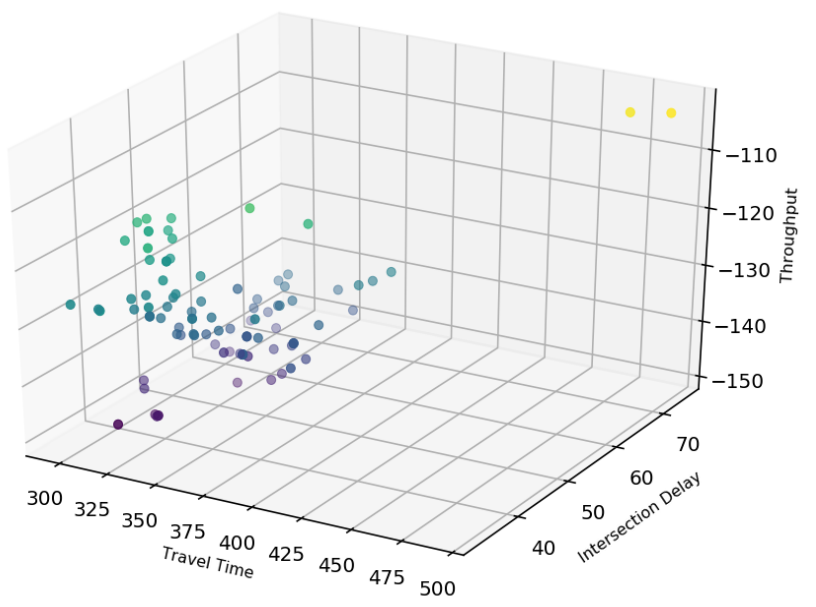

c) Demand Surge

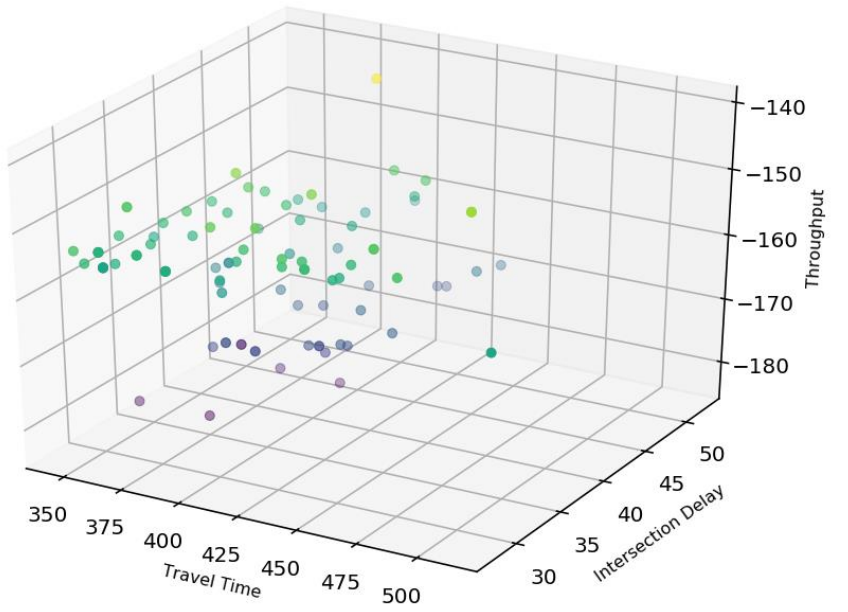

Figure 4-7: 3-D Plot of Resulted Objective Functions in Each NSGA-III Generations 

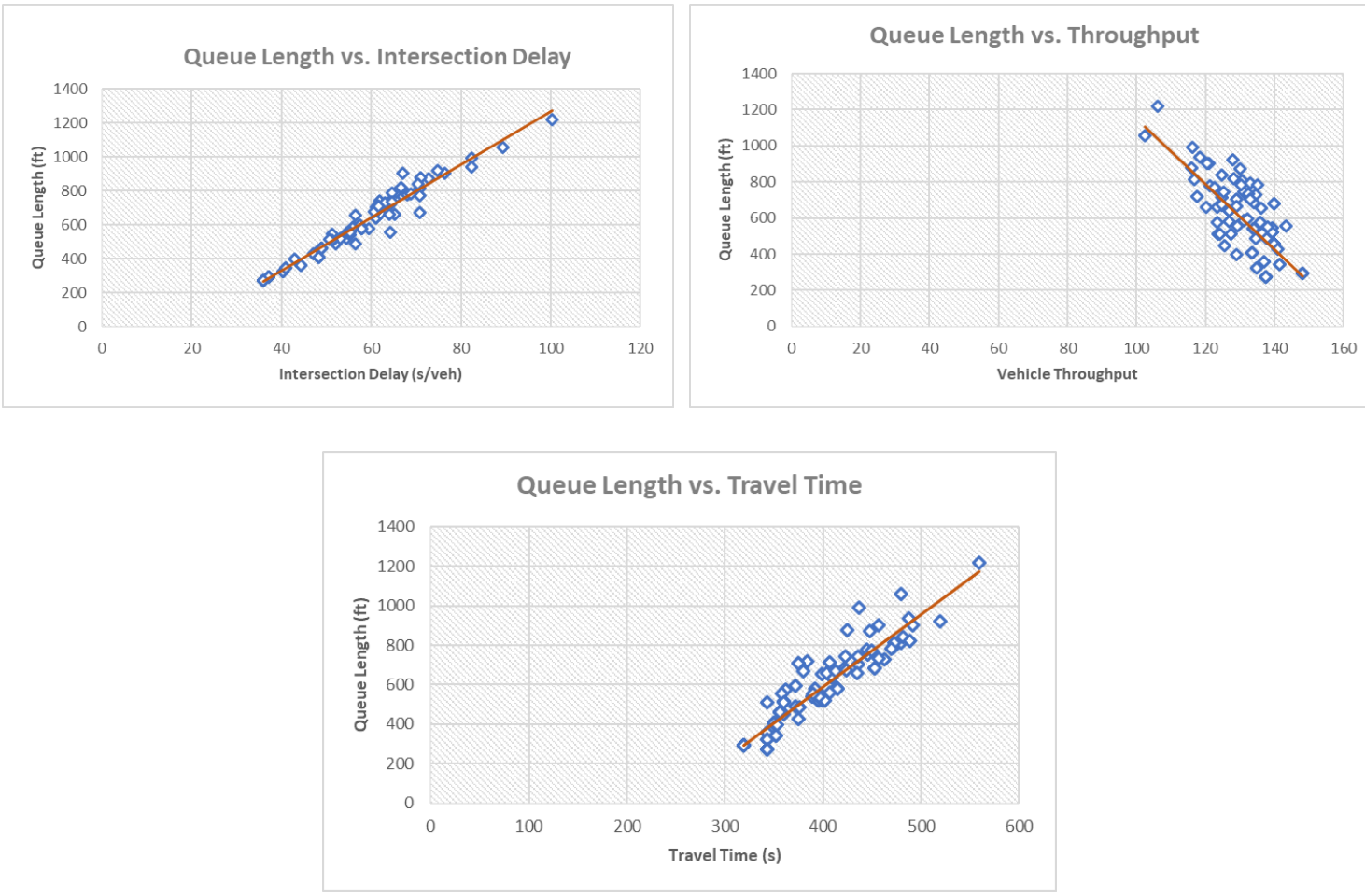

Figure 4-8: Queue Length vs. NSGA-III Fitness Values (One-Lane Blockage)
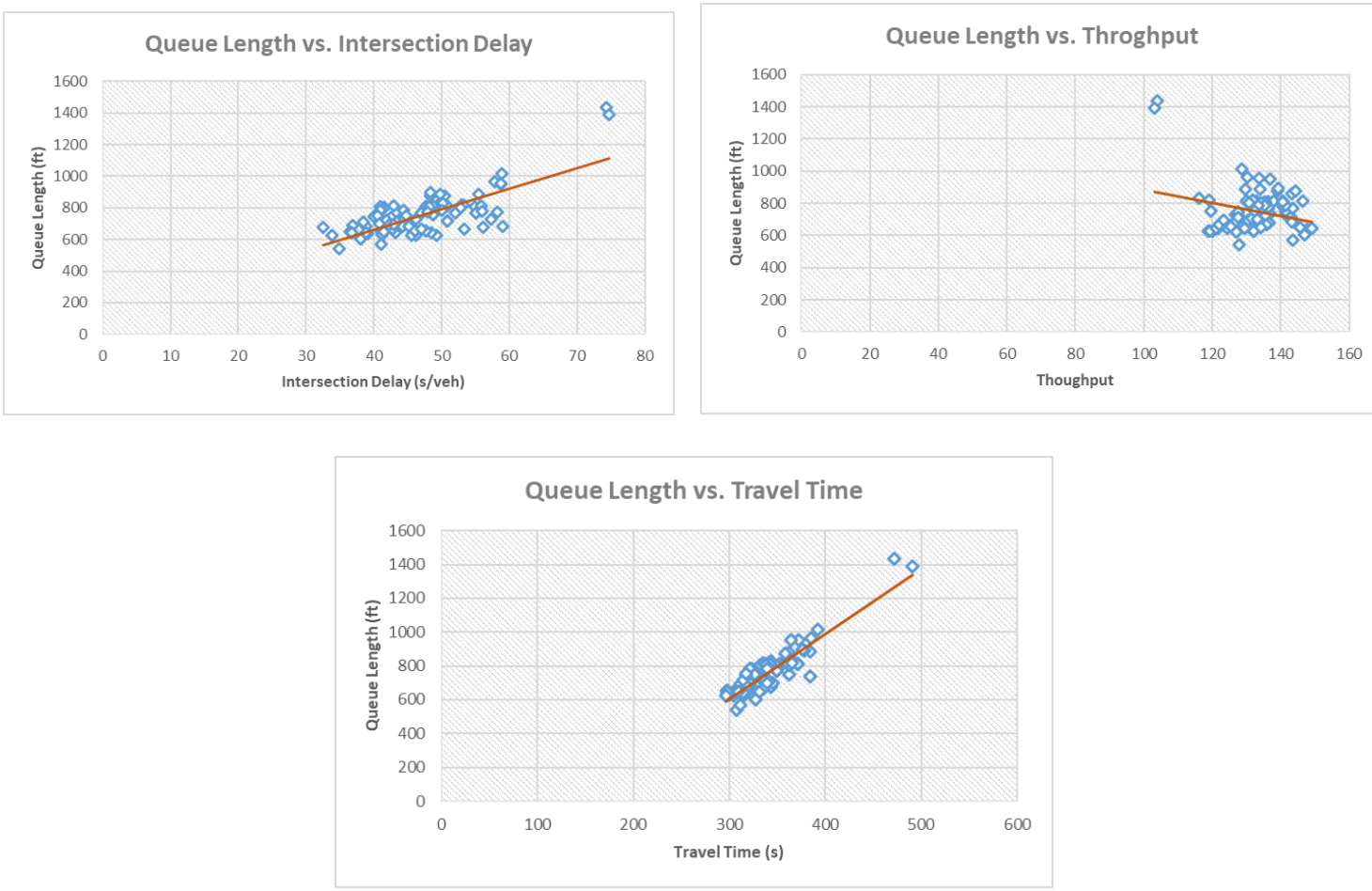

Figure 4-9: Queue Length vs. NSGA-III Fitness Values (Two-Lane Blockage) 

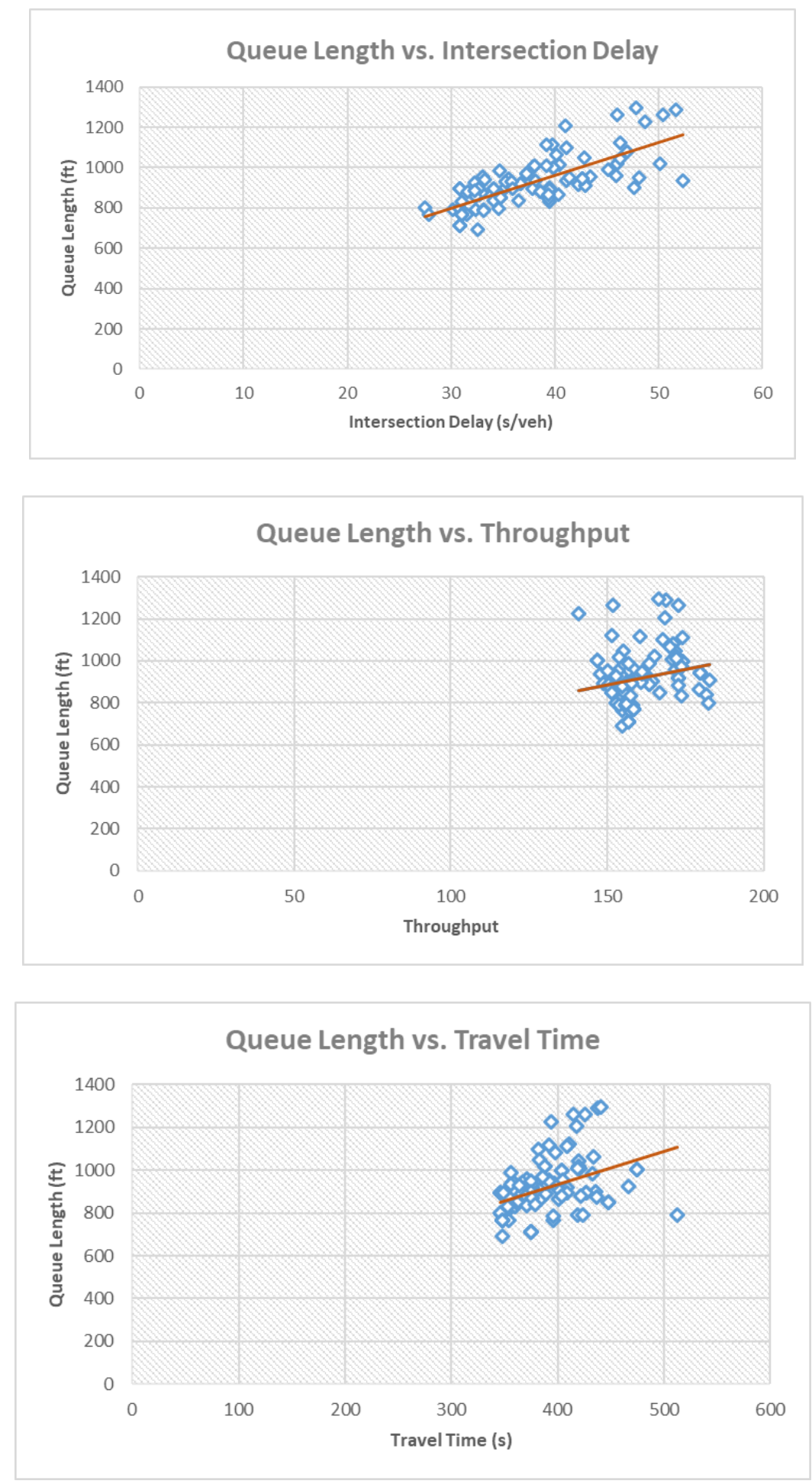

Figure 4.10: Queue Length vs. NSGA-III Fitness Values (Demand Surge) 
Table 4-10: Pareto-Optimal Sets for Non-Recurrent Congestion Conditions

\begin{tabular}{|c|c|c|c|c|c|c|c|c|c|c|c|c|c|c|c|c|}
\hline \multirow{2}{*}{$\begin{array}{c}\text { Non-recurrent } \\
\text { Congestions }\end{array}$} & \multicolumn{8}{|c|}{ Phase Split (s) } & \multicolumn{4}{|c|}{ Vehicle Delay (s/veh) } & \multirow{2}{*}{$\begin{array}{c}\text { Corridor } \\
\text { Travel Time } \\
\text { (s) }\end{array}$} & \multirow{2}{*}{$\begin{array}{c}\text { Intersection } \\
\text { Delay } \\
\text { (s/veh) }\end{array}$} & \multirow{2}{*}{ Throughput } & \multirow{2}{*}{$\begin{array}{l}\text { Queue } \\
\text { Length } \\
\text { (ft) }\end{array}$} \\
\hline & EBL & WBT & SBL & NBT & WBL & EBT & NBL & SBT & EB & WB & SB & NB & & & & \\
\hline \multirow{2}{*}{$\begin{array}{l}\text { One Lane } \\
\text { Blocked }\end{array}$} & 19 & 59 & 8 & 20 & 19 & 59 & 8 & 20 & 90.64 & 13.53 & 43.02 & 1.038 & 343.05 & 37.06 & 137 & 273.04 \\
\hline & 17 & 59 & 9 & 22 & 17 & 59 & 8 & 21 & 92.95 & 9.246 & 41 & 0.92 & 319.51 & 36.03 & 148 & 294.32 \\
\hline \multirow{2}{*}{$\begin{array}{l}\text { Two Lane } \\
\text { Blocked }\end{array}$} & 17 & 165 & 10 & 12 & 17 & 165 & 10 & 12 & 104.75 & 11.29 & 8.71 & 30.34 & 331.37 & 36.52 & 145 & 649.4 \\
\hline & 22 & 166 & 10 & 13 & 22 & 166 & 10 & 13 & 100.52 & 12.28 & 4.28 & 21.36 & 309.7 & 36.80 & 149 & 645.6 \\
\hline \multirow{5}{*}{ Demand Surge } & 17 & 181 & 8 & 20 & 17 & 181 & 8 & 20 & 81.17 & 10 & 17.43 & 15.63 & 347.55 & 31.057 & 159 & 768.4 \\
\hline & 15 & 181 & 8 & 20 & 15 & 181 & 8 & 20 & 77.58 & 8.23 & 23.74 & 13.90 & 375.31 & 30.86 & 157 & 712.09 \\
\hline & 17 & 185 & 8 & 20 & 17 & 185 & 8 & 20 & 85.24 & 10.89 & 23.51 & 4.48 & 353.04 & 31.03 & 158 & 831.35 \\
\hline & 17 & 161 & 8 & 20 & 17 & 161 & 8 & 20 & 87.38 & 8.19 & 27.15 & 13.56 & 378.89 & 34.07 & 182 & 838.07 \\
\hline & 17 & 161 & 8 & 21 & 17 & 161 & 8 & 21 & 85.19 & 6.35 & 33 & 13.7 & 345.71 & 34.56 & 183 & 798.23 \\
\hline \multicolumn{17}{|c|}{ * Bold values are selected solutions from the Pareto sets } \\
\hline
\end{tabular}




\subsubsection{Comparison of the Developed Models}

This section compares the results of the assessment of the optimization method to those of the assessment of the developed DT and FRBS by using the signal timing from experts' decisions. The developed DT and FRBS tool is used to estimate the needed increment in the $\mathrm{g} / \mathrm{C}$ ratio for the non-recurrent conditions, as shown in Table 4-11. The output from this model recommends a 20 percent increment in the $\mathrm{g} / \mathrm{C}$ ratio for the one out of three-lane blockage condition, and a 31 percent increment in the $\mathrm{g} / \mathrm{C}$ ratio for the two out of three-lane blockage and the demand increment traffic situations. Table 4-12 compares the recommended special signal timing plan from both the optimization and DT and FRBS model. The DT and FRBS model output are able to reduce the existing queue and all other performance measures by increasing the green time in the subjected direction. However, the optimization results show that the special signal timing plan obtained from the optimization produced better performance than those from the DT and FRBS system for all of the non-recurrent conditions, as indicated below:

- For the one out of three-lane blockage incident, the DT and FRBS model decreases the queue length upstream of the incident by 28 percent, whereas the optimized signal plan decreased the queue length by 73 percent. In addition to reducing the queue length; the improvements in the travel time, intersection delay, and throughput values are higher with the optimized signal plan than the DT and FRBS recommended signal plan.

- For the two out of three-lane blockage incidents, the DT and FRBS model decreases the queue length upstream of the incident by 33 percent compared to a reduction of 
62 percent with the optimized signal plan. Except for the northbound approach, the performance of the signal timing is better with the optimized signal plans.

- For the demand surge condition, the resulting performance measures of the two models are closer than what is mentioned above regarding the lane blockage conditions. The queue length is decreased by 30 percent when utilizing the DT and FRBS model, while the optimized signal timing plans reduced the queue length by 45 percent. The other performance measures are better with the optimized signal timing, except for the northbound direction delay, which is slightly higher with the optimization method. 
Table 4-11: Output from the DT and FRBS Model

\begin{tabular}{|c|c|c|c|c|c|c|c|c|c|}
\hline $\begin{array}{c}\text { Traffic } \\
\text { Conditions }\end{array}$ & Period & $\begin{array}{c}\text { Upstream } \\
\text { Cross Street } \\
\text { Importance }\end{array}$ & $\begin{array}{c}\text { Queue } \\
\text { Length (ft) }\end{array}$ & $\begin{array}{c}\text { Volume } \\
\text { Increment } \\
\text { Ratio } \\
\end{array}$ & $\begin{array}{c}\text { Capacity } \\
\text { Reduction } \\
\text { Ratio } \\
\end{array}$ & $\begin{array}{c}\text { FRBS Prediction } \\
\text { (g/C Increment } \\
\text { Percentage) }\end{array}$ & Old $\mathrm{g} / \mathrm{C}$ & New g/C & $\begin{array}{c}\text { New Green } \\
\text { Time (s) }\end{array}$ \\
\hline One Lane Blocked & $\mathrm{AM}$ & Major & 1084 & 0 & 0.26 & 20 & 0.44 & 0.53 & 106 \\
\hline Two Lane Blocked & $\mathrm{AM}$ & Major & 1685 & 0 & 0.49 & 31.0 & 0.44 & 0.58 & 116 \\
\hline Demand Surge & AM & Major & 1401 & 1.6 & 0 & 31.0 & 0.44 & 0.58 & 116 \\
\hline
\end{tabular}

Table 4-12: Comparison of the Optimized Signal Timing Settings and DT and FRBS Model

\begin{tabular}{|c|c|c|c|c|c|c|c|c|c|c|c|c|c|c|c|c|c|}
\hline \multirow{2}{*}{$\begin{array}{c}\text { Traffic } \\
\text { Conditions }\end{array}$} & \multirow{2}{*}{$\begin{array}{c}\text { Signal } \\
\text { Timing } \\
\text { Strategies }\end{array}$} & \multicolumn{8}{|c|}{ Phase Split (s) } & \multicolumn{4}{|c|}{ Vehicle Delay (s/veh) } & \multirow{2}{*}{\begin{tabular}{|c|} 
Corridor \\
Travel Time \\
(s)
\end{tabular}} & \multirow{2}{*}{$\begin{array}{c}\text { Intersection } \\
\text { Delay } \\
\text { (sec/veh) }\end{array}$} & \multirow[t]{2}{*}{ Throughput } & \multirow{2}{*}{$\begin{array}{l}\text { Queue } \\
\text { Length } \\
\text { (ft) }\end{array}$} \\
\hline & & EBL & WBT & SBL & NBT & WBL & EBT & NBL & SBT & EB & SB & WB & NB & & & & \\
\hline \multirow[t]{3}{*}{$\begin{array}{l}\text { One Lane } \\
\text { Blocked }\end{array}$} & $\begin{array}{c}\text { Regular } \\
\text { Timing Plan }\end{array}$ & 26 & 88 & 22 & 64 & 26 & 88 & 26 & 64 & 263.19 & 35.8 & 26.06 & 7.58 & 557.54 & 83.16 & 114 & 1084.16 \\
\hline & $\begin{array}{l}\text { DT and } \\
\text { FRBS }\end{array}$ & 26 & 106 & 17 & 51 & 26 & 106 & 17 & 51 & 186.93 & 50.18 & 21.95 & 9.11 & 429.45 & 67.04 & 121 & 782.96 \\
\hline & $\begin{array}{c}\text { After } \\
\text { Optimization }\end{array}$ & 17 & 59 & 9 & 22 & 17 & 59 & 8 & 21 & 92.95 & 41 & 9.25 & 0.92 & 319.51 & 36.03 & 148 & 294.32 \\
\hline \multirow[t]{3}{*}{$\begin{array}{l}\text { Two Lane } \\
\text { Blocked }\end{array}$} & $\begin{array}{c}\text { Regular } \\
\text { Timing Plan }\end{array}$ & 26 & 88 & 22 & 64 & 26 & 88 & 26 & 64 & 288.15 & 51.71 & 30.57 & 4 & 622.38 & 93.61 & 115 & 1685.05 \\
\hline & $\begin{array}{l}\text { DT and } \\
\text { FRBS }\end{array}$ & 26 & 116 & 15 & 43 & 26 & 116 & 15 & 43 & 261.19 & 49.37 & 22.43 & 8.55 & 493.92 & 85.4 & 130 & 1132.57 \\
\hline & $\begin{array}{c}\text { After } \\
\text { Optimization }\end{array}$ & 22 & 166 & 10 & 13 & 22 & 166 & 10 & 13 & 100.52 & 12.28 & 4.28 & 21.36 & 309.69 & 36.80 & 149 & 645.6 \\
\hline \multirow[t]{3}{*}{$\begin{array}{l}\text { Demand } \\
\text { Surge }\end{array}$} & $\begin{array}{c}\text { Regular } \\
\text { Timing Plan }\end{array}$ & 26 & 88 & 22 & 64 & 26 & 88 & 26 & 64 & 189.02 & 44.3 & 32.5 & 2.81 & 587 & 67.17 & 147 & 1401.9 \\
\hline & $\begin{array}{c}\text { DT and } \\
\text { FRBS } \\
\end{array}$ & 26 & 116 & 15 & 43 & 26 & 116 & 15 & 43 & 138.88 & 50 & 14.51 & 8.51 & 467.3 & 52.98 & 153 & 988.97 \\
\hline & $\begin{array}{c}\text { After } \\
\text { Optimization }\end{array}$ & 17 & 181 & 8 & 20 & 17 & 181 & 8 & 20 & 81.17 & 17.43 & 10 & 15.63 & 347.55 & 31.06 & 159 & 768.4 \\
\hline
\end{tabular}

Note: $E B L=$ Eastbound Left turn movement, WBT $=$ Westbound Through movement, $S B L=$ Southbound Left turn movement, NBT $=$ Northbound

Through movement, $W B L=$ Westbound Left turn movement, EBT=Eastbound Through movement, NBL= Northbound Left turn movement, SBT=

Southbound Through movement, EB= Eastbound movement, $S B=$ Southbound movement, WB= Westbound movement, NB= Northbound movement. 


\subsubsection{Temporal Transferability Assessment}

This section discusses the temporal transferability of the developed signal timing plan to other days in the year with similar non-recurrent events, considering that the optimization is performed for the traffic operational condition of a specific day. This assessment is conducted by examining the difference in the performance of the special signal plans developed for non-recurrent events when optimized with the demands of a specific day compared to the performance of the plans optimized using the demands for a different day. The NSGA-III optimization is performed utilizing the demands for a day that is categorized in Category 2 (Plan 2) and for a day that is categorized in Category 1 (Plan 1) to assess the temporal transferability of the optimization model (see Table 4-5). The study analyzed the difference in the performance of these two plans in terms of the conditions of Category 2. The assessment results shown in Table 4-13 indicate that there are only small differences between the performance of the two plans, indicating a good transferability of the plans between the two investigated categories. 
Table 4-13: Evaluation of Optimization Model Temporal Transferability

\begin{tabular}{|c|c|c|c|c|c|c|c|c|c|c|c|c|c|}
\hline \multirow{2}{*}{$\begin{array}{c}\text { Traffic } \\
\text { Conditions }\end{array}$} & \multirow{2}{*}{\begin{tabular}{c|} 
Signal \\
Timing \\
Strategies
\end{tabular}} & \multicolumn{8}{|c|}{ Phase Split (s) } & \multirow{2}{*}{$\begin{array}{c}\text { Corridor } \\
\text { Travel Time } \\
\text { (s) } \\
\end{array}$} & \multirow{2}{*}{$\begin{array}{c}\text { Intersection } \\
\text { Delay (s/veh) }\end{array}$} & \multirow{2}{*}{ Throughput } & \multirow{2}{*}{$\begin{array}{l}\text { Queue } \\
\text { Length } \\
\text { (ft) }\end{array}$} \\
\hline & & EBL & WBT & SBL & NBT & WBL & EBT & NBL & SBT & & & & \\
\hline $\begin{array}{c}\text { Normal } \\
\text { Traffic } \\
\text { Condition } \\
\end{array}$ & $\begin{array}{c}\text { Regular } \\
\text { Timing } \\
\text { Plan } \\
\end{array}$ & 26 & 88 & 22 & 64 & 26 & 88 & 26 & 64 & 279.03 & 22.28 & 138 & 64.18 \\
\hline \multirow[t]{3}{*}{$\begin{array}{l}\text { One Lane } \\
\text { Blocked }\end{array}$} & $\begin{array}{c}\text { Regular } \\
\text { Timing } \\
\text { Plan } \\
\end{array}$ & 26 & 88 & 22 & 64 & 26 & 88 & 26 & 64 & 566.69 & 98.57 & 124 & 1128.66 \\
\hline & Plan 2* & 17 & 57 & 10 & 22 & 17 & 57 & 10 & 22 & 329.71 & 40.44 & 134 & 279.83 \\
\hline & Plan 1* & 17 & 59 & 9 & 22 & 17 & 59 & 8 & 21 & 361.34 & 46.87 & 132 & 287.67 \\
\hline \multirow[t]{3}{*}{$\begin{array}{l}\text { Two Lane } \\
\text { Blocked }\end{array}$} & $\begin{array}{c}\text { Regular } \\
\text { Timing } \\
\text { Plan } \\
\end{array}$ & 26 & 88 & 22 & 64 & 26 & 88 & 26 & 64 & 470.4 & 67.15 & 124 & 1149.93 \\
\hline & Plan 2* & 16 & 163 & 8 & 18 & 16 & 163 & 8 & 18 & 333.26 & 38.60 & 144 & 690.39 \\
\hline & Plan 1* & 22 & 166 & 10 & 13 & 22 & 166 & 10 & 13 & 335.31 & 46.29 & 141 & 729.84 \\
\hline \multirow[t]{3}{*}{$\begin{array}{l}\text { Demand } \\
\text { Surge }\end{array}$} & $\begin{array}{c}\text { Regular } \\
\text { Timing } \\
\text { Plan }\end{array}$ & 26 & 88 & 22 & 64 & 26 & 88 & 26 & 64 & 521.56 & 59.44 & 163 & 1359.20 \\
\hline & Plan 2* & 14 & 186 & 8 & 20 & 14 & 186 & 8 & 20 & 440.67 & 26.35 & 165 & 668.46 \\
\hline & Plan 1* & 17 & 181 & 8 & 20 & 17 & 181 & 8 & 20 & 462.60 & 28.75 & 161 & 675.02 \\
\hline \multicolumn{14}{|c|}{$\begin{array}{l}\text { *Plan } 1 \text { is the optimized signal plan for Category } 1 \text { traffic scenario, and } \\
\text { Plan } 2 \text { is the optimized signal plan for Category } 2 \text { traffic scenario. } \\
\text { Note: } E B L=\text { Eastbound Left turn, WBT=Westbound Through movement, SBL= Southbound Left turn movement, NBT= } \\
\text { Northbound Through movement, WBL=Westbound Left turn movement, EBT=Eastbound Through movement, NBL= } \\
\text { Northbound Left turn movement, SBT= Southbound Through movement. }\end{array}$} \\
\hline
\end{tabular}




\subsection{Summary}

This analysis and results chapter provided an assessment of the developed methodologies to select a special signal control plan during non-recurrent conditions utilizing both the automation of expert decision-making and signal timing optimization. The chapter demonstrated the prerequisites for signal timing optimization and simulation modeling application for the purpose of the study, such as accurate traffic movement count or estimation, partitioning the traffic operational conditions, and calibration of the simulation model. The results showed the benefits of implementing special signal timing plans for non-recurrent traffic congestions for lane blockage and sudden demand surge due to rerouting or diversion as a result of freeway incidents. 


\section{CHAPTER V}

\section{CONCLUSION AND RECOMMENDATIONS}

\subsection{Summary and Conclusions}

Congestion on arterial networks continues to be a major challenge for all road users, policymakers, and traffic signal maintenance agencies around the nation. Non-recurrent congestion can occur due to lane blockages from incidents that cause significant roadway capacity reductions, which in turn impacts system performance. Significant congestion on arterials can also result from demand surges due to traffic diversions caused by incidents on freeways and other alternative routes. These scenarios create an unexpected increase in the volume over capacity ratio of the system, resulting in long vehicle queues and possible spillbacks to the upstream intersections.

This study investigated methods to mitigate the above-mentioned impacts. First, the study focused on automating traffic signal engineer's/expert's decisions to implement appropriate signal timing plans during non-recurrent conditions. This process utilizes a combination of the Decision Tree and Fuzzy Rule-Based System to recommend modifications to signal timings during non-recurrent events, including incidents, construction, and a surge in demands. One of the most important aspects of the solution is that it is easy to interpret in terms of the inputs and outputs, making it a viable option for use by agencies. The minimal resource requirements also make the solution attractive to agencies with limited resources.

Although the system can be beneficial, this system only recommends the changes in green time to the prominent direction impacted by the event. It does not produce an 
optimized solution that considers all movements, and it does not help in deciding how to optimally distribute the change in green times to other movements at the intersection. Thus, this study developed another method to derive an optimized signal-timing plan that considers the travel conditions in the critical direction, the overall corridor, and the overall intersection performance. A critical component of the method is identifying traffic operational conditions based on accurate and detailed measurements of traffic flow conditions. An important aspect of the method is using a microscopic simulation-based optimization model to derive the plans and use detailed data, including high-resolution controller data, to calibrate the simulation model.

The high-resolution signal controller data and travel time data are utilized in this study for accurate measurement of vehicle flow, turning movement counts, and signal control performance measures. The performance measures based on high-resolution controller data are used for the first time in this study for calibrating simulation models. The data is used for partitioning traffic operational conditions for use in the optimization and in more detailed calibration and validation of simulation models. Clustering analysis was successfully used to categorize the traffic patterns based on segment travel time and the movement GOR values. The evaluation of the calibration parameters resulting from the multi-objective optimization based on travel time and high-resolution controller data indicated that the resulting simulation model produces significantly lower errors in the split utilization ratio, green utilization ratio, arrival on green, and travel time compared to a simulation model that uses the default parameters of the simulation model. The multiobjective optimization solution also produces slightly lower travel time errors, and significantly lower errors in terms of the high-resolution controller data measures, 
compared to a simulation model calibrated based on the optimization of the single objective of minimizing the travel time.

This study successfully developed and demonstrated an advanced method for the calibration and validation of microscopic simulation models of arterial networks utilizing high-resolution controller data combined with a two-level unsupervised clustering technique for scenario identifications and multi-objective optimization for simulation model calibration identification. The study introduced the use of several new parameters to calibrate and validate simulation models, including the split utilization ratio, green utilization ratio, and arrival on green, in combination with other commonly used measures like vehicle travel time and throughput. The utilized multi-objective optimization technique belongs to a set of multi-objective optimization algorithms that aim to find the Pareto front of compromised solutions of all objectives rather than integrating all objectives together in a single objective in the optimization.

Given that the calibrated simulation models are able to replicate field traffic operational conditions, the NSGA-III multi-objective optimization technique is implemented to generate optimized signal timing plans for three types of non-recurrent scenarios; one out of a two-lane blockage, two out of a three-lane blockage, and demand surge events. All of the incident scenarios are assumed to be near the upstream of the subject intersection. In this study, the objective functions for signal timing optimization are chosen to balance delays in the system and the throughputs of the impacted movements, considering the overall corridor performance, as well as the signal control performance. 
The optimized signal timing plan improved the signal and overall corridor performance in terms of queue length, overall throughput, intersection delay, and corridor travel time. In the case of a one-lane blockage, the optimization procedure decreased the cycle length to 107 seconds, which is almost half of the regular signal timing settings. These results may indicate that double cycling is useful when the capacity of an approach is reduced.

This study evaluates the recommended special signal timing plan from both the optimization and DT and FRBS models. Although DT and FRBS model outputs are able to reduce the queue length and improve other performance measures, the evaluation results show that the special signal timing plans obtained from optimization produced better results in terms of various performance measures compared to the developed DT and FRBS model for all three investigated non-recurrent conditions.

\subsection{Study Contribution}

Despite the significant contributions of research activities to the advancements of AAM and ICM, there is a significant need for research to support the derivation and activation of special signal timing plans to mitigate non-recurrent congestion. For the first time, this study investigates the use of high resolution data that only became available in

the last few years with advanced techniques, including supervised and unsupervised machine learning, fuzzy logic, multi-objective optimization techniques, and simulation modeling to identify the best method to select the signal timing plans during non-recurrent congestion. The study developed two different approaches that agencies can select from based on the capability and resources of the agencies. The first is based on machine learning 
and the fuzzy logic system, and the second is based on microscopic simulation-based optimization. In addition, the developed expert's decision learning, multi-objective simulation-based optimization and high-resolution data-based calibration of simulation models will form the basis for future research on this subject and other transportation system modeling and transportation system management and operations subjects.

This dissertation also identifies methods for the use of ATSPMs based on highresolution controller data, which allows agencies to effectively optimize and manage traffic signals without extensive field data collection. Even when such data are available, the agencies currently lack advanced procedures and strategies to process and use such data to better monitor and manage signal control operations. This study proposes methods that will allow traffic signal personnel to identify and prioritize problem areas using microscopic signal performance measures and retime the signal plan accordingly.

\subsection{Recommendations for Future Research}

This study successfully developed a methodology for developing and implementing signal timing changes during non-recurrent conditions. Future studies to extend this dissertation research could include:

- The benefit assessment of the developed special signal timing plans is performed using simulation models in this study. It is recommended to further evaluate the methodology in a real-world environment.

- This research develops an effective method to mitigate traffic congestions during non-recurrent events using plans derived in an off-line environment but are activated in real-time environments. The methodology developed in 
this research can be further extended by optimizing the signal timing plans in real time.

- This study explores the lane blockage scenario due to incidents just upstream of the stop line of the subjected approach. Further analysis is needed for incidents at other locations of the segment. 


\section{REFERENCES}

Abdel-Aty, M. A., Cai, Q., Eluru, N., Hasan, S., Chung, W., Rahman, S., Gong, Y., \& Rahman, H. (2019). Integrated Freeway/Arterial Active Traffic Management. Florida Department of Transportation. BDV-24-977-22

Adby, P. (2013). Introduction to Optimization Methods. Springer Science \& Business Media.

Abonyi, J., Roubos, J. A., \& Szeifert, F. (2003). Data-driven generation of compact, accurate, and linguistically sound fuzzy classifiers based on a decision-tree initialization. International Journal of Approximate Reasoning, 32(1), 1-21.

Aboudolas, K., Papageorgiou, M., Kouvelas, A., \& Kosmatopoulos, E. (2010). A rollinghorizon quadratic-programming approach to the signal control problem in large-scale congested urban road networks. Transportation Research Part C: Emerging Technologies, 18(5), 680-694.

Abu-Lebdeh, G., \& Benekohal, R. F. (1997). Development of Traffic Control and Queue Management Procedures for Oversaturated Arterials. Transportation Research Record, 1603(1), 119-127.

Abu-Lebdeh, G., \& Benekohal, R. F. (2000). Genetic Algorithms for Traffic Signal Control and Queue Management of Oversaturated Two-Way Arterials. Transportation Research Record, 1727(1), 61-67.

Abu-Lebdeh, G., \& Benekohal, R. F. (2003). Design and evaluation of dynamic traffic management strategies for congested conditions. Transportation Research Part A: Policy and Practice, 37(2), 109-127.

Abu-Lebdeh, G., Chen, H., \& Benekohal, R. F. (2007). Modeling Traffic Output for Design of Dynamic Multi-Cycle Control in Congested Conditions. Journal of Intelligent Transportation Systems, 11(1), 25-40.

Alexiadis, V., Chu, A., \& Systematics, C. (2016a). Integrated Corridor Management: Analysis, Modeling, and Simulation for the US-75 Corridor in Dallas, Texas-PostDeployment Assessment Report (No. FHWA-JPO-16-396). United States. Department of Transportation. Intelligent Transportation Systems Joint Program Office.

Alexiadis, V., Chu, A., \& Systematics, C. (2016b). Integrated Corridor Management Analysis, Modeling, and Simulation for the I-15 Corridor in San Diego, California PostDeployment Assessment Report (No. FHWA-JPO-16-403). United States. Department of Transportation. Intelligent Transportation Systems Joint Program Office. 
Ali, M. S., Kaisar, E. I., \& Hadi, M. (2017). Guidance for identifying corridor conditions that warrant deploying transit signal priority and queue jump. In 2017 5th IEEE International Conference on Models and Technologies for Intelligent Transportation Systems (MT-ITS) (pp. 657-662). IEEE. https://doi.org/10.1109/MTITS.2017.8005595

Arafat, M., Nafis, S. R., Sadeghvaziri, E., \& Tousif, F. (2020). A data-driven approach to calibrate microsimulation models based on the degree of saturation at signalized intersections. Transportation Research Interdisciplinary Perspectives, 8, 100231.

Arafat, M., Iqbal, S., \& Hadi, M. (2020). Utilizing an Analytical Hierarchy Process with Stochastic Return on Investment to Justify Connected Vehicle-Based Deployment Decisions. Transportation Research Record, 2674(9), 462-472.

Antoniou, A., \& Lu, W. S. (2007). Practical Optimization: Algorithms and Engineering Applications. Springer Science \& Business Media.

Atkinson, E. J., \& Therneau, T. M. (2000). An Introduction to Recursive Partitioning Using the RPART Routines. Rochester: Mayo Foundation.

Beasley, D., Bull, D. R., \& Martin, R. R. (1993). An Overview of Genetic Algorithms: Part 2, Research Topics. University computing, 15(4), 170-181.

Benekohal, R. F., El-Zohairy, Y. M., \& Saak, J. E. (2001). Comparison of Delays from HCM, Synchro, PASSER II, PASSER IV and CORSIM for an Urban Arterial.

Benekohal, R. F., Elzohairy, Y. M., \& Saak, J. E. (2002). Comparison of Delays from Highway Capacity Software, Synchro, PASSER II and IV, and CORSIM for Urban Arterials. Transportation Research Record, 1802(1), 133-144.

Binning, J. C., Burtenshaw, G., and Crabtree, M. (2008). TRANSYT 13 User Guide, Transport Research Laboratory, Wokingham, Berkshire, UK.

Benekohal, R. R. F., \& Abu-Lebdeh, G. (1994). Variability Analysis of Traffic Simulation Outputs: Practical Approach for TRAF-NETSIM. Transportation Research Record, (1457).

Bullock, D. M., \& Day, C. M. (2009). Performance Measures for Managing Urban Traffic Signal Systems. Urban Transport XV: Urban Transport and the Environment, 15, 167.

Campbell, R., \& Skabardonis, A. (2014). Issues Affecting Performance of Adaptive Traffic Control Systems in Oversaturated Conditions. Transportation Research Record, 2438(1), 23-32. 
Chang, G. L., \& Rochon, S. (2011). Performance Evaluation and Benefit Analysis for Chart-The Real-Time Incident Management System (Year 2010). Final Report. University of Maryland, 20.

Chang, T. H., \& Lin, J. T. (2000). Optimal signal timing for an oversaturated intersection. Transportation Research Part B: Methodological, 34(6), 471-491.

Chang, T. H., \& Sun, G. Y. (2004). Modeling and Optimization of An Oversaturated Signalized Network. Transportation Research Part B: Methodological, 38(8), 687-707.

Chang, J. (2001). Real-Time Traffic Control Policy for Oversaturated Arterials. PhD dissertation. Polytechnic Institute of New York University, Brooklyn, N.Y.

Chaudhary, N. A., Kovvali, V. G., \& Alam, S. M. (2002). Guidelines for Selecting Signal Timing Software (No. FHWA/TX-03/0-4020-P2,). Texas Transportation Institute, Texas A \& M University System.

Chaudhary, N. A., \& Chu, C. L. (2003). New PASSER Program for Timing Signalized Arterials. Texas Transportation Institute, Texas A \& M University System.

Chang, E. C. P., \& Messer, C. J. (1991). Arterial Signal Timing Optimization Using Passer II-90, Program User's Manual. Final Revised Report (No. FHWA/TX-90/467-2F).

Cheng, D., Messer, C. J., Tian, Z. Z., \& Liu, J. (2003, July). Modification of Webster's minimum delay cycle length equation based on HCM 2000. Paper Submitted to the Transportation Research Board for Presentation and Publication at the 2003 Annual Meeting in Washington. DC.

Cheng, D., Tian, Z. Z., \& Messer, C. J. (2005). Development of an Improved Cycle Length Model over the Highway Capacity Manual 2000 Quick Estimation Method. Journal of transportation engineering, 131(12), 890-897.

Cohen, S. L., \& Liu, C. C. (1986). The Bandwidth-Constrained TRANSYT Signal Optimization Program. Transportation Research Record, 1057, 1-7.

Cuena, J., Hernández, J., \& Molina, M. (1995). Knowledge-based models for adaptive traffic management systems. Transportation Research Part C: Emerging Technologies, 3(5), 311-337.

Cuena, J., Ambrosino, G., \& Boero, M. (1992). A General Knowledge-Based Architecture for Traffic Control: The KITS Approach. In International Conference on Artificial Intelligence Applications in Transportation Engineering (1992: Ventura, Calif.). Conference preprints. 
Dakic, I., Stevanovic, A., Zlatkovic, M., \& Kergaye, C. (2017). Refinement of Performance Measures based on High-Resolution Signal and Detection Data. Transportation research procedia, 22, 372-381.

Day, C. M., Smaglik, E. J., Bullock, D. M., \& Sturdevant, J. R. (2008). Real-Time Arterial Traffic Signal Performance Measures. Publication FHWA/IN/JTRP-2008/09. Joint Transportation Research Program, Indiana Department of Transportation and Purdue University, West Lafayette, Indiana, 2008.

Day, C. M., \& Bullock, D. M. (2011). Arterial Performance Measures, Volume 1: Performance Based Management of Arterial Traffic Signal Systems. Final Report, NCHRP 3-79A.

Day, C. M., \& Bullock, D. M. (2012). Calibration of Platoon Dispersion Model with HighResolution Signal Event Data. Transportation Research Record, 2311(1), 16-28.

Deb, K. (2001). Multi-objective Optimization using Evolutionary Algorithms (Vol. 16). John Wiley \& Sons.

Deeter, D. L., \& Ritchie, S. G. (1993). A Prototype Real-Time Expert System For Surface Street Traffic Management and Control. In Pacific Rim TransTech Conference (1993: Seattle, Wash.). Proceedings Pacific Rim TransTech Conference. Vol. 1.

Dion, F., Butler, J., Hammon, L., \& Xuan, Y. (2015). Connected Corridors: I-210 Pilot Integrated Corridor Management System. Concept of Operations. California PATH, Berkeley, CA.

Dowling, R., Skabardonis, A. and Alexiadis, V. (2004). Traffic Analysis Toolbox, Volume III: Guidelines for Applying Traffic Microsimulation Modeling Software (No. FHWAHRT-04-040). United States. Federal Highway Administration. Office of Operations.

Dowling, R., R. Margiotta, H. Cohen, and A. (2013) Skabardonis. Guide for Highway Capacity and Operations Analysis of Active Transportation and Demand Management Strategies. No. FHWA-HOP-13-042.

Emmerich, M. T., \& Deutz, A. H. (2018). A Tutorial on Multiobjective Optimization: Fundamentals and Evolutionary Methods. Natural Computing, 17(3), 585-609.

Eriskin, E., Karahancer, S., Terzi, S., \& Saltan, M. (2017). Optimization of Traffic Signal Timing at Oversaturated Intersections Using Elimination Pairing System. Procedia Engineering, 187, 295-300

Essa, M., \& Sayed, T. (2015). Simulated Traffic Conflicts: Do They Accurately Represent Field-Measured Conflicts? Transportation research record, 2514(1), 48-57. 
Florida Department of Transportation, District 5 (2016). Intelligent Transportation Systems Master Plan. Final Report.

Florida Department of Transportation (FDOT) District Four (2017). 2017 TSM\&O Annual Report. http://www.smartsunguide.com/pdf/2017\%20Annual\%20Report\%20web.pdf.

Florida Department of Transportation (FDOT) District Four (2018). Broward Regional Transportation Management Center Performance Measures Monthly Report from January to December 2018, http://www.smartsunguide.com/\#/aboutUs.

Florida Department of Transportation (FDOT) District Four (2019). Broward Regional Transportation Management Center Performance Measures Monthly Report from January to June 2019, http://www.smartsunguide.com/\#/aboutUs.

Gartner, N. H., Assman, S. F., Lasaga, F., \& Hou, D. L. (1991). A Multi-Band Approach to Arterial Traffic Signal Optimization. Transportation Research Part B: Methodological, 25(1), 55-74.

Gazis, D.C. \& Potts, R.B. (1963). The Oversaturated Intersection. In Proceeding of 2nd International Symposium on the Theory of Traffic Flow. London, Paris OECD.

Gazis, D. C. (1964). Optimum Control of A System of Oversaturated Intersections. Operations Research, 12(6), pp. 815-831.

Gettman, D., Folk, E., Curtis, E., Ormand, K. K. D., Mayer, M., \& Flanigan, E. (2013). Measures of Effectiveness and Validation Guidance for Adaptive Signal Control Technologies (No. FHWA-HOP-13-031). United States. Federal Highway Administration.

Girianna, M., \& Benekohal, R. F. (2004). Using Genetic Algorithms to Design Signal Coordination for Oversaturated Networks. Journal of Intelligent Transportation Systems, $8(2), 117-129$.

Gordon, R.L. (1969). A Technique for Control of Traffic at Critical Intersections. Transportation Science, vol. 4, pp. 279-287.

Goldenberg, D. E. (1989). Genetic Algorithms in Search, Optimization and Machine Learning. Addison-Wesley Publishing Co., Inc., Reading, Mass.

Hadi, M. A., \& Wallace, C. E. (1993). Hybrid Genetic Algorithm to Optimize Signal Phasing and Timing. Transportation Research Record, 1421, 104-112.

Hadi, M. A., \& Wallace, C. E. (1995, August). Treatment of Saturated Conditions Using TRANSYT-7F. In 1995 Compendium of Technical Papers. Institute of Transportation Engineers 65th Annual Meeting. Institute of Transportation Engineers (ITE). 
Hadi, M., C.E. Wallace, and C. Jacks (1999). TRANSYT-7F Simulation Model for Congested Conditions. Proceedings of the 78th Annual Meeting of the Transportation Research Board, Washington, D.C.

Hadi, M., Xiao, Y., Iqbal, M. S., Wang, T., Saha, R., \& Tariq, M. T. (2019). Data and Modeling Support of Off-Line and Real-Time Decisions Associated with Integrated Corridor Management. Florida Department of Transportation.

Hall, L. O., \& Lande, P. (1996). Generating Fuzzy Rules from Data. In Proceedings of IEEE 5th International Fuzzy Systems (Vol. 3, pp. 1757-1762). IEEE.

Han, L., \& May, A. (1988). Artificial Intelligence Approaches for Signalized Network Control. Institute of Transportation Studies, University of California

Han, J., Pei, J., \& Kamber, M. (2011). Data Mining: Concepts and Techniques. Elsevier.

Hartigan, J. A. (1975). Clustering Algorithms. John Wiley \& Sons, Inc..

Hartigan, J. A., \& Wong, M. A. (1979). AK-Means Clustering Algorithm. Journal of the Royal Statistical Society Series C, 28(1), 100-108.

Hastie, T., Tibshirani, R., \& Friedman, J. (2009). The Elements of Statistical Learning: Data Mining, Inference, and Prediction. Springer Science \& Business Media.

Hegyi, A., De Schutter, B., Hoogendoorn, S., Babuska, R., van Zuylen, H., \& Schuurman, H. (2001). A Fuzzy Decision Support System for Traffic Control Centers. In ITSC 2001. 2001 IEEE Intelligent Transportation Systems. Proceedings (Cat. No. 01TH8585) (pp. 358-363). IEEE.

Hellinga, B. R. (1998). Requirements for the Calibration of Traffic Simulation Models. Proceedings of the Canadian Society for Civil Engineering, 4, 211-222.

Henry, R. D., \& Sabra, W. (2005). Signal Timing on a Shoestring (No. FHWA-HOP-07006). United States. Federal Highway Administration.

Highway Capacity Manual (HCM). (2000). Transportation Research Board, Washington, DC, fourth edition, ISBN 0-309-06681-6.

Horn, J., Nafpliotis, N., \& Goldberg, D. E. (1994). A niched Pareto genetic algorithm for multiobjective optimization. In Proceedings of the first IEEE conference on evolutionary computation. IEEE world congress on computational intelligence (pp. 82-87). IEEE.

Huang, Z. (1998). Extensions to the K-Means Algorithm for Clustering Large Data Sets with Categorical Values. Data Mining and Knowledge Discovery, 2(3), 283-304. 
Jie, L., Van Zuylen, H., Chen, Y., Viti, F., \& Wilmink, I. (2013). Calibration of a Microscopic Simulation Model for Emission Calculation. Transportation Research Part C: Emerging Technologies, 31, 172-184.

Kesting, A., \& Treiber, M. (2008). Calibrating Car-Following Models by Using Trajectory Data: Methodological Study. Transportation Research Record, 2088(1), 148-156.

Ketchen, D. J., \& Shook, C. L. (1996). The Application of Cluster Analysis in Strategic Management Research: An Analysis and Critique. Strategic Management Journal, 17(6), 441-458.

Kim, K. O., \& Rilett, L. R. (2003). Simplex-Based Calibration of Traffic Microsimulation Models with Intelligent Transportation Systems Data. Transportation Research Record, 1855(1), 80-89.

Kim, S. J., Kim, W., \& Rilett, L. R. (2005). Calibration of Microsimulation Models Using Nonparametric Statistical Techniques. Transportation Research Record, 1935(1), 111119.

Li, M., and Gan, A. C. (1999). Signal Timing Optimization for Oversaturated Networks Using TRANSYT-7F. Transportation Research Record, 1683, 118-126. Washington, D.C.

Li, Z. (2010). Modeling Arterial Signal Optimization with Enhanced Cell Transmission Formulations. Journal of Transportation Engineering, 137(7), 445-454

Lieberman, E. B., \& Woo, J. L. (1976). SIGOP II: A New Computer Program for Calculating Optimal Signal Timing Patterns. Transportation Research Record, 596, 16-21.

Lieberman, E. B., Chang, J., \& Shenk Prassas, E. (2000). Formulation of Real-Time Control Policy for Oversaturated Arterials. Transportation Research Record, 1727(1), 7788.

Lieberman, E., and Chang, J. (2005). Optimizing Traffic Signal Timing Through Network Decomposition. Transportation Research Record, 1925(1), 167-175.

Lin, M. H., Tsai, J. F., \& Yu, C. S. (2012). A Review of Deterministic Optimization Methods in Engineering and Management. Mathematical Problems in Engineering.

Little, J. D. (1966). The Synchronization of Traffic Signals by Mixed-Integer Linear Programming. Operations Research, 14(4), 568-594.

Little, J. D., Kelson, M. D., \& Gartner, N. H. (1981). MAXBAND: A Versatile Program for Setting Signals on Arteries and Triangular Networks. Report no. 1185-81 
Liu, Y., \& Chang, G. L. (2011). An Arterial Signal Optimization Model for Intersections Experiencing Queue Spillback and Lane Blockage. Transportation Research Part C: Emerging Technologies, 19(1), 130-144.

Long, J., Gao, Z., Orenstein, P., \& Ren, H. (2011). Control Strategies for Dispersing Incident-Based Traffic Jams in Two-Way Grid Networks. IEEE Transactions on Intelligent Transportation Systems, 13(2), 469-481.

Ma, T., \& Abdulhai, B. (2002). Genetic Algorithm-Based Optimization Approach and Generic Tool for Calibrating Traffic Microscopic Simulation Parameters. Transportation research record, 1800(1), 6-15.

Mamdani, E. H. (1974). Application of fuzzy algorithms for control of simple dynamic plant. In Proceedings of the institution of electrical engineers (Vol. 121, No. 12, pp. 15851588). IET.

Mamdani, E. H., \& Assilian, S. (1975). An Experiment in Linguistic Synthesis with A Fuzzy Logic Controller. International Journal of Man-Machine Studies, 7(1), 1-13.

Mcshane, W. R., Crowley, K. W., Lee, B., \& Casey, T. W. (1978). Traffic Control in Oversaturated Street Networks. NCHRP Report, (194).

Michalopoulos, P. G., \& Stephanopoulos, G. (1978). Optimal Control of Oversaturated Intersections: Theoretical and Practical Considerations. Traffic Engineering and Control, 19(5), 216-221.

Mishra, S. K., Ganapati, P., Meher, S., \& Majhi, R. (2002). A Fast Multi-objective Evolutionary Algorithm for Finding Well-Spread Pareto-Optimal Solutions. KanGAL Report No. 2003002, Indian Institute of Technology Kanpur.

Mitra, S., Konwar, K. M., \& Pal, S. K. (2002). Fuzzy Decision Tree, Linguistic Rules and Fuzzy Knowledge-based Network: Generation and Evaluation. IEEE Transactions on Systems, Man, and Cybernetics, Part C (Applications and Reviews), 32(4), 328-339.

Nafis, S. R., Alluri, P., Jung, R., Ennemoser, R., \& Gan, A. (2019). A Comprehensive Review of States' Existing Practices in Using Communication Technologies to Increase Public Involvement for Transportation Projects. Transportation Research Board 98th Annual MeetingTransportation Research Board, (19-01674).

Olaru, C., \& Wehenkel, L. (2003). A Complete Fuzzy Decision Tree Technique. Fuzzy sets and Systems, 138(2), 221-254.

Park, B., Messer, C. J., \& Urbanik, T. (1999). Traffic Signal Optimization Program for Oversaturated Conditions: Genetic Algorithm Approach. Transportation Research Record, 1683(1), 133-142. 
Park, B., Messer, C. J., \& Urbanik, T. (2000). Enhanced Genetic Algorithm for SignalTiming Optimization of Oversaturated Intersections. Transportation Research Record, 1727(1), 32-41.

Park, B., \& Qi, H. (2005). Development and Evaluation of a Procedure for the Calibration of Simulation Models. Transportation Research Record, 1934(1), 208-217.

Park, B. B., Rouphail, N. M., Hochanadel, J. P., \& Sacks, J. (2001). Evaluating Reliability of TRANSYT-7F Optimization Schemes. Journal of Transportation Engineering, 127(4), 319-326.

Patire, A. D., Butler, J., Xuan, E., Schreiter, T., Gomes, G., Dion, F., ... \& Winik, F. (2016). I-210 Connected Corridors Pilot: Analysis, Modeling, and Simulation: Report for Phase 1 Version 2. California PATH, Berkeley, CA.

Platman, D., Hurtado, R., Muhs, C. D., Whitt, D., Bachman, J., Bauer, J., ... \& Grant, M. (2018). Model Transportation Systems Management and Operations Deployments in Corridors and Subareas Primer(No. FHWA-HOP-18-026). United States. Federal Highway Administration.

PTV Group, PTV Vistro User Manual, 2014.

Quinn, D. J. (1992). A Review of Queue Management Strategies. Traffic Engineering Control, 33(11), 600-5.

Rausch, R. (2007). Testing Programs for Transportation Management Systems: A Technical Handbook (No. FHWA-HOP-07-088). United States. Federal Highway Administration. Office of Transportation Management.

Ritchie, S. G. (1990). A Knowledge-Based Decision Support Architecture for Advanced Traffic Management. Transportation Research Part A: General, 24(1), 27-37.

Riza, L. S., Bergmeir, C., Herrera, F., \& Benitez, J. M. (2014, July). Learning from data using the R package "FRBS". In 2014 IEEE International Conference on Fuzzy Systems (FUZZ-IEEE) (pp. 2149-2155). IEEE.

Riza, L. S., Bergmeir, C. N., Herrera Triguero, F., \& Benítez Sánchez, J. M. (2015). frbs: Fuzzy Rule-Based Systems for Classification and Regression in R. Journal of Statistical Software.

Saha, R., Hadi, M., Hunsanon, T., \& Tariq, M. T. (2021). Integrated Approach for Optimizing Traffic Management Plans during Freeway Incidents. 100th Annual Meeting of the Transportation Research Board, Washington DC, USA. 
Saha, R., Tariq, M. T., Hadi, M., \& Xiao, Y. (2019). Pattern Recognition Using Clustering Analysis to Support Transportation System Management, Operations, and Modeling. Journal of Advanced Transportation.

Saha, R., Tariq, M. T., \& Hadi, M. (2020a). Deep Learning Approach for Predictive Analytics to Support Diversion during Freeway Incidents. Transportation Research Record, 0361198120917673.

Saha, R., Tahnin Tariq, M., \& Hadi, M. (2020b). Identification of Traffic Congestion Patterns Using Connected Vehicle for Active Traffic Management. In International Conference on Transportation and Development 2020 (pp. 215-226). Reston, VA: American Society of Civil Engineers.

Sarkar, D., Bali, R., \& Sharma, T. (2018). Practical Machine Learning with Python. A Problem-Solvers Guide to Building Real-World Intelligent Systems. Apress, Berkeley.

Scemama, G. (1994). ClAIRE: A Context-Free AI Based Supervisor for. Artificial Intelligence Applications to Traffic Engineering, 137.

Singh, M. G., \& Tamura, H. (1974). Modeling and Hierarchical Optimization for Oversaturated Urban Road Networks. International Journal for Control, vol. 20, No, 6, pp. 913-934.

Singh, S., \& Gupta, P. (2014). Comparative study ID3, cart and C4. 5 Decision Tree Algorithm: A Survey. International Journal of Advanced Information Science and Technology (IJAIST), 27(27), 97-103.

Smaglik, E. J., Sharma, A., Bullock, D. M., Sturdevant, J. R., \& Duncan, G. (2007). EventBased Data Collection for Generating Actuated Controller Performance Measures. Transportation Research Record, 2035(1), 97-106.

Smaglik, E. J., Bullock, D. M., \& Sharma, A. (2007). Pilot Study on Real-Time Calculation of Arrival Type for Assessment of Arterial Performance. Journal of Transportation Engineering, 133(7), 415-422.

Stevanovic, A., Martin, P., \& Stevanovic, J. (2007). Vissim-Based Genetic Algorithm Optimization of Signal Timings. Transportation Research Record: Journal of the Transportation Research Board, (2035), 59-68.

Sturdevant, J. R., Overman, T., Raamot, E., Deer, R., Miller, D., Bullock, D. M., ... \& Remias, S. M. (2012). Indiana Traffic Signal Hi Resolution Data Logger Enumerations.

Sugeno, M., \& Kang, G. T. (1988). Structure Identification of Fuzzy Model. Fuzzy Sets and Systems, 28(1), 15-33. 
Sugeno, M., \& Yasukawa, T. (1993). A Fuzzy-Logic-Based Approach to Qualitative Modeling. IEEE Transactions on Fuzzy Systems, 1(1), 7-31.

Takagi, T., \& Sugeno, M. (1985). Fuzzy Identification of Systems and Its Applications to Modeling and Control. IEEE Transactions on Systems, Man, and Cybernetics, (1), 116132.

Tan, P. N., Steinbach, M., \& Kumar, V. (2016). Introduction to Data Mining. Pearson Education India.

Tariq, M. T., Saha, R. C., \& Hadi, M. (2019). Methodology to Derive Route Diversion during Freeway Incident Conditions Based on Field Data, Transportation Research Board 98th Annual Meeting, Washington DC, United States.

Tariq, M. T., Massahi, A., Saha, R., \& Hadi, M. (2020). Combining Machine Learning and Fuzzy Rule-Based System in Automating Signal Timing Experts' Decisions during NonRecurrent Congestion. Transportation Research Record, 0361198120918248.

Tariq, M. T., Hadi, M., \& Saha, R. (2021). Using High-Resolution Controller Data in the Calibration of Traffic Simulation Models. Transportation Research Record.

Therneau, T. M. (1983). A Short Introduction to Recursive Partitioning. Orion Technical Report, 21. Stanford University, Department of Statistics.

Urbanik, T., Tanaka, A., Lozner, B., Lindstrom, E., Lee, K., Quayle, S., \& Sunkari, S. (2015). Signal Timing Manual (Vol. 1). Washington, DC: Transportation Research Board.

Vasudevan, M., \& Wunderlich, K. (2013). Analysis, Modeling, and Simulation (AMS) Testbed Framework for Dynamic Mobility Applications (DMA) and Active Transportation and Demand Management (ATDM) Programs (No. FHWA-JPO-13-095). United States. Department of Transportation. Intelligent Transportation Systems Joint Program Office.

Wallace, C. E., Courage, K. G., Hadi, M. A. and Gan, A. (1998). Methodology for Optimizing Signal Timing $(M|O| S \mid T)$, Volume 4: TRANSYT-7F Users Guide, Prepared for the Federal Highway Administration, University of Florida, Gainesville, FL.

Webster, F. V. (1966). Traffic Signals. Road Research Technical Paper, 56.

Whitley, D. (1994). A genetic algorithm tutorial. Statistics and Computing, 4(2), 65-85.

Wild, B. (1994). SAPPORO, A Framework for Intelligent Integrated Traffic Management Systems. Artificial Intelligence Applications to Traffic Engineering, 117-136.

WisDOT (2017). Traffic Engineering, Operations and Safety Manual (TEOpS). 
Wood, K. (1970). Traffic Restraint by SCOOT Gating. WIT Transactions on the Built Environment, 18.

Wu, X., \& Liu, H. X. (2014). Using high-resolution event-based data for traffic modeling and control: An overview. Transportation Research Part C: Emerging Technologies, 42, $28-43$.

Wunderlich, K., Vasudevan, M., \& Sandelius, T. (2013). Analysis, Modeling, and Simulation (AMS) Testbed Requirements for Dynamic Mobility Applications (DMA) and Active Transportation and Demand Management (ATDM) Programs (No. FHWA-JPO13-098).

Wunderlich, K. E., Vasudevan, M., \& Wang, P. (2019). TAT Volume III: Guidelines for Applying Traffic Microsimulation Modeling Software 2019 Update to the 2004 Version (No. FHWA-HOP-18-036). United States. Federal Highway Administration.

Yang, X. S. (2013). Optimization and Metaheuristic Algorithms in Engineering. Metaheuristics in Water, Geotechnical and Transport Engineering, 1-23.

Yelchuru, B., Abdelghany, K., Zohdy, I., Singuluri, S., Kamalanathsharma, R., \& Hamilton, B. A. (2017). Analysis, Modeling, and Simulation (AMS) Testbed Development and Evaluation to Support Dynamic Mobility Applications (DMA) and Active Transportation and Demand Management (ATDM) Programs: Dallas Testbed Analysis Plan [supporting datasets-Dallas Testbed] (No. FHWA-JPO-16-373). United States. Joint Program Office for Intelligent Transportation Systems.

Yuan, Y., \& Shaw, M. J. (1995). Induction of fuzzy decision trees. Fuzzy Sets and systems, 69(2), 125-139.

Yuan, Y., Xu, H., \& Wang, B. (2014, July). An improved NSGA-III procedure for evolutionary many-objective optimization. Proceedings of the 2014 Annual Conference on Genetic and Evolutionary Computation (pp. 661-668). 
VITA

\section{MOSAMMAT TAHNIN TARIQ}

Born, Bangladesh

$2008-2011$

B.Sc., Civil Engineering

Khulna University of Engineering and Technology,

Khulna, Bangladesh

$2012-2015$

M.Sc., Civil Engineering (Transportation)

Bangladesh University of Engineering and Technology,

Dhaka, Bangladesh

2011- 2016

Lecturer

Stamford University, Bangladesh,

Dhaka, Bangladesh

2017 - Present $\quad$ PhD. Student

Department of Civil and Environmental Engineering

Florida International University

Miami, Florida

2017 - Present $\quad$ Graduate Research Assistant

Department of Civil and Environmental Engineering

Florida International University

Miami, Florida

2017 - $2018 \quad$ Secretary, Women's Transportation Seminar Chapter at FIU

2018 - $2019 \quad$ President, Women's Transportation Seminar Chapter at FIU

2018 - $2019 \quad$ Secretary, Bangladesh Student Organization at FIU

2020

Dissertation Year Fellowship, University Graduate School, FIU

2020

SGA Graduate Scholarship, University Graduate School, FIU

\section{PUBLICATIONS AND PRESENTATIONS}

Tariq, M. T., Hadi, M., \& Saha, R. (2021). Using High-Resolution Controller Data in the Calibration of Traffic Simulation Models. Accepted for the 100th Annual Meeting of the Transportation Research Board, Washington DC, USA. 
Saha, R., Hadi, M., Hunsanon, T., \& Tariq, M. T. (2021). Integrated Approach for Optimizing Traffic Management Plans during Freeway Incidents. Transportation Research Board 100th Annual Meeting, Washington DC, USA.

Tariq, M. T., Massahi, A., Saha, R., \& Hadi, M. (2020). Combining Machine Learning and Fuzzy Rule-Based System in Automating Signal Timing Experts' Decisions during NonRecurrent Congestion. Transportation Research Record, 0361198120918248.

Saha, R., Tariq, M. T., \& Hadi, M. (2020). Deep Learning Approach for Predictive Analytics to Support Diversion during Freeway Incidents. Transportation Research Record, 0361198120917673.

Saha, R., Tahnin Tariq, M., \& Hadi, M. (2020). Identification of Traffic Congestion Patterns Using Connected Vehicle for Active Traffic Management. In International Conference on Transportation and Development 2020 (pp. 215-226). Reston, VA: American Society of Civil Engineers.

Saha, R., Tariq, M. T., Hadi, M., \& Xiao, Y. (2019). Pattern Recognition Using Clustering Analysis to Support Transportation System Management, Operations, and Modeling. Journal of Advanced Transportation, 2019.

Hadi, M., Xiao, Y., Iqbal, M. S., Wang, T., Saha, R., \& Tariq, M. T. (2019). Data and Modeling Support of Off-Line and Real-Time Decisions Associated with Integrated Corridor Management. Final Report, FDOT Project BDV29-977-38. FDOT.

Tariq, M. T., Saha, R. C., \& Hadi, M. (2019). Methodology to Derive Route Diversion during Freeway Incident Conditions Based on Field Data. (No. 19-03539) Proceedings of the 98th Annual Meeting of the Transportation Research Board, Washington DC, USA.

Hadi, M., Xiao, Y., Wang, T., Fartash, H., Tariq, M. T., \& Sharmin, N. (2017). Guidelines for Evaluation of Ramp Signaling Deployments in a Real-Time Operations Environment. Final Report, FDOT Project BDV29-977-25. FDOT. 